\title{
Transportable Xenon Laboratory (TXL-1) Operations Manual
}

RC Thompson

TL Stewart

JA Willett VT

Woods

March 2011

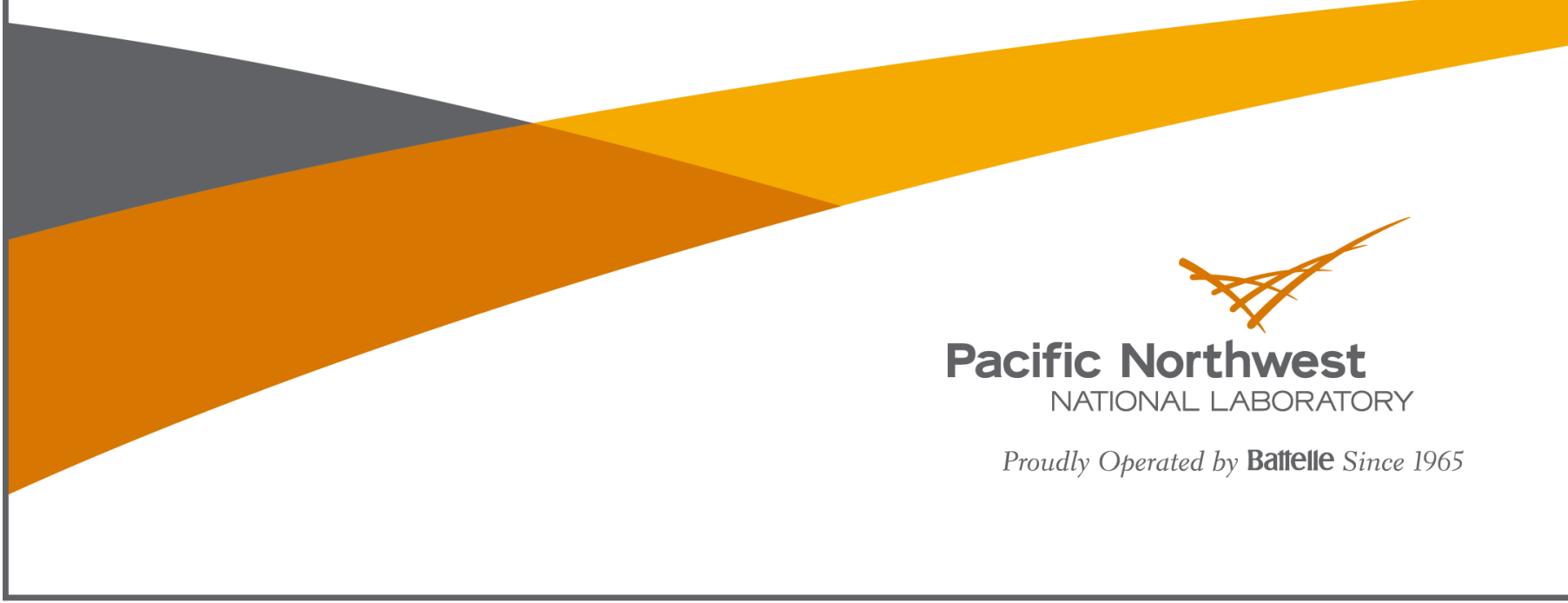




\section{DISCLAIMER}

This report was prepared as an account of work sponsored by an agency of the United States Government. Neither the United States Government nor any agency thereof, nor Battelle Memorial Institute, nor any of their employees, makes any warranty, express or implied, or assumes any legal liability or responsibility for the accuracy, completeness, or usefulness of any information, apparatus, product, or process disclosed, or represents that its use would not infringe privately owned rights. Reference herein to any specific commercial product, process, or service by trade name, trademark, manufacturer, or otherwise does not necessarily constitute or imply its endorsement, recommendation, or favoring by the United States Government or any agency thereof, or Battelle Memorial Institute. The views and opinions of authors expressed herein do not necessarily state or reflect those of the United States Government or any agency thereof.

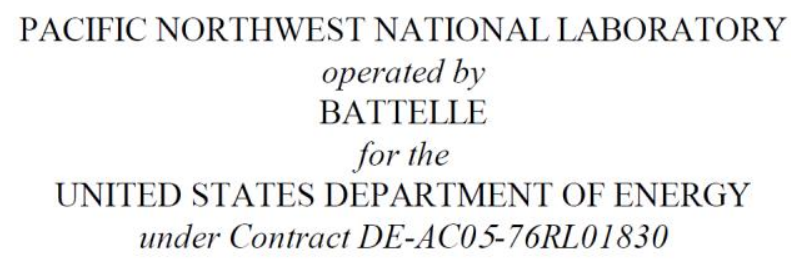

Printed in the United States of America

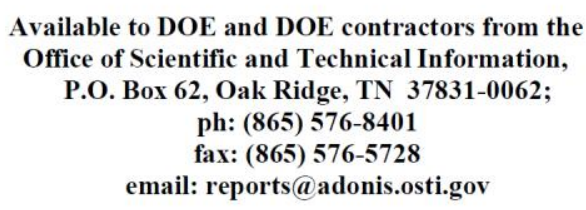

Available to the public from the National Technical Information Service,

U.S. Department of Commerce, 5285 Port Royal Rd., Springfield, VA 22161

ph: (800) 553-6847

fax: (703) 605-6900

email: orders@ntis.fedworld.gov

online ordering: http://www.ntis.gov/ordering.htm

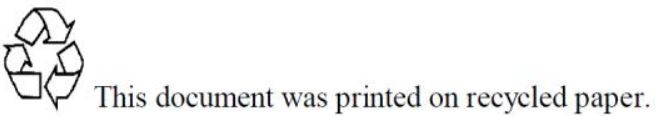

(9/2003) 


\section{Transportable Xenon Laboratory (TXL-1) Operations Manual}

March 2011

$\begin{array}{ll}\text { RC Thompson } & \text { JA Willett } \\ \text { TL Stewart } & \text { VT Woods }\end{array}$

Prepared for

the U.S. Department of Energy

under Contract DE-AC05-76RL01830

Pacific Northwest National Laboratory

Richland, Washington 99352 



\section{Acronyms and Abbreviations}

$\mathrm{AC}$

$\mathrm{cm}$

HVAC

in.

KVM

LCD

LED

radioxenon

SAUNA

TOX Gard

TXL

UPS alternating current

centimeter

heating, ventilation, and air-conditioning

inch

keyboard video monitor

liquid crystal display

light-emitting diode (warning light)

radioactive isotopes of xenon

Swedish Automated Unit for Noble gas Analysis

oxygen monitor

Transportable Xenon Laboratory

uninterruptable power supply 



\section{Contents}

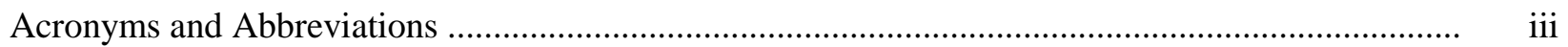

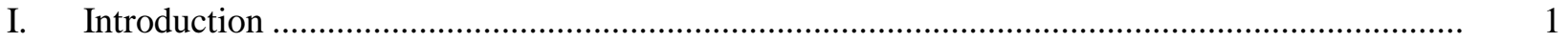

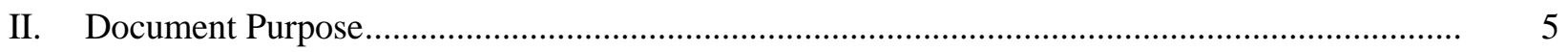

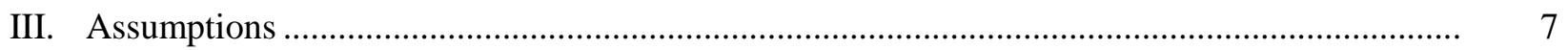

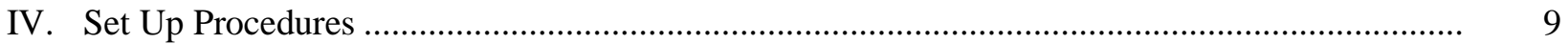

A. Procedure for Opening the TXL Outer Doors and Checking the Oxygen Monitor ............ 11

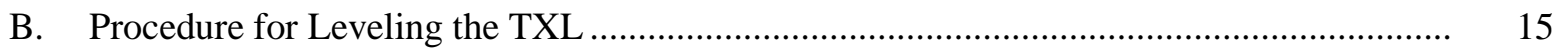

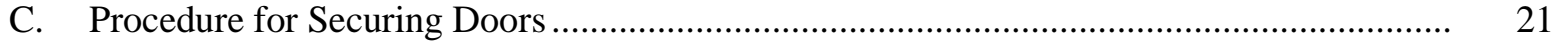

D. Procedure for Setting Up the Rear Storage Area of TXL …........................................... 23

E. Procedure for Installing the Generator Exhaust Diverter onto the Tail Pipe....................... 33

F. Procedure for Storing Equipment Used in TXL Setup................................................... 35

G. Procedure for Hooking Up Power to the Available Utility Power ..................................... 37

H. Procedure for Powering Up the TXL ........................................................................... 39

I. Procedure for Filling the Diesel Fuel Tank ...................................................................

J. $\quad$ Procedure for Removing the Shipping Mounts for the SAUNA Translation Frame .......... 47

K. Procedure for Removing Shipping Containers from Inside TXL and Stowing Them on

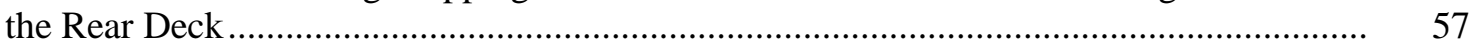

L. Procedure for Setting Up the Helium Cylinders for SAUNA Use ................................... 59

M. Procedure for Detecting a Helium Leak ........................................................................ 65

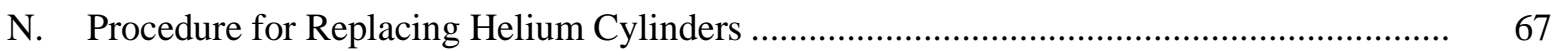

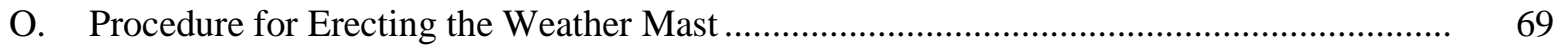

P. Procedure for Powering Up the SAUNA …...................................................................... 73

Q. Procedure to Begin Operation of SAUNA …...................................................................... 77

V. Shut Down Procedure........................................................................................................ 79

A. Procedure for Powering Down the SAUNA ….............................................................. 81

B. Procedure for Powering Down the TXL Computer ......................................................... 83

C. Procedure for Stowing the Weather Mast …................................................................... 85

D. Procedure for Shutting Off and Securing Helium Cylinders............................................ 87

E. Procedure for Preparing the SAUNA for Shipping ......................................................... 89

F. Procedure for Securing SAUNA Translation Frame for Shipping .................................... 93

G. Procedure for Draining the Diesel Fuel Tank ............................................................... 99

H. Procedure for Powering Down the TXL ….................................................................. 103

I. Procedure for Removing the Generator Exhaust Diverter From the Tail Pipe .................. 109

J. Procedure for Stowing the Rear Storage Area of TXL …............................................... 111

K. Procedure for Removing the Dunnage from Under the Container................................... 119

L. Procedure for Closing the TXL, Securing Doors, and Checking the Oxygen Monitor........ 123 


\section{Figures}

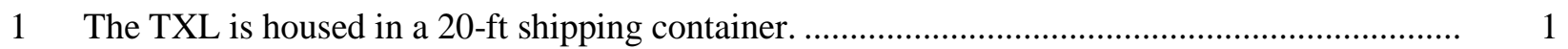

2 The TXL can be shipped anywhere in the world.............................................................. 2

3 Inside the TXL, the SAUNA system analyzes air samples for radioisotope concentrations. ....... 3

4 Shipping container locks secure the TXL during transport. ........................................................ 11

5 After opening the outer container doors, return the latch handles to shipping configuration....... 12

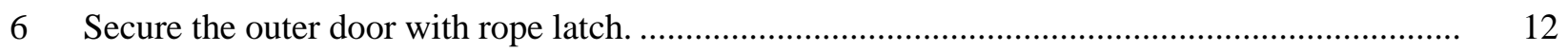

$7 \quad$ Insert the master electrical activation key into the oxygen monitor's key switch. ...................... 13

8 The pedestrian door is secured in an open position with a hook. .............................................. 13

9 The warning light of the oxygen monitor flashes red if the air inside TXL is oxygen-

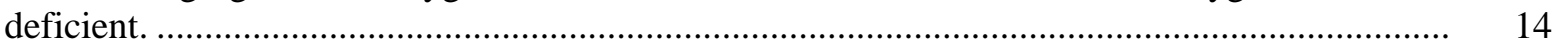

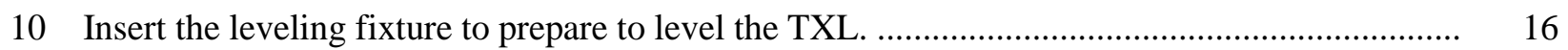

11 The bottle jack is engaged inside the antislip ring of the leveling fixture. ................................. 17

12 Using the tip of the bottle jack handle, tighten the valve to hold the pressure of the hydraulic

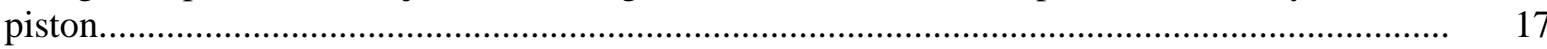

13 The handle of the jack is inserted into the pump shaft, and the jack is ready to raise the

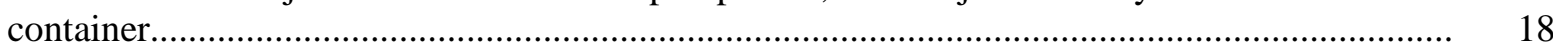

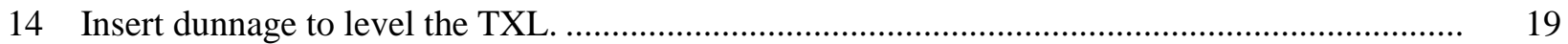

15 Main power cable, jacks, and leveling fixtures are stored in a yellow shipping box................... 19

16 Position the door to feed the threaded end of the J-hook through the hole................................. 21

17 The outside doors of the TXL are secured in the open position using a padlock. ...................... 21

18 Secure the outer doors in the open position with rope latch................................................... 23

19 Unlatch the floor of the rear deck of the TXL. ............................................................................... 24

20 Lower the TXL rear deck floor to the deployed position. ........................................................ 24

21 Loosen the T-bolts located on the right and left sides of the floor. ........................................... 25

22 Slide the TXL rear deck floor to abut the laboratory frame........................................................ 25

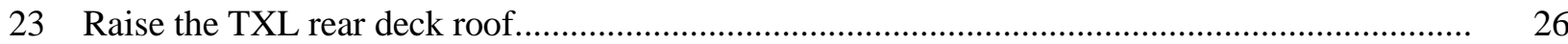

24 Raise the TXL rear deck roof higher than the doors............................................................. 26

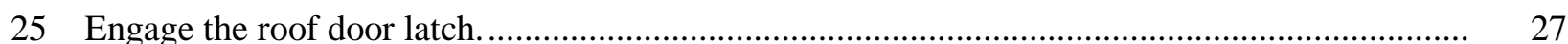

26 Route the power cable and green grounding wire, if needed, through the opening between the left rear door, the rear deck floor, and the container frame................................................ 27

27 The floor locking pins secure the TXL rear deck floor to the container doors........................... 28

28 Insert a J-hook through the holes in the floor and door. ...................................................... 28

29 The J-hooks are locked in place with a padlock and the floor is secure..................................... 29

30 A D-ring and chain secure the rear deck roof to the side of the container................................. 29

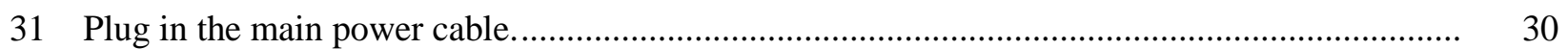

32 Disengage the latch on the lower panel of the screen door......................................................

33 Extend the lower screen panel on the rear screen door and latch it into place. .......................... 31

34 Generator exhaust diverter is in place........................................................................ 
35 Remove pink tie down eye bolts, used to secure shipping boxes to floor during transport of TXL

36 Remove the bung from the hole in front of the SAUNA.

37 Location of master power switch and generator switch on the rear deck

38 The house UPS is shown with the front panel removed and the batteries unplugged.

The house UPS is shown with the front panel removed and the internal batteries connected......

40 The uninterruptable power supply for the TXL is located in the SAUNA rack.

41 The master electrical activation key is inserted on in the Line Power Activation switch on the TXL master control panel.

42 Turn the diesel generator automatic control module on.

43 Check the power meters to assess which phase is wired improperly......

44 Remove these two bolts to remove fuel pump.

45 The pumping direction is noted on the fuel transfer pump.

46 The upper vibration isolation assemblies prevent the equipment rack from swaying. .

47 Key is inserted in the SAUNA rack transport motor.

48 Unbolting the bottom-mounted bracket.

49 Components of the upper vibration isolation assembly are labeled.

50 Secure the rod marked " $D$ " temporarily to the holes in the ceiling mounted C-channel...

51 Three bottom mounting brackets are positioned in shipping box.

52 The vibration isolation assemblies are loaded in shipping box.

53 The connecting rods of the vibration isolator assembly are folded in when stowed.

54 The vibration isolation assemblies are packed into a shipping box along with shipping tiedown straps, red metal storage boxes, foam, and bungee cords.

55 Removing the SAUNA detector lid brackets.

56 The water condensation tube is inserted through a hole in the floor.

57 Final storage configuration of shipping boxes stowed on rear deck.

58 Secure fire extinguisher with safety lanyard.......

59 Do not obstruct the master power switch or transformers at the rear of the TXL.

60 The helium supply is provided by five helium cylinders configured in two separate banks .........

61 The helium distribution system and spare helium cylinders are mounted on the rear and left walls of the TXL

62 The gas manifold controller is located inside the TXL opposite the pedestrian access door ........

63 Ensure that helium cylinders are secured with safety pins at all times except when replacing a cylinder.

64 The displays and controls on the gas manifold controller are identified. .....

65 The formation of bubbles indicates a leak is present in this fitting.

66 The gas manifold indicates both banks of helium cylinders are empty.

67 Before replacing helium cylinders, close the isolation and cylinder valves.

68 Never unsecure a helium cylinder from the storage rack or move a helium cylinder without the protective cap in place. 


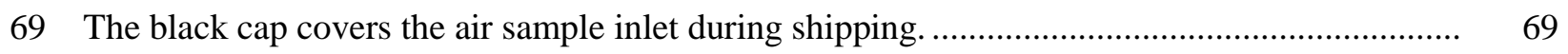

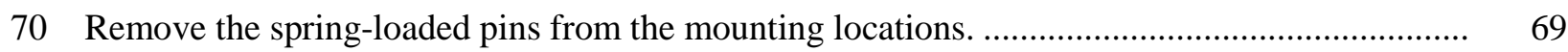

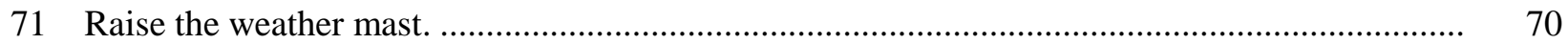

72 Replace the pins in the mounting holes to secure the weather mast in the deployed position...... 71

73 Insert the pins into the lower mounting fixture holes. ........................................................... 71

74 The UPS is shown with the front panel removed and the batteries unplugged............................ 73

75 The UPS is shown with the front panel removed and the internal batteries connected............... 74

76 Turn on the SAUNA UPS by pushing the ON button. ............................................................ 74

77 Use the KVM switch to select the SAUNA computer, labeled SOH. ....................................... 75

78 The KVM Switch is mounted above the house computer ...................................................... 83

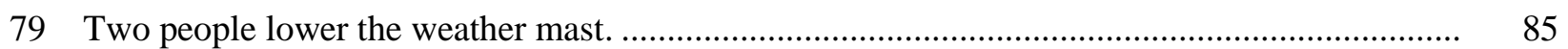

80 Secure the weather mast in its shipping configuration using the three pins. ............................ 86

81 The black cap covers the air sample inlet during shipping. ..................................................... 86

82 Note the components of the helium distribution system to follow Shut Down Procedure V.D. .. 87

83 Insert stud plates through the holes on the detector lid hinge supports. .................................... 89

84 Guide studs through the holes in the detector lid bracket and secure with nylock nuts. ............. 90

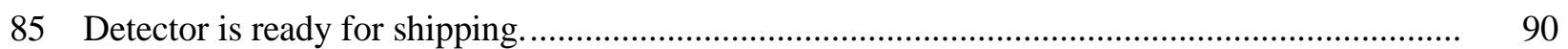

86 Secure the condensation line to the SAUNA frame with a tie wrap ............................................. 91

87 Insert the bung in the floor where the condensation tube was removed................................... 91

88 Vibration isolator assembly components are noted. .......................................................... 93

89 To move the SAUNA transport rack to the right, turn the key on the transport motor in the

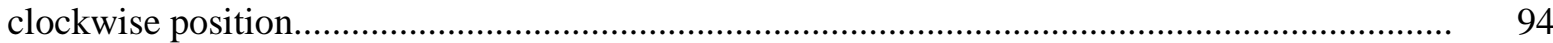

90 Vibration isolator assembly attached to the wall with T-handle pins. ....................................... 95

91 Secure the connecting rods marked " $D$ " and " $A$ " temporarily to the holes in the ceiling

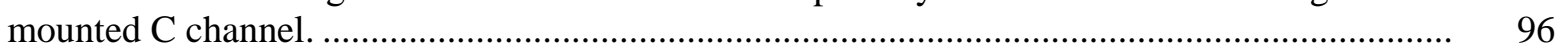

92 Align and secure the upper connecting rod to the SAUNA rack............................................ 96

93 When properly installed, the upper vibration isolation assemblies look like this...................... 97

94 Secure the bottom-mounted bracket to the lower SAUNA translational base and the floor. ....... 98

95 Lock the padlock on the tank cap with the body pointing toward the rear deck........................ 99

96 Unbolt the fuel transfer pump from the tank frame. ............................................................. 100

97 The pumping direction is noted on the fuel transfer pump. .................................................. 100

98 Secure monitor for transport with bungee cords and foam.................................................... 103

99 The generator automatic control unit is set to MANUAL..................................................... 103

100 Control panel key is in the OFF position. .......................................................................... 104

101 The TXL Uninterruptable Power Supply has the ON and OFF buttons labeled. ....................... 104

102 The house UPS is shown with the front panel removed and the internal batteries connected...... 105

103 The house UPS is shown with the front panel removed and the batteries unplugged. ............... 106

104 The power switch is in the OFF position............................................................................. 107

105 Disconnecting the power from the receptacle on the rear deck. ................................................ 108 


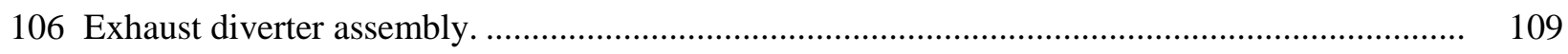

107 Unlatching the lower panel of the left screen door............................................................. 111

108 Pushing up the lower panel of the screen door, and latching it in the "up" position. .................. 112

109 D Ring and chain securing the rear deck roof to the side of the container. ............................... 112

110 Unlocking padlock securing the J-hook and outside door in the open position.......................... 113

111 Unhooking the $\mathrm{J}$ hook from the rear deck floor and door.................................................... 113

112 One person releases the floor-locking pin. ..................................................................... 114

113 Raise the roof to disengage the roof-door latches................................................................ 114

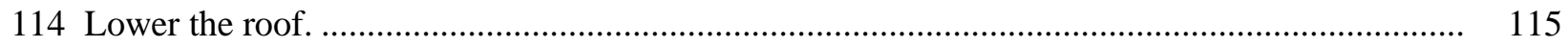

115 Stow the electrical power cord in the shipping box, along with jacks and leveling fixtures. ....... 115

116 Coil the green grounding cable next to the fuel tank ......................................................... 116

117 Loosen the T-bolts on the floor frame. .............................................................................. 116

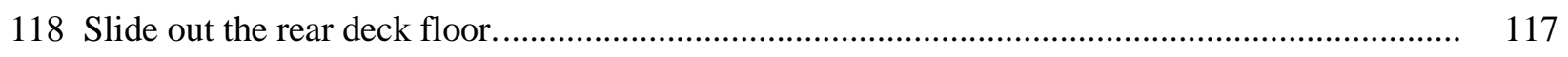

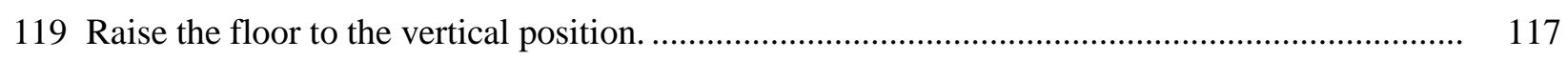

120 Engage the latch to secure the floor in the shipping position. ................................................. 118

121 A lock is in place on one of the exterior shipping container doors......................................... 118

122 Insert the leveling fixtures into oval hole on the corner block............................................... 119

123 The hydraulic jack engages the leveling fixture inside the safety ring. .................................... 120

124 Pump the jack handle to raise the corner of TXL enough to remove dunnage........................... 121

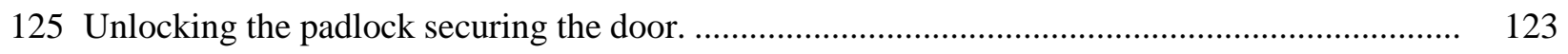

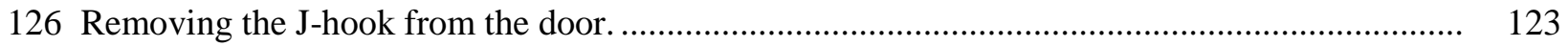

127 Securing the door in the open position with the rope loop. .................................................... 124

128 Insert the removable pink tie down eye bolts in the locations noted. ........................................ 124

129 The spare parts shipping box is secured in front of the SAUNA system................................... 125

130 Place the shipping boxes and equipment in the locations noted............................................ 126

131 Use the orange straps to secure the ladder, folding chair, and hard hats to the shipping boxes. .. 126

132 Secure the vacuum cleaner atop the Detector shipping box.................................................... 127

133 Turn off the power for the oxygen monitor. ...................................................................... 127

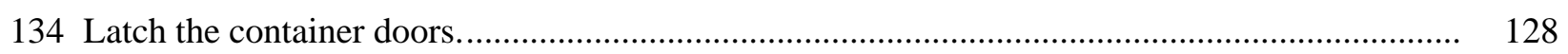

135 The lock is in place on one of exterior shipping container doors. ........................................... 129

136 Instructions for installation of the lock on the exterior shipping container doors. ..................... 129 



\section{Introduction}

The Transportable Xenon Laboratory, also known as the TXL, housed in a standard 20-foot International Organization for Standards (ISO)/International Maritime Organization (IMO) certified shipping container (Figure 1), is a fully contained laboratory made up of instruments to identify and measure concentrations of the radioactive isotopes of xenon (also known collectively as radioxenon) by taking air samples and analyzing them. The TXL can be shipped to, and function in, any country in the world (Figure 2).

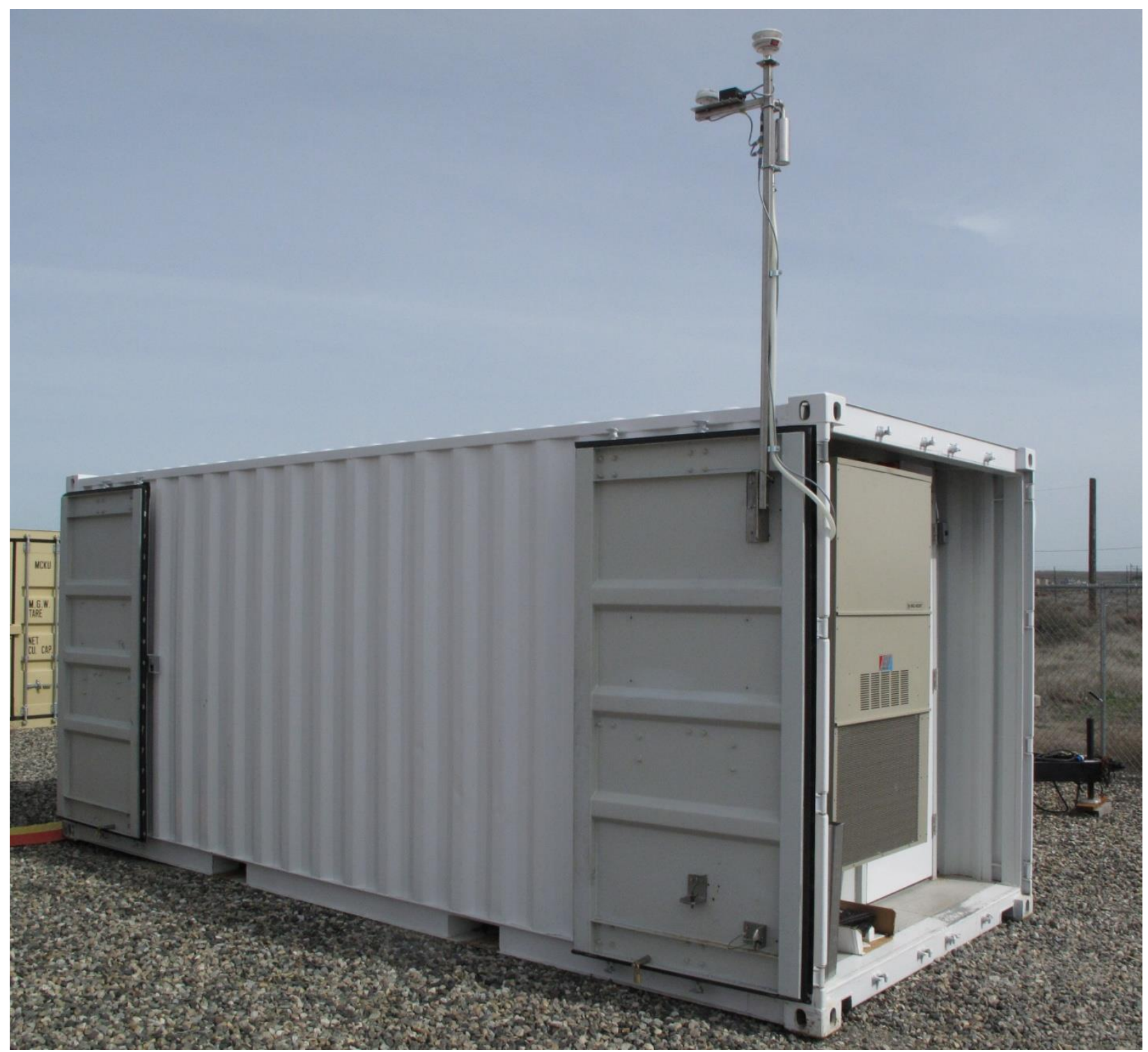

Figure 1. The TXL is housed in a $20-\mathrm{ft}$ shipping container. 


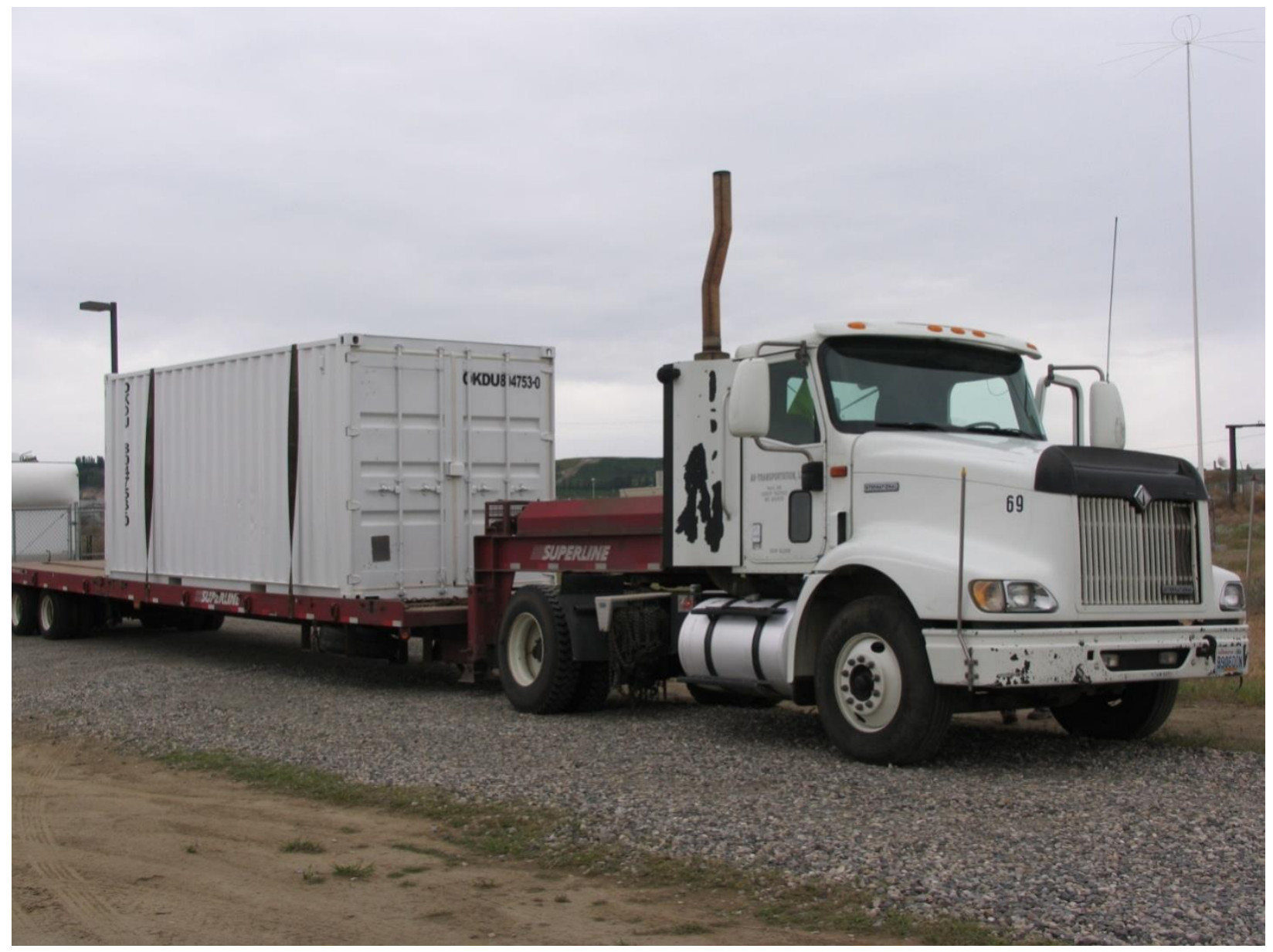

Figure 2. The TXL can be shipped anywhere in the world.

The Comprehensive Test Ban Treaty, adopted by the United Nations in 1996, will ban all nuclear testing in all environments, for military and civilian purposes. Although the treaty has not yet entered into force, the Preparatory Committee for the Comprehensive Test Ban Treaty Organization is establishing its verification network, based on five technologies: two seismic and hydro acoustic, one infrasound, and two radionuclear technologies (for particulate and radionuclear noble gas measurements). The TXL provides information on the background levels of man-made radioxenon, radioactive isotopes of a noble gas. The isotopes TXL can measure are created from the operation of nuclear reactors, medical isotope production and use, and research activity. The TXL can be used to determine the levels of radioxenon before an event of concern occurs.

Air samples are collected by TXL. The SAUNA (Swedish Automated Unit for Noble gas Analysis) system inside TXL analyzes the air samples and reports the concentrations of the radioisotopes xenon-131, xenon-133, xenon-133m, and xenon-135 (Figure 3). These data are shared with the Comprehensive Test Ban Treaty Organization/Professional Technical Secretariat, the country hosting the TXL, Sweden, and the United States. 


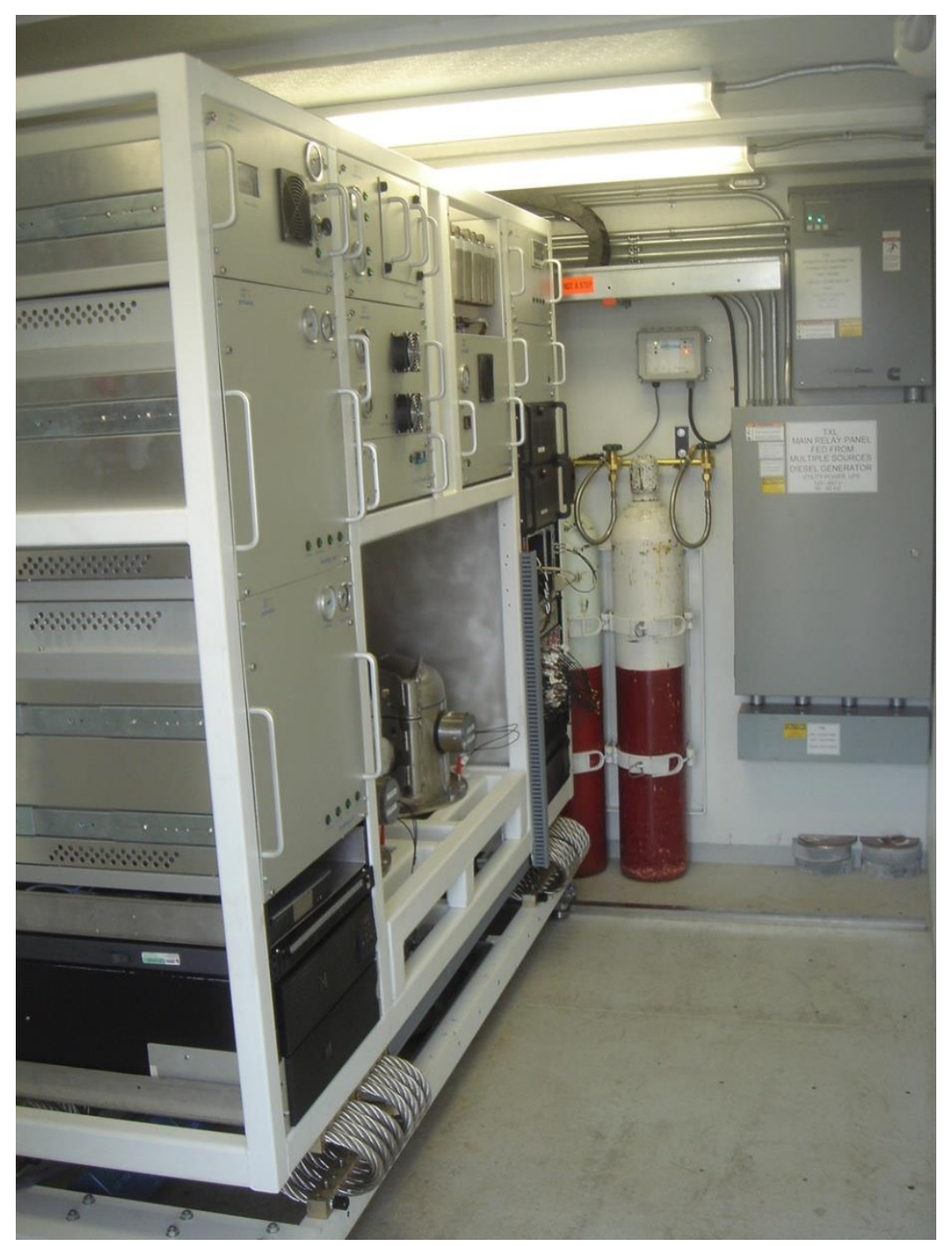

Figure 3. Inside the TXL, the SAUNA system analyzes air samples for radioisotope concentrations.

Safety and security are key features of the TXL. Risks have been minimized wherever possible. The exterior doors of the shipping container have been designed to be securely locked in the open position to prevent operators from being trapped within the container. An oxygen monitor has been incorporated to monitor the mobile laboratory's environment and to alarm if the oxygen level approaches a hazardous level. The TXL provides interior emergency lighting. Fire extinguishers are located in the laboratory and the generator compartments. The mobile laboratory is secured using an Omnilock and heavy duty steel doors and frames. A peep hole allows operators to view outside before opening the laboratory door. Communication, both data and voice, is provided with Iridium Satellite Communications. 



\section{Document Purpose}

This document presents the instructions for setting up the TXL once it has been delivered to the its sampling location, and once it has completed its sampling assignment, shutting it down and readying the TXL for its next deployment. This document also contains illustrations or photos of component parts or steps in setting up or shutting down TXL, and information on equipment functions and safety precautions. 



\section{Assumptions}

The authors of this document assume that TXL will be delivered to a location that is level and that has power nearby. Site preparation will be the responsibility of the organization receiving and hosting the TXL. A minimum of two people (at least one being a SAUNA-trained operator) are required to set up the TXL and shut it down. The authors also assume that the transportation away from the hosted site will be the responsibility of the hosting organization.

The outside of the TXL is labeled with Front and Rear markings. These markings are used to designate which end of the container faces the front and which end faces the rear of the delivery trailer. These exterior Front and Rear markings are not relevant to this manual.

Within this manual, the front of the TXL is considered the end with the personnel access door and the rear of the container is the expandable storage deck.

One complete set of TXL keys have been provided to the TXL set up team. Additional keys that are stored in the TXL include:

1. One master electrical activation key. The key is stored in key pouch located on the upper right wall of the front porch during shipping and is relocated to the TXL master control panel, Line Power Activation switch during normal operation.

2. A second master electrical activation key. The key is tethered to the SAUNA frame and is used to control the SAUNA rack transport motor.

3. One 12 volt power switch key. The key is tethered to the generator support frame. 



\section{Set Up Procedures}

\section{BACKGROUND}

\section{CONFIGURATION AND ORIENTATION OF THE TXL}

A shipping container with doors on each end was chosen to provide two distinct compartments within the mobile laboratory. Behind one set of container doors is the personnel access to the laboratory and the wall-mounted heating, ventilation and air-conditioning (HVAC) unit. In this document, this will be referred to as the "front" of the container.

The other end of the container will be known as the "rear" and the container doors open to a secured electrical utilities, generator, diesel fuel tank, and storage area.

The exterior markings of the shipping container indicate the position of the container on a delivery trailer. These markings not relevant to the procedures that follow. 



\section{A. Procedure for Opening the TXL Outer Doors and Checking the Oxygen Monitor}

\section{BACKGROUND}

\section{HELIUM GAS REQUIREMENT AND OXYGEN MONITOR IN THE TXL}

Helium is required to operate the SAUNA system. The TXL has incorporated ruggedized helium bottle racks and an automated switch-over manifold system to allow the SAUNA system to operate unattended for an extended period of time. When deployed, the TXL will contain 12 standard helium tanks, thus reducing or eliminating the need to purchase helium from a local supplier during deployment. Before opening the laboratory for the first time after the TXL is delivered to a site, TXL's oxygen monitoring system should be activated before people enter the laboratory to make sure a helium leak has not occurred during transportation.

1. Unlock the exterior shipping container locks (Figure 4) at the shipping container end marked Rear with the WOR-LOK key on the TXL key ring (provided by FedEx).

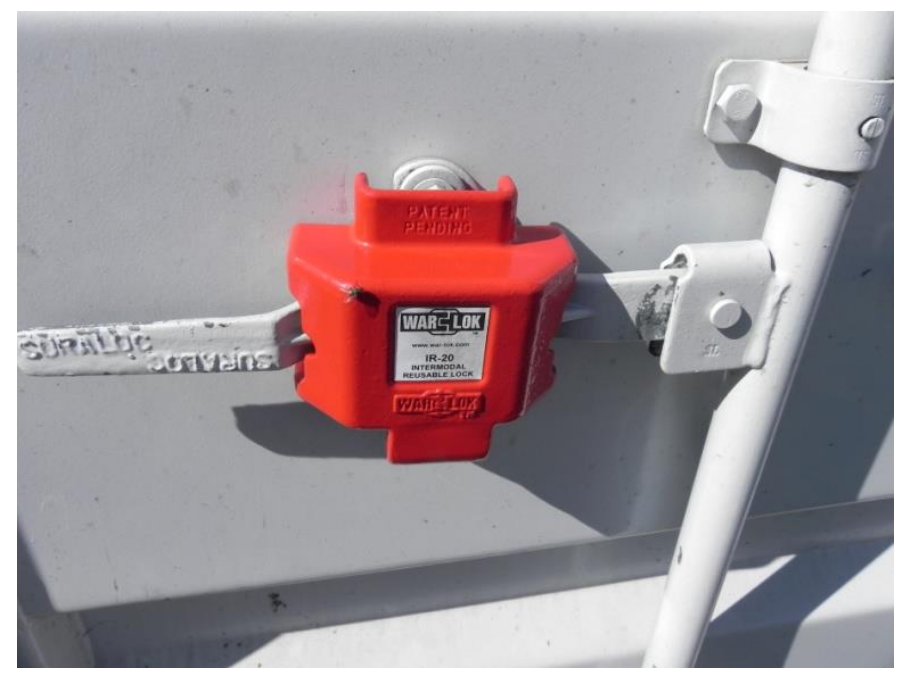

Figure 4. Shipping container locks secure the TXL during transport.

2. Place the locks aside. They will be stored later in a shipping box labeled Jacks/Leveling Fixtures/AC Cord.

3. Open the outer container doors, return latch handles to shipping configuration (Figure 5). 


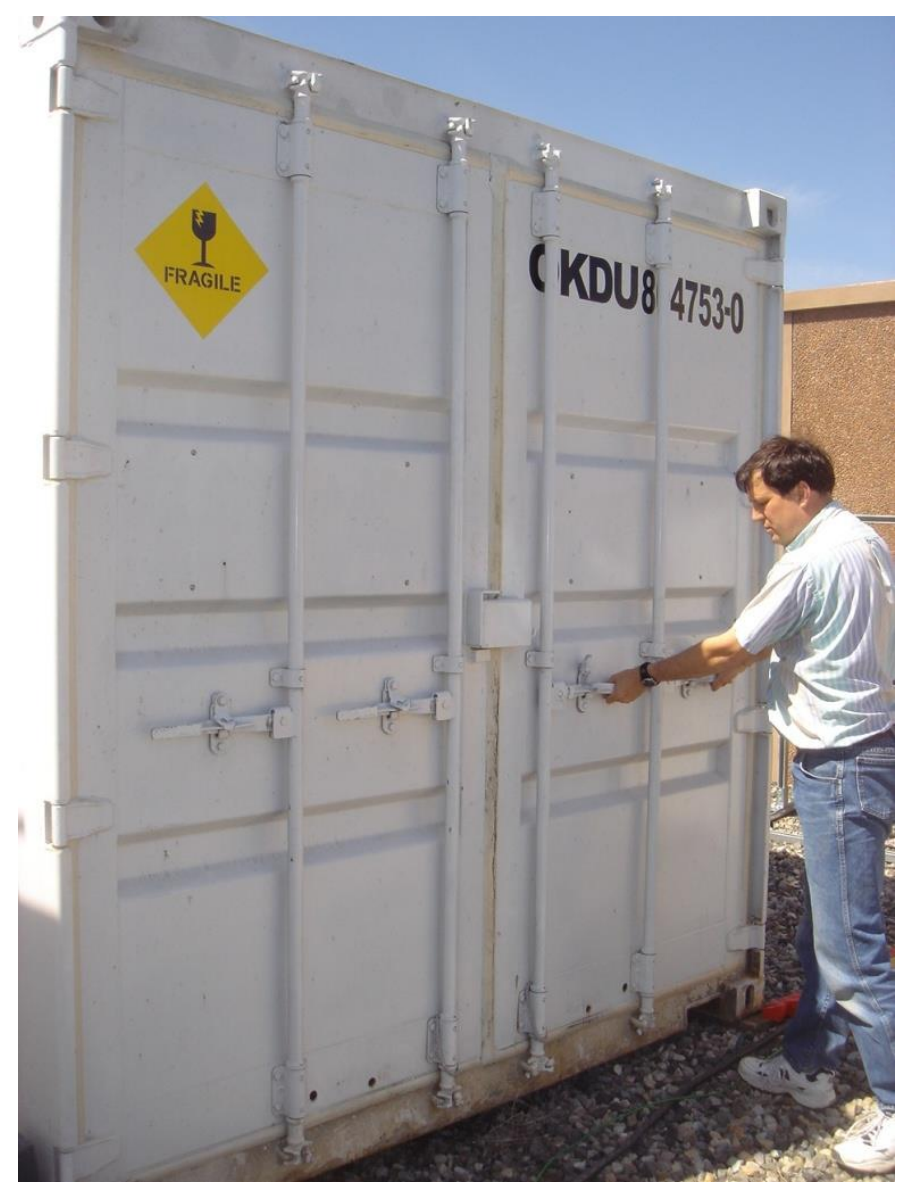

Figure 5. After opening the outer container doors, return the latch handles to shipping configuration.

4. Secure the doors in the open position by placing the rope loop located on the container door latch bar, over the hook welded to the container's exterior wall (Figure 6).

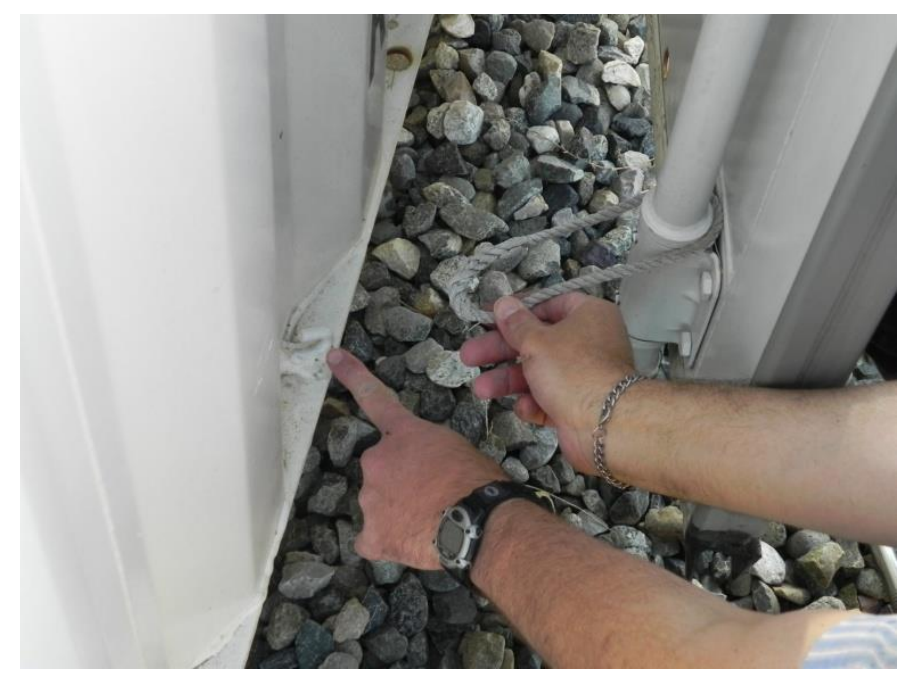

Figure 6. Secure the outer door with rope latch. 
5. The oxygen monitor activation key will be in the key pouch located on the upper right wall of the front porch.

6. Insert key (master electrical activation key) into the oxygen monitor's key switch, also located on the front porch, upper right and turn it to the ON position (Figure 7).

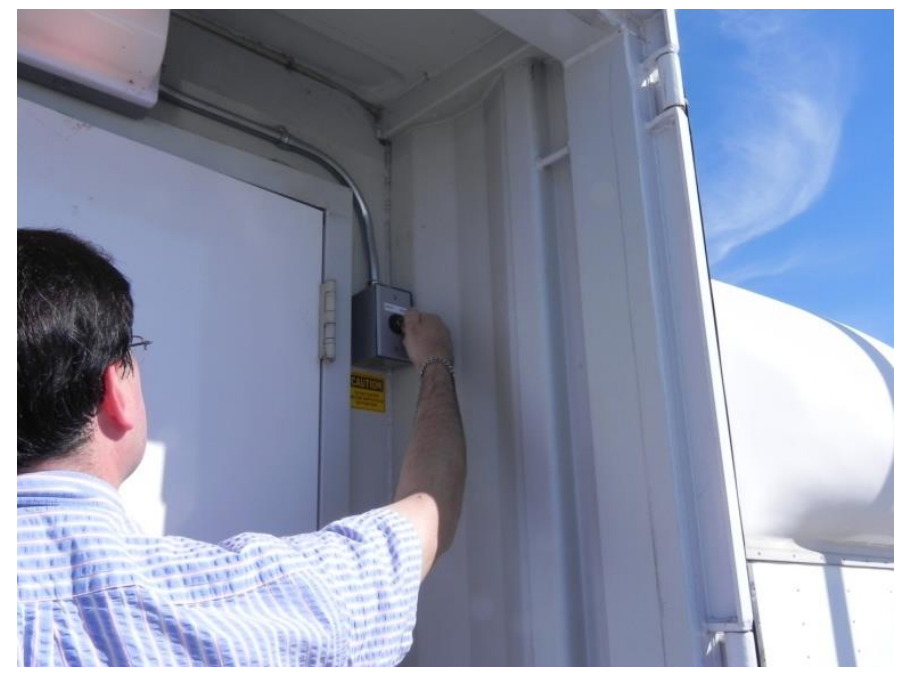

Figure 7. Insert the master electrical activation key into the oxygen monitor's key switch.

7. Open the pedestrian access door with the provided Omnilock code or the key (only authorized personnel have this key).

8. Latch the pedestrian door in open position by hooking it to the hook located on the wall (Figure 8).

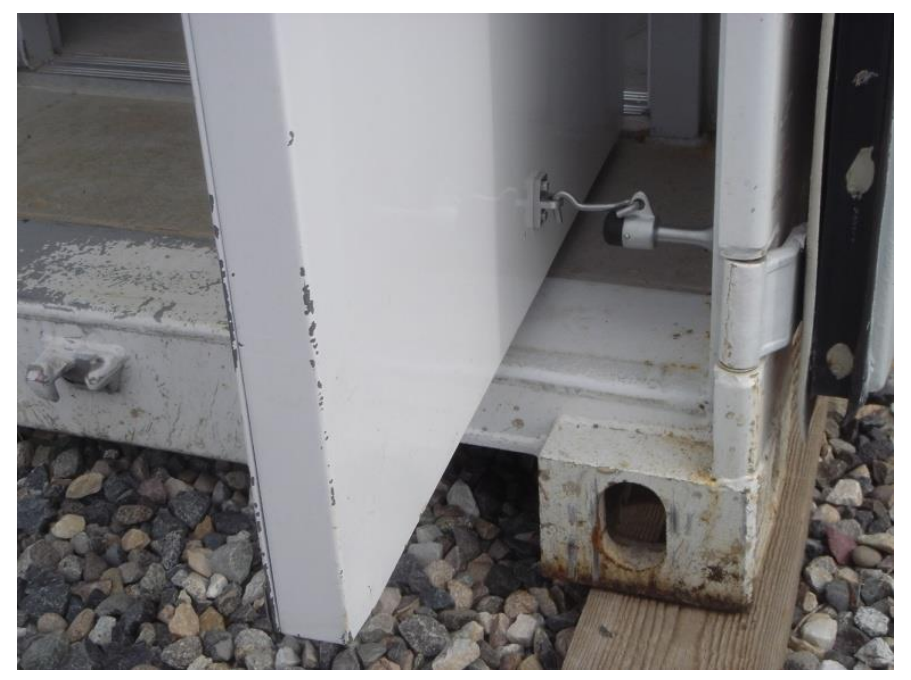

Figure 8. The pedestrian door is secured in an open position with a hook.

9. If the red light (located above the door, see Figure 9) of the oxygen monitor (TOX Gard) is flashing, open the door, BUT DO NOT ENTER, until oxygen deficiency has cleared and the red light turns off. (This may take several minutes.) During normal operations with a safe oxygen level, the red light should not be illuminated. 


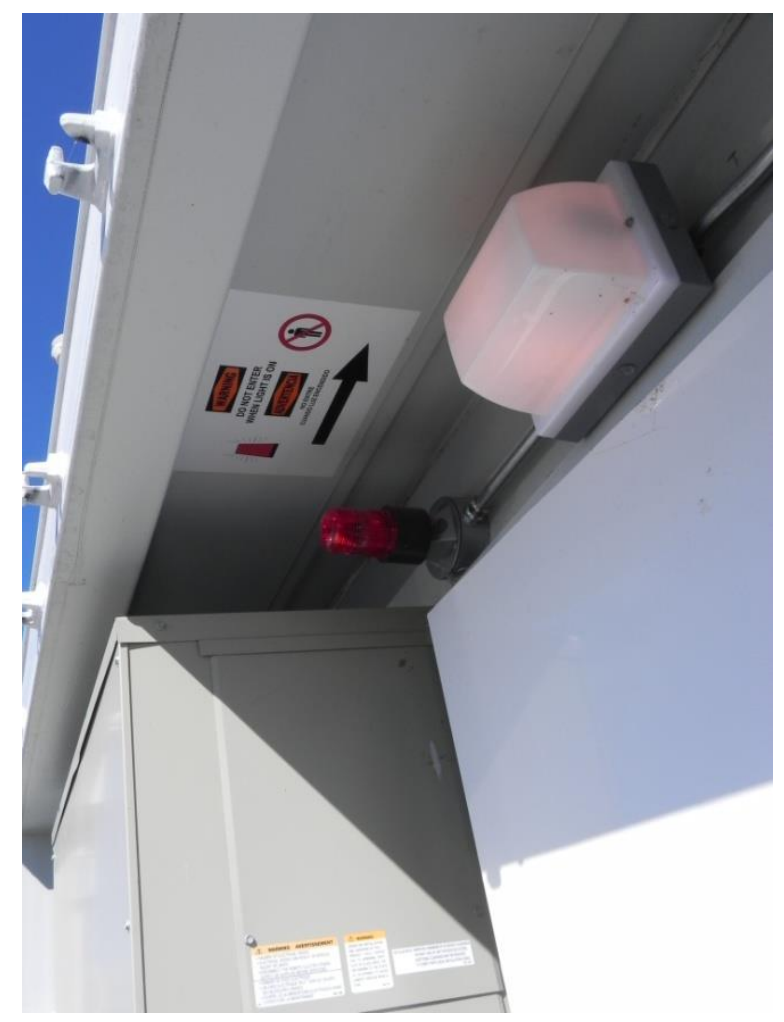

Figure 9. The warning light of the oxygen monitor flashes red if the air inside TXL is oxygen-deficient.

\section{SAFETY NOTE}

IF THE RED LIGHT HAS BEEN FLASHING, LEAVE THE ACCESS DOOR OPEN. There is a helium leak, and you will follow IV.M Procedure to check this.

END OF PROCEDURE IV.A 


\section{B. Procedure for Leveling the TXL}

1. If the oxygen monitor's red light is off, it is safe to enter the laboratory. You may do so at this time.

2. Remove the shipping tie down straps from the three yellow shipping boxes, ladder, folding chair, vacuum cleaner, and hard hats, which are secured directly inside the laboratory door. These boxes are labeled as Jacks/Leveling Fixture/AC Cord, Dunnage/SAUNA Shipping Brackets, and Detector.

3. Hang the hard hats on the coat hooks located on the inner right wall of the TXL.

4. Remove the three yellow shipping boxes, ladder, folding chair, and vacuum cleaner. Stage these items outside the TXL in an area that is convenient. These boxes are labeled as Jacks/Leveling Fixtures/AC Cord, Dunnage/SAUNA Shipping Brackets, and Detector. If the boxes are too heavy for two individuals to move comfortably, the contents may be removed from the boxes and taken outside the TXL.

5. Open the shipping boxes labeled Jacks/Leveling Fixtures/AC Cord and Dunnage/SAUNA Shipping Brackets.

6. Remove the grey shipping box labeled SAUNA Spare Parts from the TXL, and stage it near the rear of the container.

7. Turn the emergency light switch from TRAVEL to OPERATE. The emergency light switch is located in the middle of the right wall near the ceiling.

8. Unlock the tool cabinet and retrieve the bubble level and zippered bags marked Shipping Tie Down Straps from Drawer 4. Place the shipping straps into bags and zip the bags closed. Set the bags next to the Dunnage/SAUNA Shipping Brackets shipping box outside the TXL.

9. Place the bubble level on the laboratory floor inside the front (pedestrian access) door.

10. Orient the level in several angular positions to determine which corner of the TXL is lowest.

11. Retrieve leveling fixtures, jacks, and dunnage from shipping boxes.

12. Begin leveling the laboratory by adjusting height of the lowest corner.

13. Insert leveling fixture into the oval hole of the corner block. The lifting fixture may be inserted into either the end or side lifting hole of the corner block. (Figure 10). 


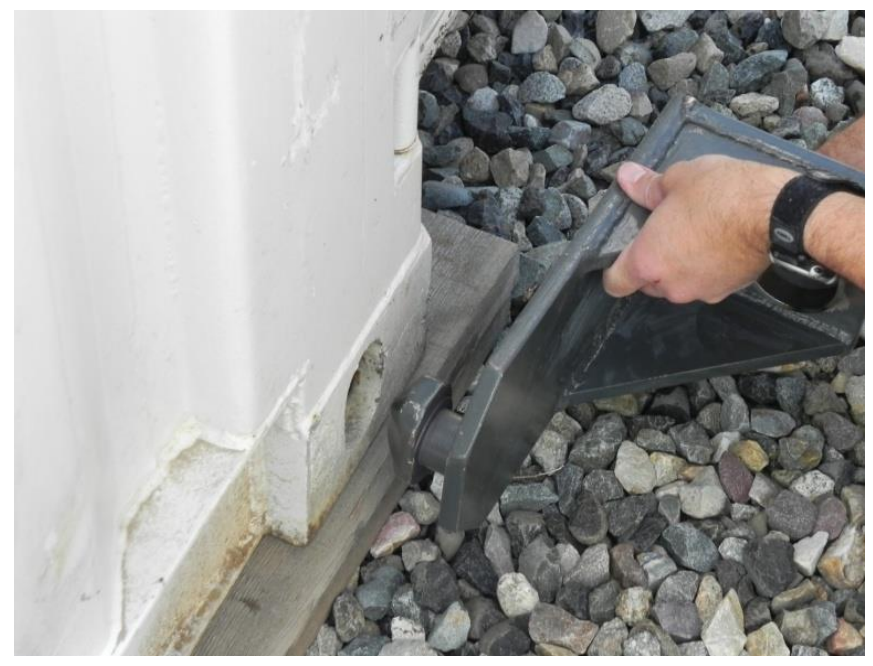

Figure 10. Insert the leveling fixture to prepare to level the TXL.

14. Rotate leveling fixture 90 degrees and place the hydraulic jack under fixture on a piece of dunnage.

15. Place at least one 18-in.-long (45.7-cm-long) piece of dunnage on the ground where the jack will be positioned during the lifting process. Place the jack under the leveling fixuture. Align the jack such that the jack's central axis is vertical and directly under the lifting fixture's safety antislip ring. Adjust the height of the piston ram to engage the elevated lifting fixture. The height of the piston ram is adjusted by turning the head of the piston ram counterclockwise to unthread from the bore of the jack. The top of the piston ram should be within 1 in. $(2.5 \mathrm{~cm})$ of mating with the leveling fixture. The piston ram will unthread, and allow you more height for the bottle jack to engage or nearly engage the fixture. If additional dunnage is required to raise the jack body, place it underneath the jack to accomplish this, use no more than 4 in. $(10 \mathrm{~cm})$ of dunnage in height. Be sure that the jack's central axis is vertical and not on an angle as this can cause a dangerous situation.

16. Make sure that the hydraulic jack engages the leveling fixture inside the safety (antislip) ring (Figure 11). 


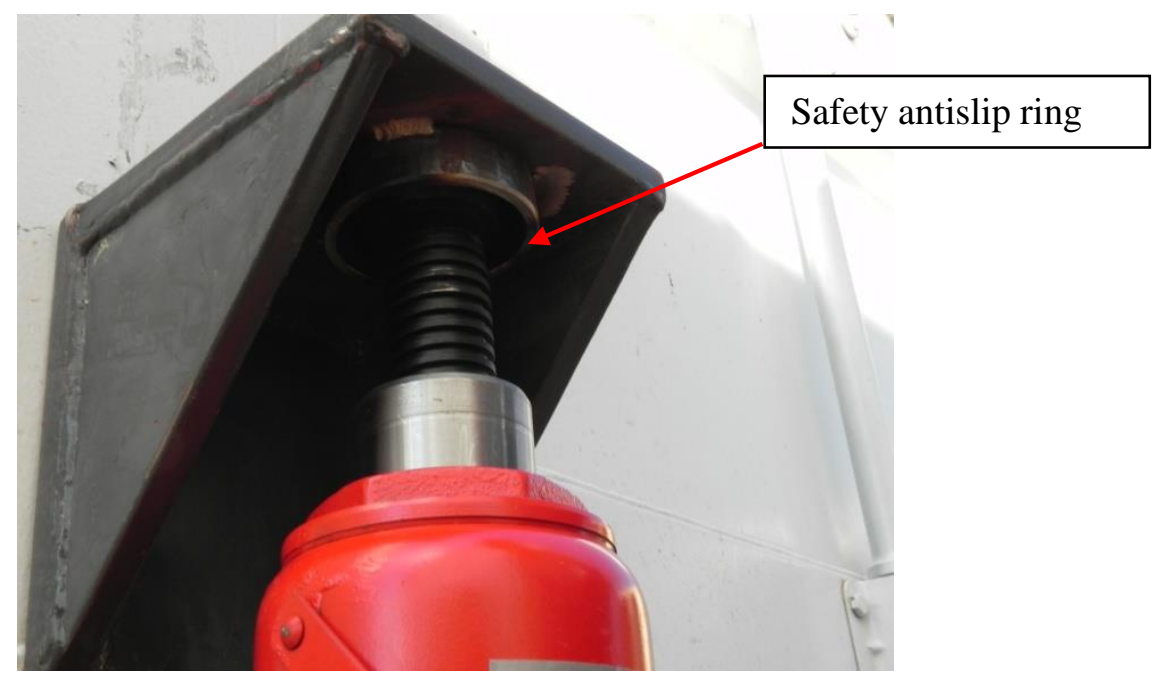

Figure 11. The bottle jack is engaged inside the antislip ring of the leveling fixture.

17. Locate the valve at the bottom of the bottle jack. It is a small flattened screw-top device that holds the pressure of the hydraulic piston when locked, and then releases the hydraulic pressure when opened (Figure 12). Using the tip of the bottle jack handle as a key for the valve, turn it clockwise until it is tight. The bottle jack is now in the locked position, and will allow the piston ram to raise.

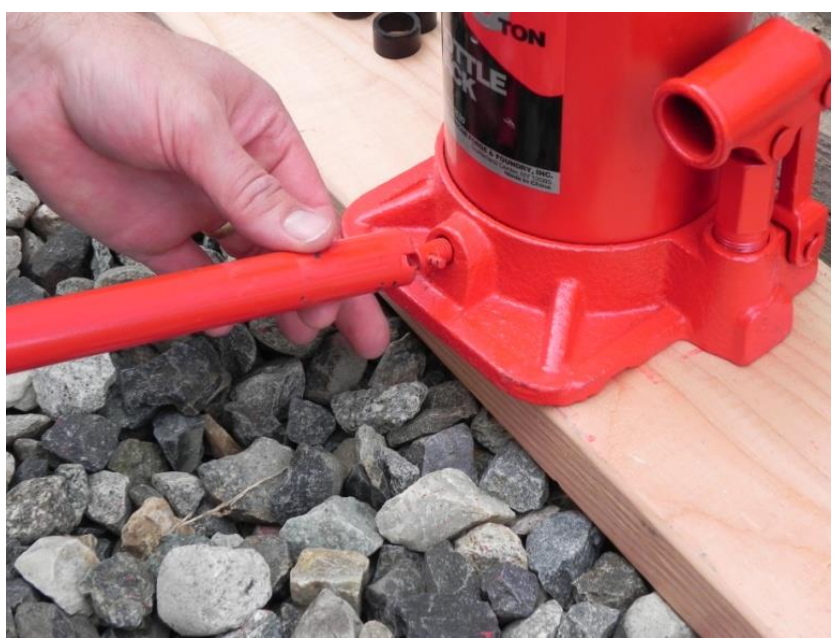

Figure 12. Using the tip of the bottle jack handle, tighten the valve to hold the pressure of the hydraulic piston.

18. Place the handle assembly (this is a two-piece handle for leverage) into the pump shaft (Figure 13). 


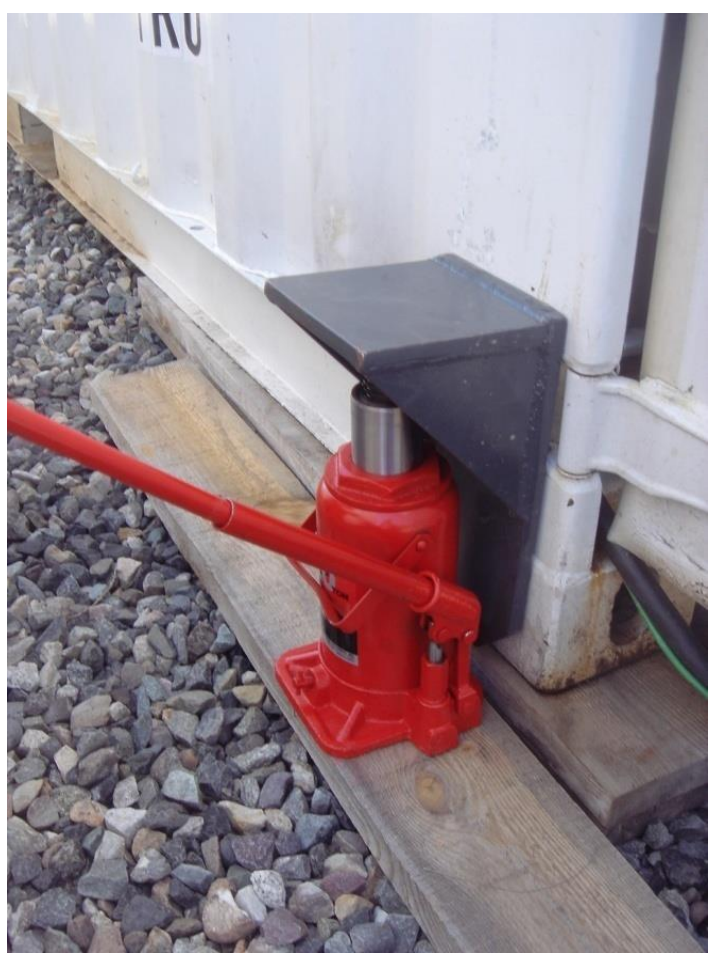

Figure 13. The handle of the jack is inserted into the pump shaft, and the jack is ready to raise the container.

19. Raise the container using the hydraulic jack. Pump the handle up and then down. Each time the pump shaft moves in the down position, the hydraulic piston of the bottle jack raises. Be sure that the jack's cylinder is placed securely within the leveling fixture inside the safety (antislip) fixture.

20. Recheck the bubble level.

21. Continue to raise the container until the container is level.

22. Use second jack and leveling fixture, if needed, to level the laboratory.

23. Repeat process until the laboratory is level.

24. Insert dunnage and release pressure on jacks (Figure 14). Leave jacks in place and check the level. 


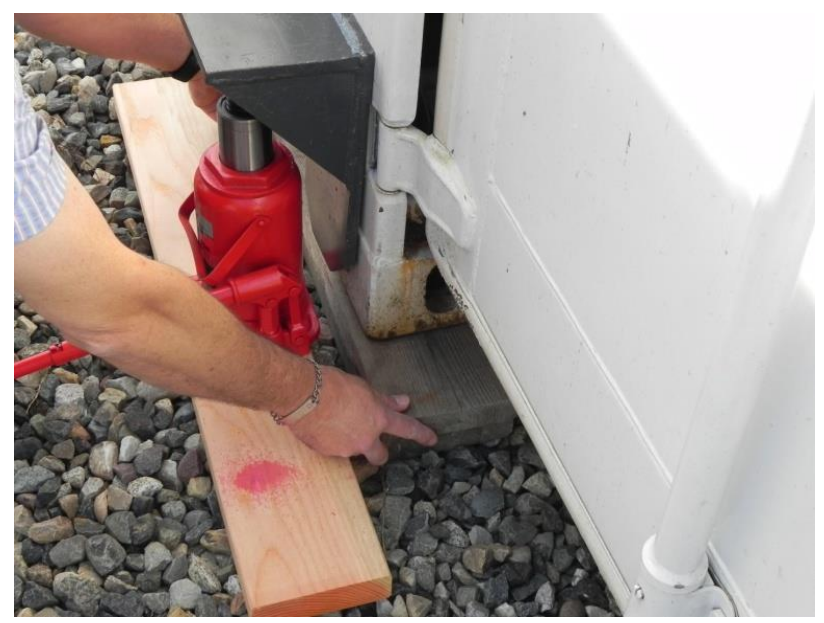

Figure 14. Insert dunnage to level the TXL.

25. Check level of laboratory and insert additional dunnage if required.

26. If more dunnage is required than is supplied, use nominal 2-in. by 6-in. (5.1-cm by $15.2-\mathrm{cm}$ ) by 24-in.to 36-in.-long (61.0-cm to 91.4-cm-long) lumber to level the laboratory.

27. Remove the handle from the pump shaft, and place the tip back into the valve when you are ready to lower the bottle jack. Turn the valve counterclockwise as slowly as possible to lower the container. Opening the valve quickly will result in dropping the piston rapidly, and can damage the TXL or cause bodily injury.

28. Remove the bottle jack(s) and leveling fixtures(s).

29. Store jacks, fixtures, 18 -in.-long (45.7-cm-long) dunnage in shipping boxes (as shown in Figure 15).

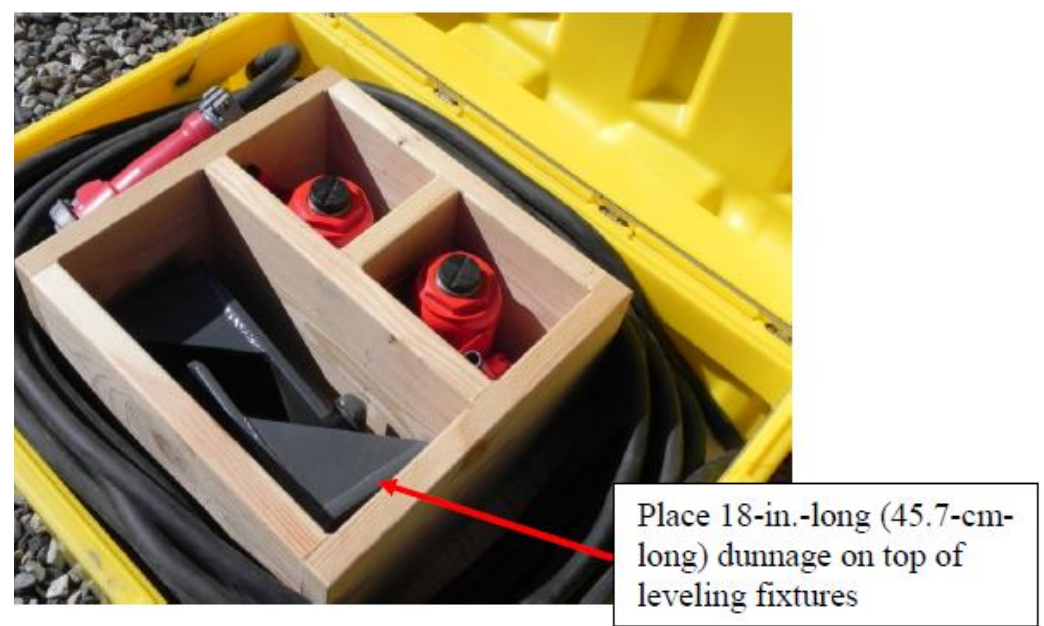

Figure 15. Main power cable, jacks, and leveling fixtures are stored in a yellow shipping box.

30. Remove unused dunnage from shipping box and stage the dunnage near the rear container doors.

END OF PROCEDURE IV.B 



\section{Procedure for Securing Doors (for Tamper Resistance and Safety of Operating Personnel)}

1. Retrieve the J-hooks and nuts marked $F R$, and two padlocks from the Drawer 4 of the tool cabinet. The padlocks' key is on the TXL key ring sent by FedEx.

Note the J-hooks and nuts are stamped with $F R$ and $R R$. The $F R \mathrm{~J}$-hooks and nuts are to be used to secure the doors on the container end marked Front. The $R R$ J-hooks and nuts are to be used to secure the doors on the container end marked Rear. Note that the marking of the J-hook nuts are the only exception to the labeling convention outlined in Section III Assumptions.

2. Unhook the rope holding the doors in the open position.

3. Move the doors enough to place the hook of the J-hook through hole on side of container (see Figure 16). Feed threaded end of J-hook through the hole (lower middle portion of door) in the container door.

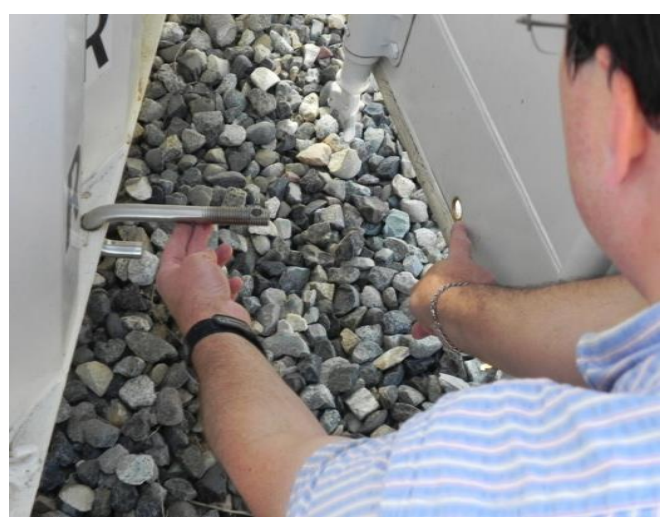

Figure 16. Position the door to feed the threaded end of the J-hook through the hole.

4. Screw nut onto J-hook.

5. Insert padlock through the hole in J-hook and lock in it place (Figure 17).

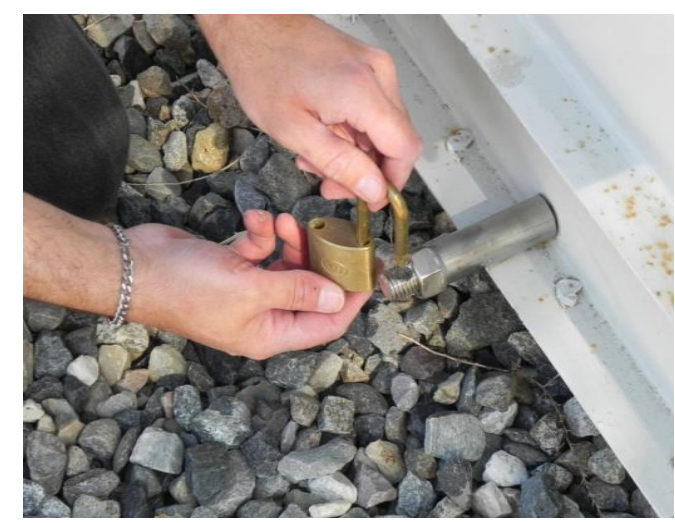

Figure 17. The outside doors of the TXL are secured in the open position using a padlock.

END OF PROCEDURE IV.C 



\section{Procedure for Setting Up the Rear Storage Area of TXL}

\section{SAFETY NOTE}

Be aware that winds may cause unsecured shipping doors and screen doors to open and close unexpectedly. If possible, deploy the rear storage area in winds speeds less than 5 miles per hour (8 kilometers per hour).

1. Open the rear deck fully and attach doors to container with supplied rope attached to the door locking rods (Figure 18).

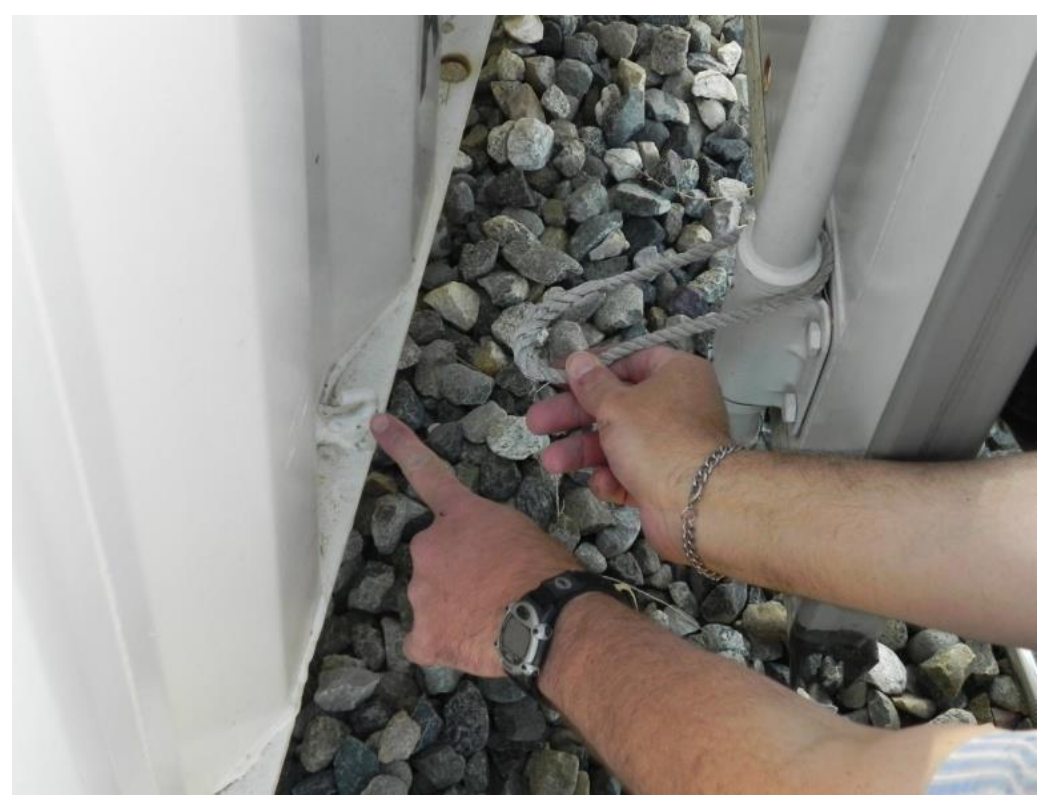

Figure 18. Secure the outer doors in the open position with rope latch.

2. Unlatch the floor using the latch located on the right side (Figure 19).

CAUTION!: The floor is now capable of hinging out to the deployed position. If the floor is allowed to deploy freely, it can damage the TXL or cause bodily injury. 


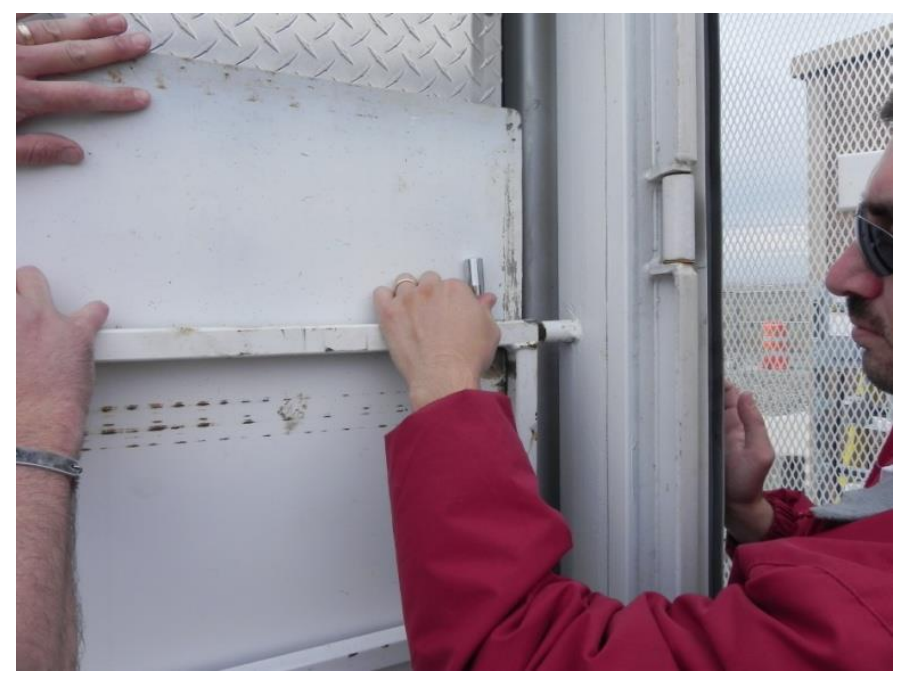

Figure 19. Unlatch the floor of the rear deck of the TXL.

3. Using proper lifting technique, two people should lower the floor to deployed position (Figure 20).

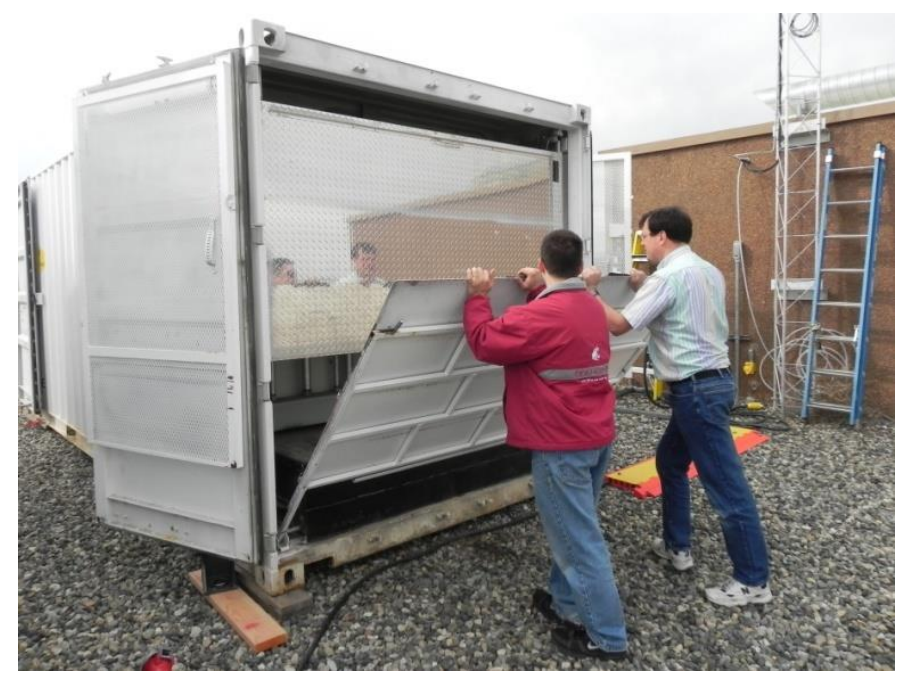

Figure 20. Lower the TXL rear deck floor to the deployed position.

4. Loosen four T-bolts located on the right and left sides of the floor frame ( Figure 21) and slide floor to abut the laboratory frame (Figure 22). Tighten the T-bolts. 


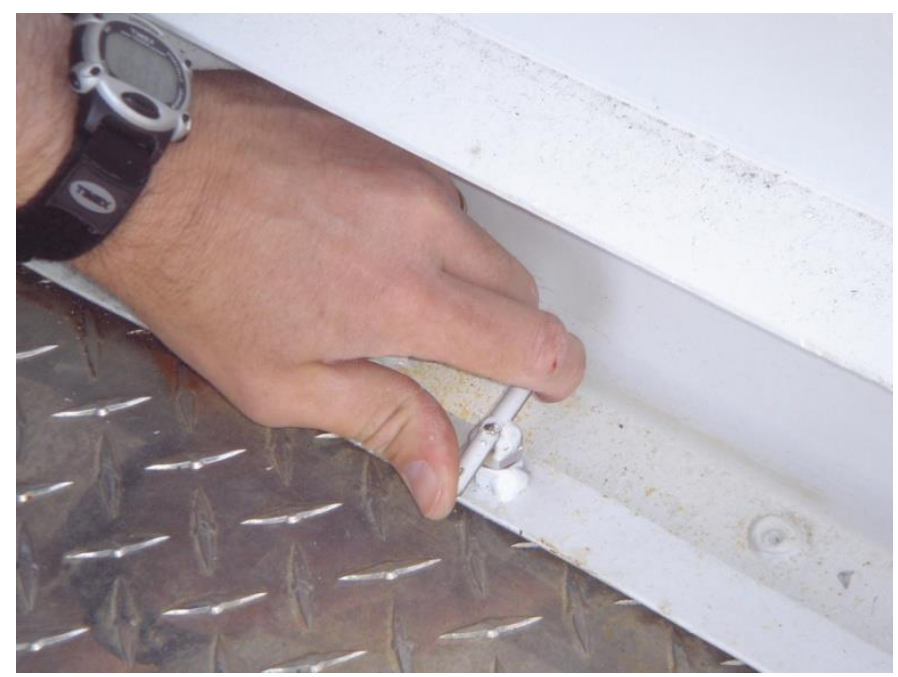

Figure 21. Loosen the T-bolts located on the right and left sides of the floor.

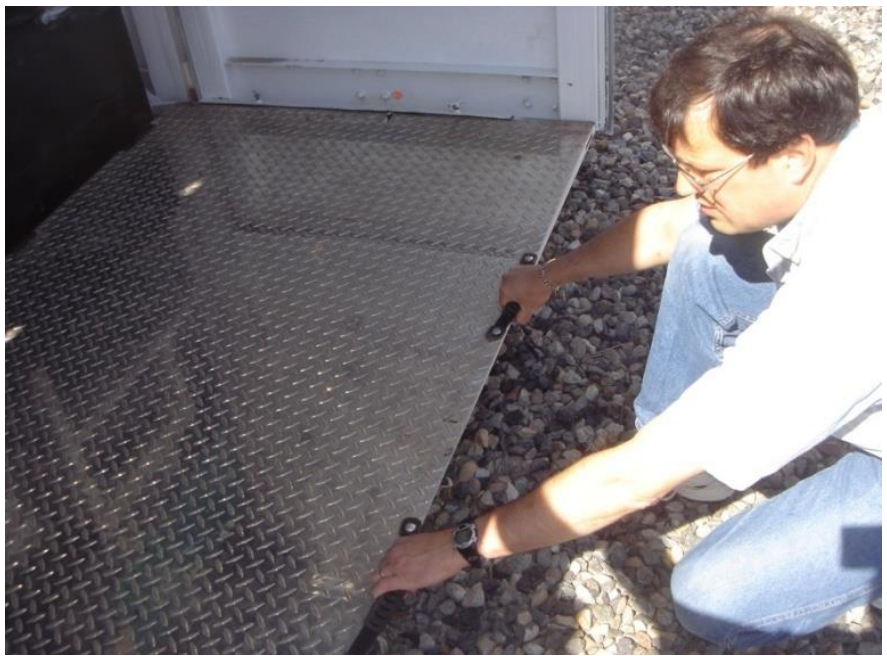

Figure 22. Slide the TXL rear deck floor to abut the laboratory frame.

5. If country electrical codes require a secondary grounding cable, uncoil green grounding cable located on the left side of the rear storage area.

6. Retrieve the AC power cord from the Jacks/Leveling Fixture/AC Cord shipping box. Place the connector on the left side of the rear storage area. Do not connect it to the main utility plug at this time. Position the AC power cord and green grounding wire to the left of the container so that they are not a tripping hazard.

7. Unlatch the rope holding both external doors and swing the doors to approximately a 135-degree position in preparation to lift and secure the roof. Swing the screen doors to their full open position.

8. Stage the ladder at the center of the floor. Ensure that the ladder is standing securely on the ground.

9. Raise the roof with two people, to shoulder height (Figure 23). 


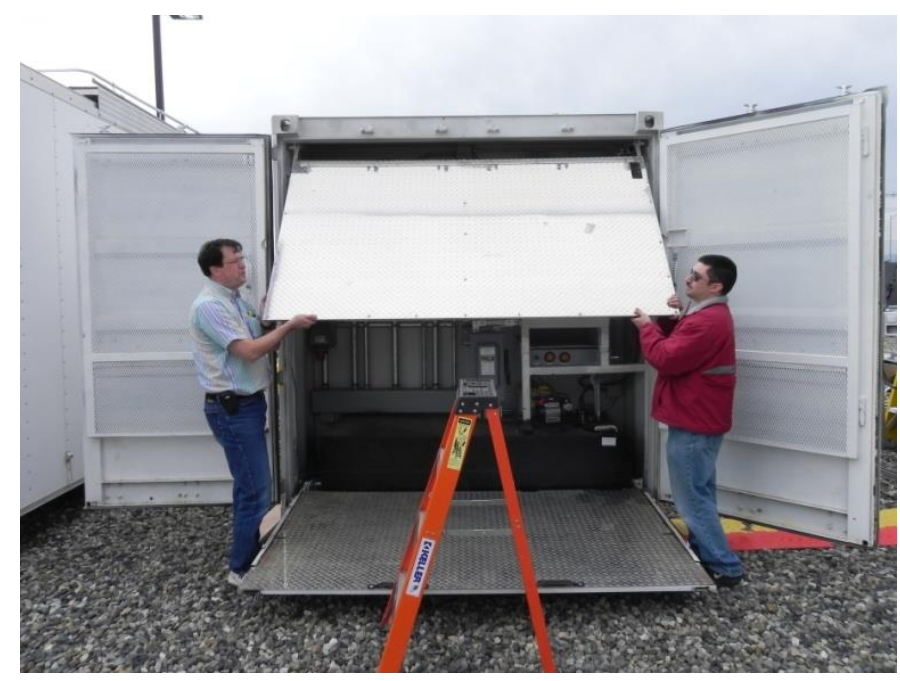

Figure 23. Raise the TXL rear deck roof.

10. With both people supporting the roof, have the taller person move to the ladder and raise the roof higher that the top of the container doors (Figure 24).

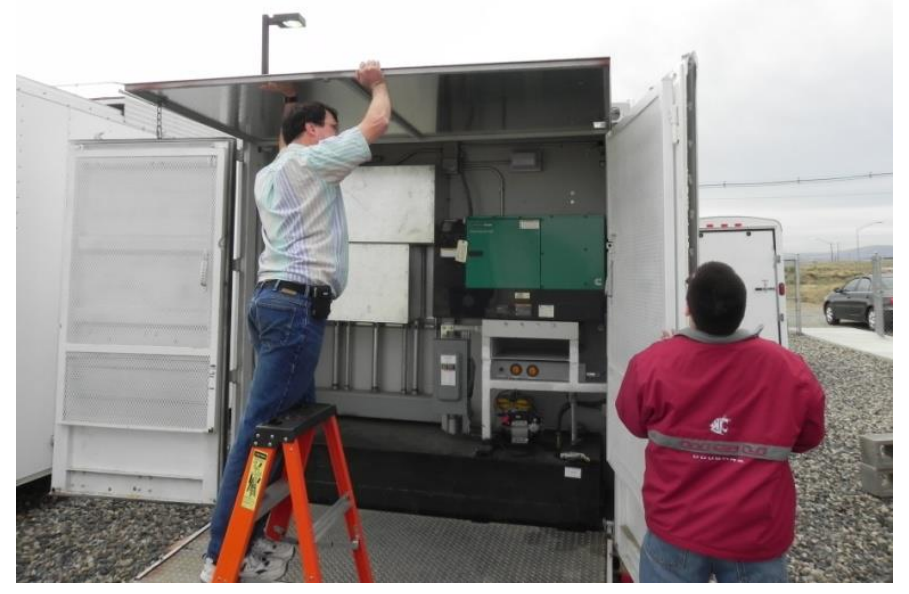

Figure 24. Raise the TXL rear deck roof higher than the doors.

11. Facing the rear deck, the second person should close the right container door to 90 degrees and engage the roof/door latch located at the top of the container door. Lower the roof to engage the roof/door latch (Figure 25). 


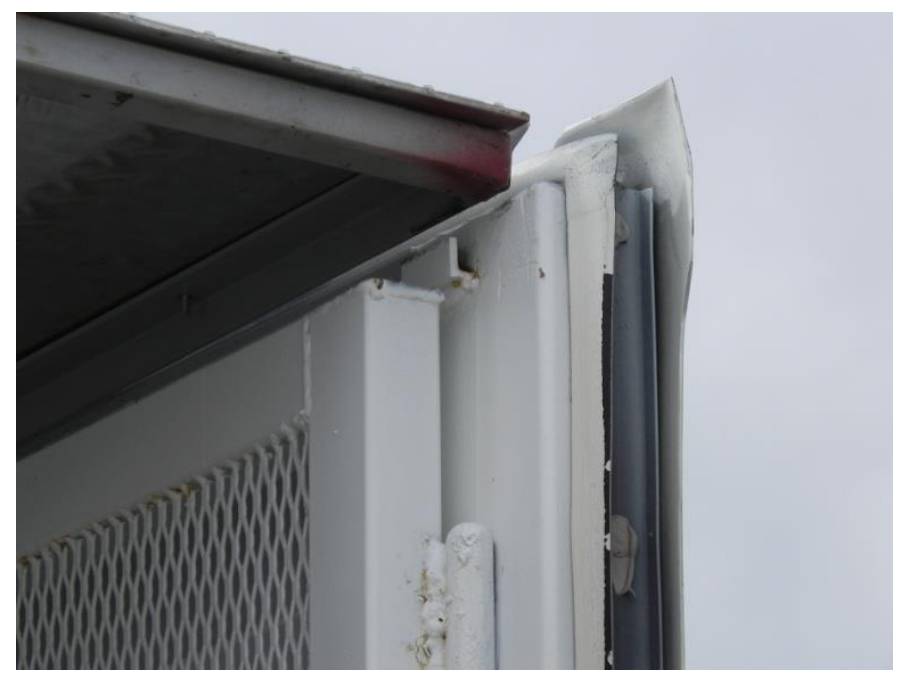

Figure 25. Engage the roof door latch.

12. Route power cable, and green grounding wire if needed, through the opening between the left rear door, the rear deck floor, and the container frame (Figure 26).

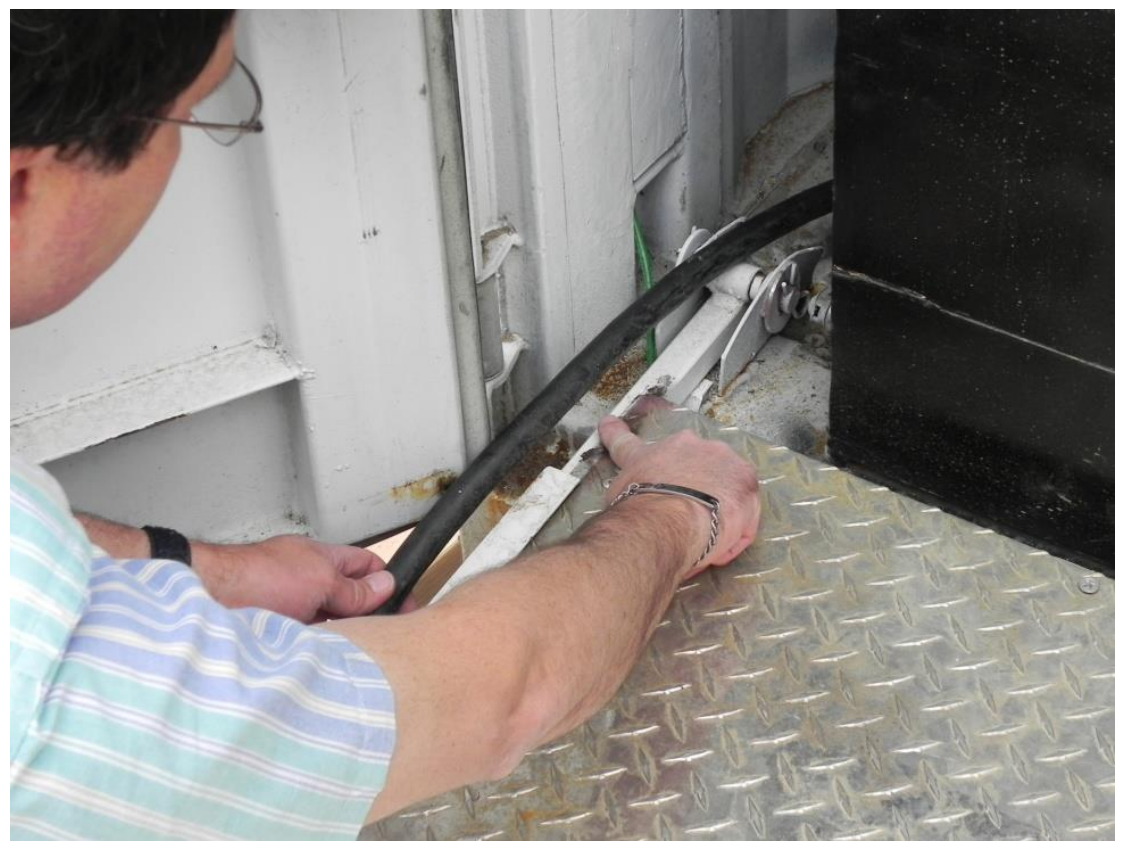

Figure 26. Route the power cable and green grounding wire, if needed, through the opening between the left rear door, the rear deck floor, and the container frame.

13. Repeat Step 11 for the left door. Ensure that the electric cables are not pinched in this process.

14. Raise up the floor such that the floor locking pin is in line with the receiving hole in the container doors. The second person slides the two floor locking pins into the holes (Figure 27). 


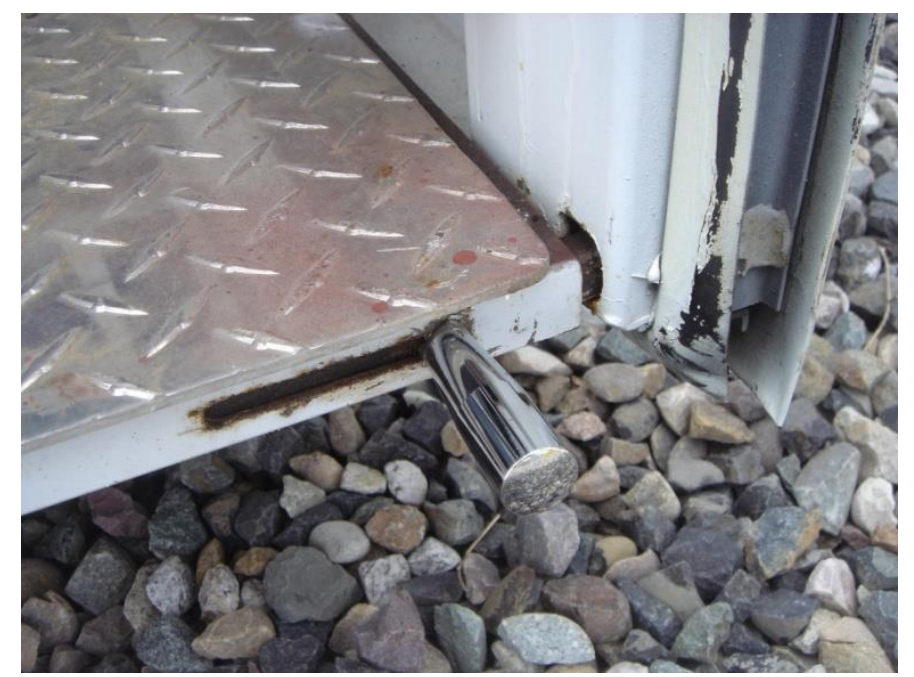

Figure 27. The floor locking pins secure the TXL rear deck floor to the container doors.

15. Retrieve the J-hooks, nuts marked $F R$, and two padlocks from Drawer 4 of the tool cabinet.

16. Insert J-hooks through the holes in container door and the oval holes in rear deck floor (Figure 28).

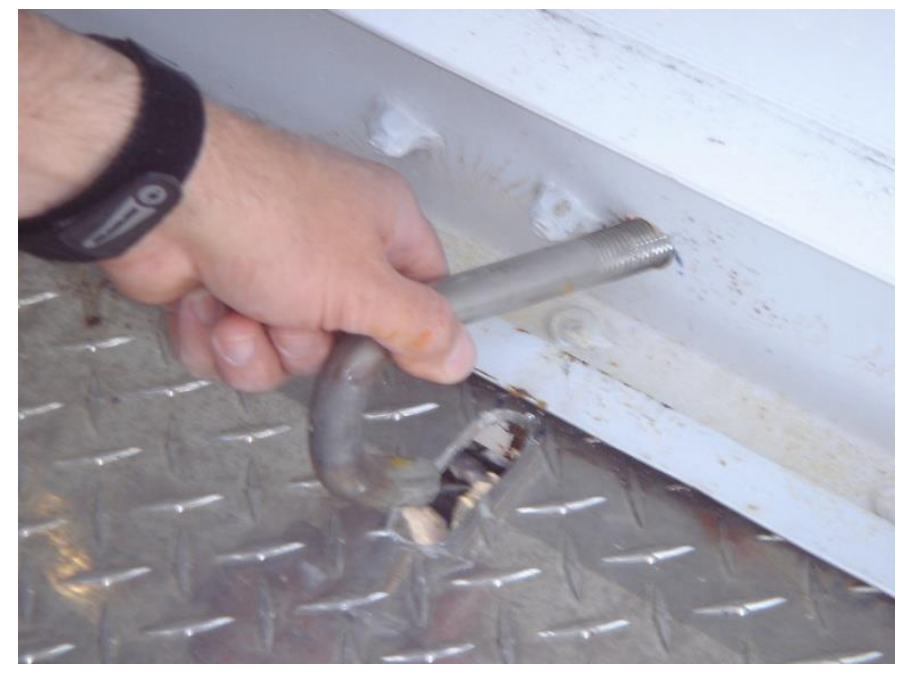

Figure 28. Insert a J-hook through the holes in the floor and door.

17. Secure the two J-hooks with nuts and padlocks on outside face of door (Figures 29.) The floor is now secured and can support a ladder. 


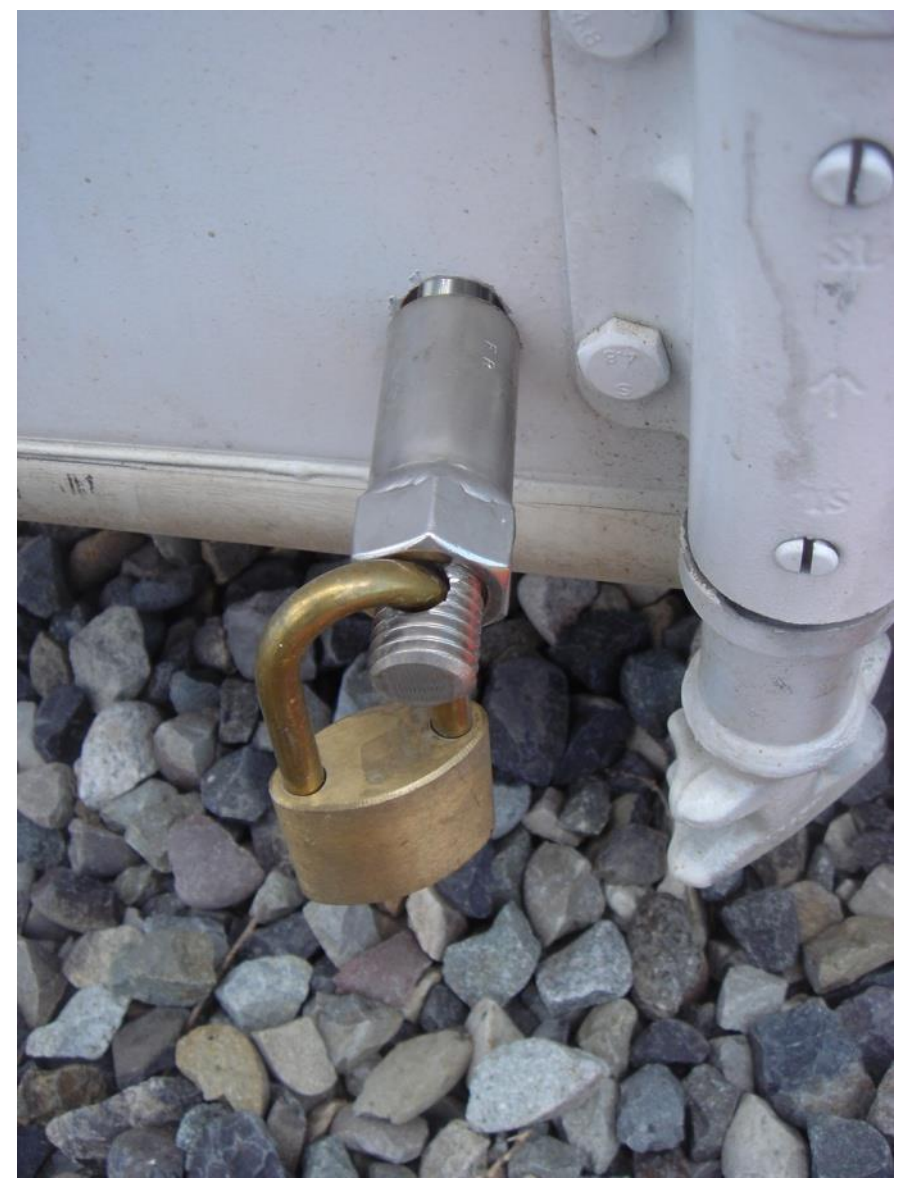

Figure 29. The J-hooks are locked in place with a padlock and the floor is secure.

18. Secure the roof with chain and bolts (Figure 30).

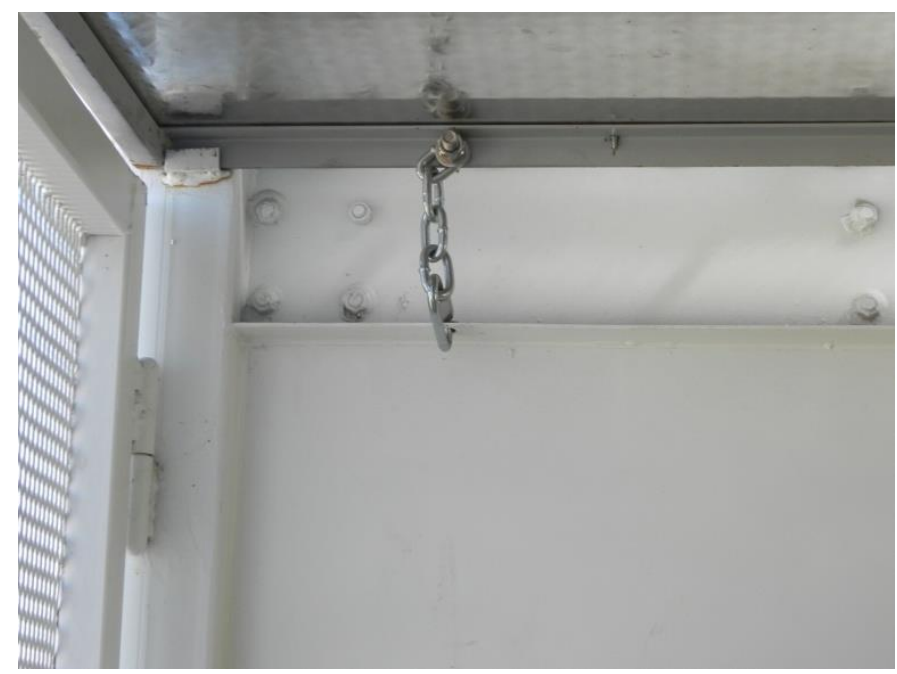

Figure 30. A D-ring and chain secure the rear deck roof to the side of the container. 
19. Plug main power cord into the receptacle on the left side (rear) of TXL (Figure 31).

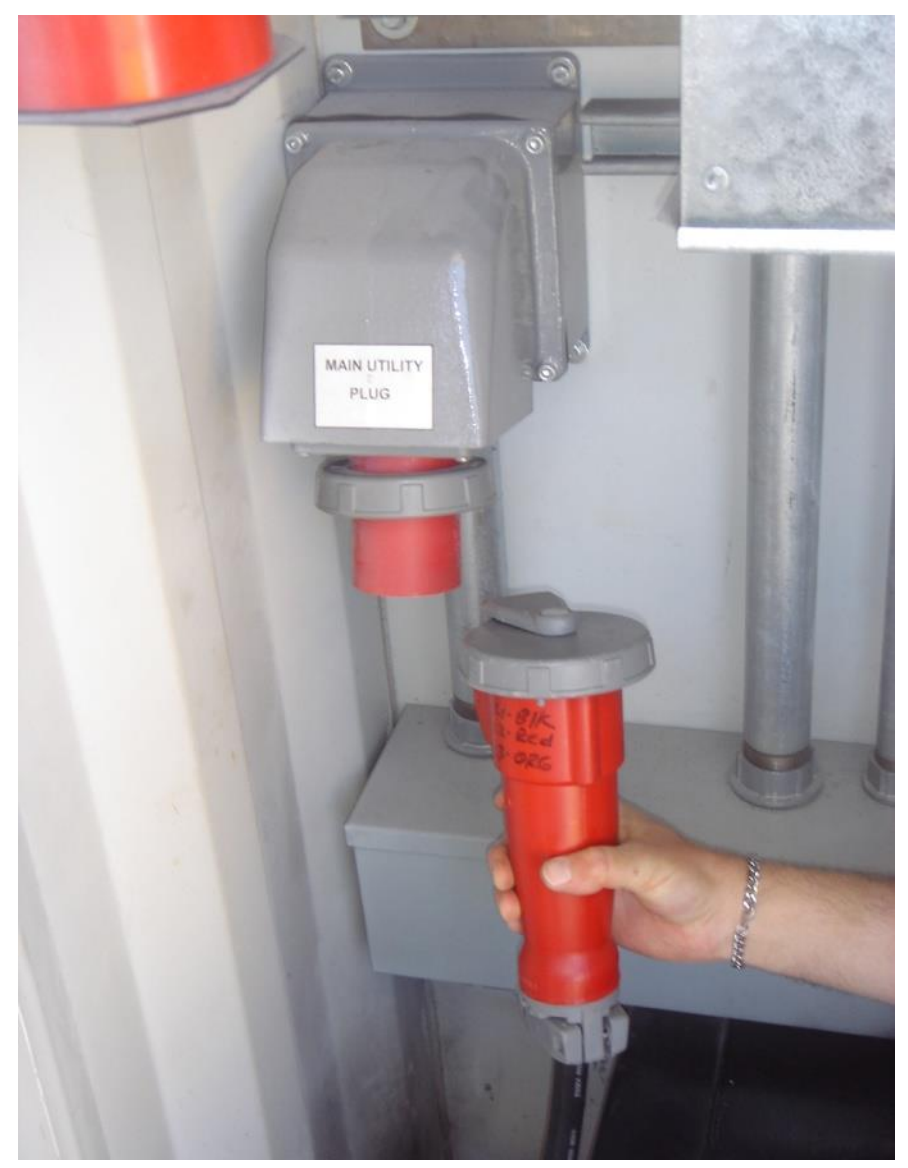

Figure 31. Plug in the main power cable.

20. Close the left screen door. Latch it in place by pulling down on the latch pin chain and releasing it.

21. Disengage the latch holding the lower panel of the screen door (Figure 32). 


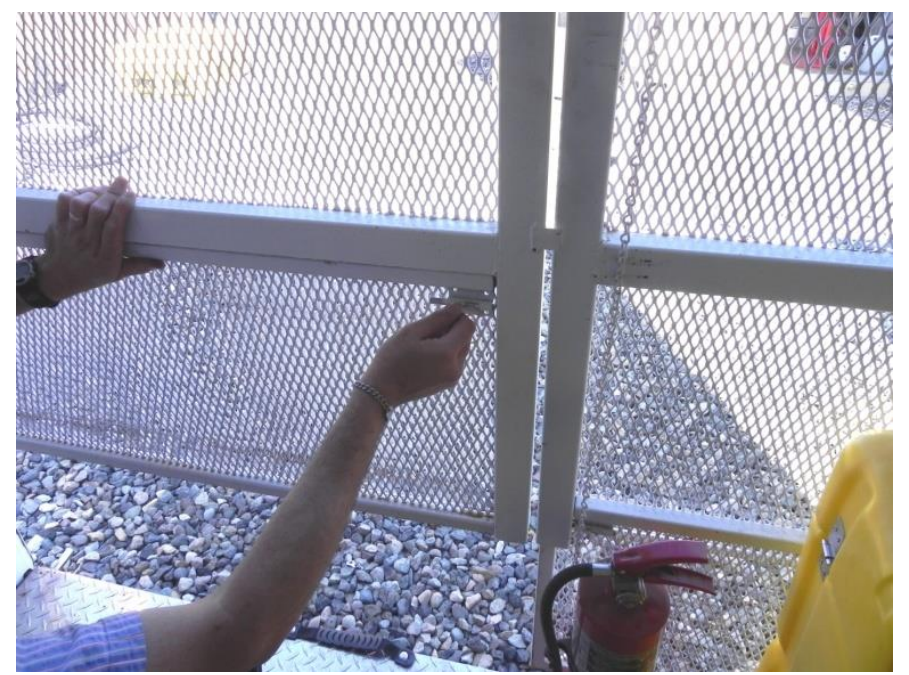

Figure 32. Disengage the latch on the lower panel of the screen door.

22. Extend the lower panel of the screen door and latch in place (Figure 33). Repeat for other door.

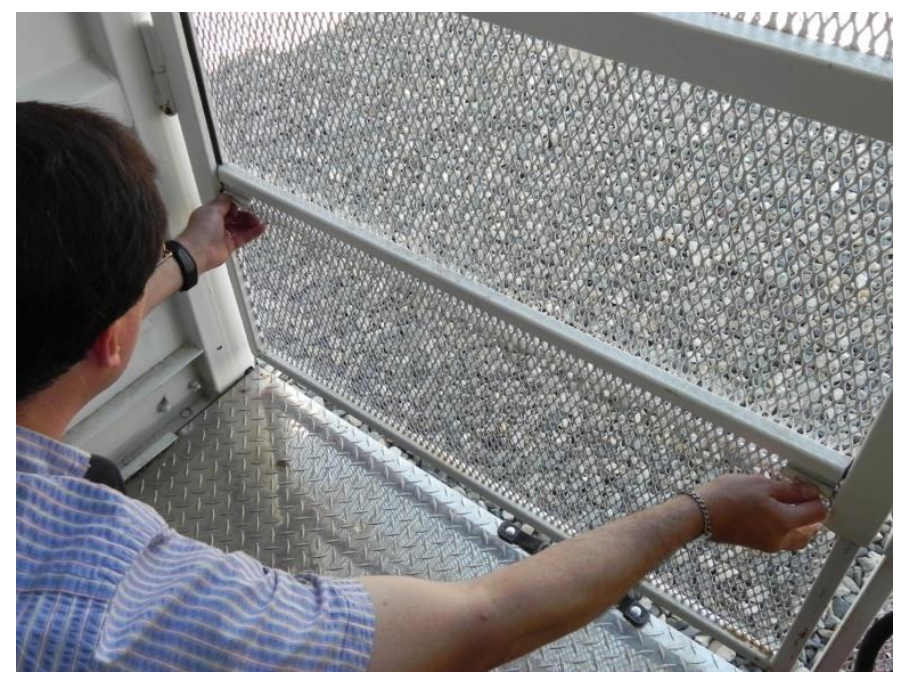

Figure 33. Extend the lower screen panel on the rear screen door and latch it into place.

23. Step outside.

24. Close the right screen door. From the outside, latch the door to the ceiling with the spring-loaded latch.

25. Secure rear deck screen doors with cylindrical padlock when access is not needed.

\section{END OF PROCEDURE IV.D}





\section{E. Procedure for Installing the Generator Exhaust Diverter onto the Tail Pipe}

1. Remove exhaust diverter assembly from shipping box labeled Dunnage/SAUNA Shipping Brackets.

2. Remove the tethered spring pin from exhaust pipe.

3. Feed the diverter through the hole in the roof of the rear deck and slide over exhaust pipe. Use the ladder provided, if needed.

4. Replace the tethered spring pin in place with spring-loaded pin (Figure 34).

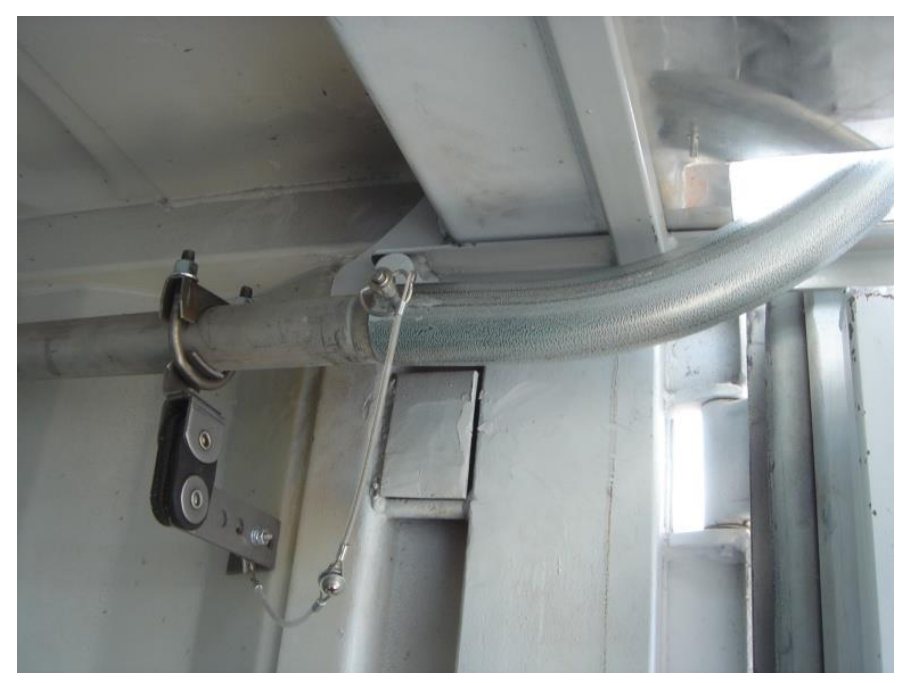

Figure 34. Generator exhaust diverter is in place.

END OF PROCEDURE IV.E 



\section{F. Procedure for Storing Equipment Used in TXL Setup}

1. Remove the pink tie down eye bolts used to secure shipping boxes from the floor in the front of the TXL (Figure 35). Store them in the red parts box marked Shipping eye bolts, which is stored in the Dunnage/SAUNA Shipping Brackets shipping box, or in the tool cabinet.

\section{NOTE}

Insert the brass-colored captive locking key connected to the eye into hex hole in the eye bolt to prevent the eyes from rotating (Figure 35).

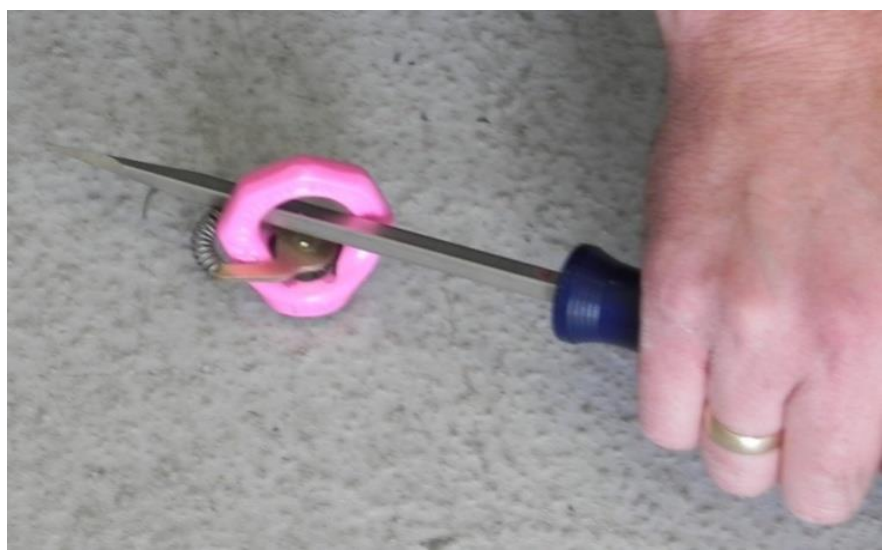

Figure 35. Remove pink tie down eye bolts, used to secure shipping boxes to floor during transport of TXL.

2. Insert 16, 3/8-in. set screws into shipping anchor tapped holes in the floor to prevent insects from entering the container from the underside. The set screws are located in a zippered bag within the red parts box marked Shipping eye bolts.

3. Stage the shipping boxes labeled Jacks/Leveling Fixtures/AC Cord, Dunnage/SAUNA Shipping Brackets and the ladder, near the rear deck.

4. Remove bungee cords and foam used to secure the computer monitor located above the tool cabinet.

5. Place the bungee cords and foam in the Dunnage/SAUNA Shipping Brackets shipping box.

6. Remove the bung from the hole in front of the SAUNA (Figure 36), place it into a zippered bag, and store it in the Dunnage/SAUNA Shipping Brackets shipping box. 


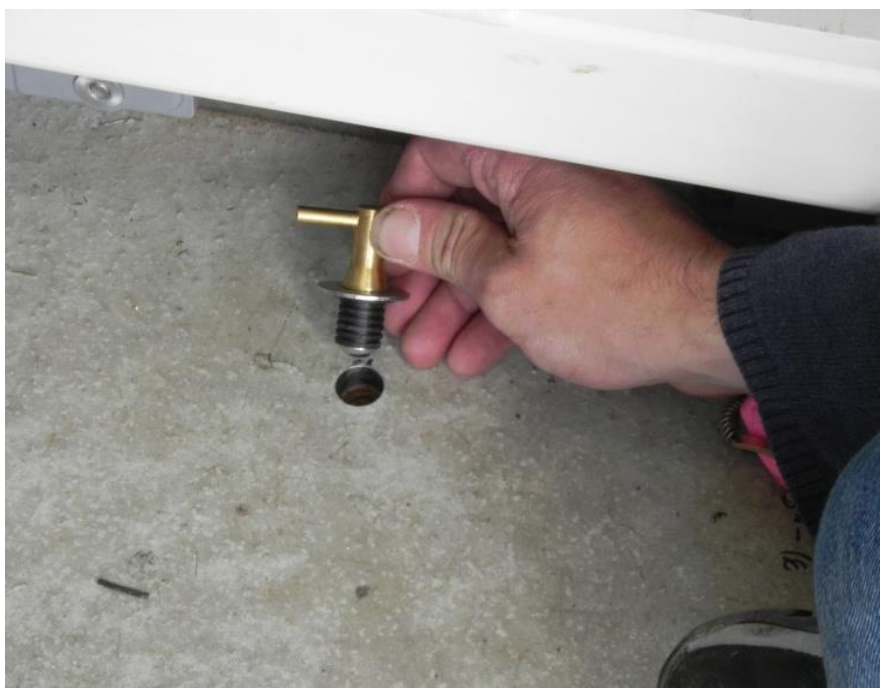

Figure 36. Remove the bung from the hole in front of the SAUNA.

END OF PROCEDURE IV.F 


\section{G. Procedure for Hooking Up Power to the Available Utility Power}

\section{BACKGROUND}

\section{POWER SYSTEM INFORMATION}

The TXL was developed with world-wide deployments in mind. The mobile laboratory is designed to operate on both single-phase and three-phase power. It contains automated line-voltage detection and switching gear to accommodate the 11 worldwide standard voltages. Uninterruptable power supplies and a $12 \mathrm{kVA}$ diesel generator allow the SAUNA and the TXL to remain operational during an interruption of the host country's power. The generator also will allow the system to function in a standalone manner if needed.

The power cord can be terminated into either single-phase or three-phase power. Determine what power is available from the local utility power either by discussion with the host or by measurement with a voltmeter.

If the local power is single phase, connect the power cord wires to the utility power enclosure as follows:

1. Connect the black wire on the power cord to line 1 .

2. Do not connect the orange wire on the power cord to any termination.

3. Connect the red wire on the power cord to line 2.

4. Connect the green wire on the power cord to ground.

5. Connect the white wire on the power cord to neutral.

If the local power is three phase, connect the power cord wires to the utility power enclosure as follows:

1. Connect the black wire on the power cord to phase 1 .

2. Connect the orange wire on the power cord to phase 2 .

3. Connect the red wire on the power cord to phase 3.

4. Connect the green wire on the power cord to ground.

5. Connect the white wire on the power cord to neutral.

In some countries, connecting an additional separate ground wire from the TXL container to the utility power enclosure ground is required. The host facility coordinator will check local electrical codes. A green wire is coiled up near the TXL power receptacle on the left side of the rear deck and attached to the TXL container ground for this purpose.

\section{END OF PROCEDURE IV.G}





\section{H. Procedure for Powering Up the TXL}

1. Turn on the local utility power by what ever means is supplied: usually a circuit breaker or safety switch.

2. Turn the master power switch, located on the rear deck, to the ON position (Figure 37).

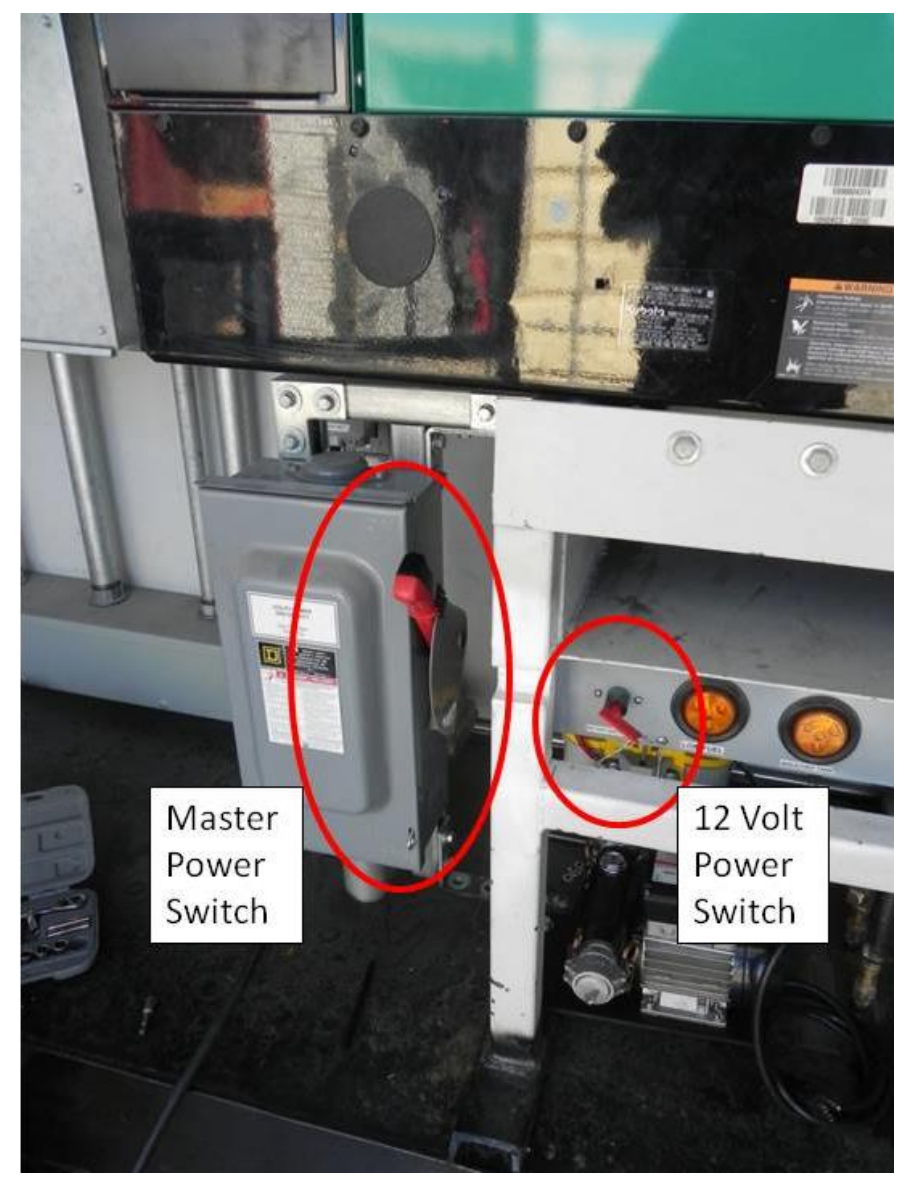

Figure 37. Location of master power switch and generator switch on the rear deck.

3. Turn the Generator Set 12 volt on/off switch, located adjacent to the master power switch, clockwise to the ON position.

4. Go back into the laboratory.

5. Connect the internal batteries to the TXL house uninterruptable power supply (UPS) located in the SAUNA rack (Figures 38 and 39). 


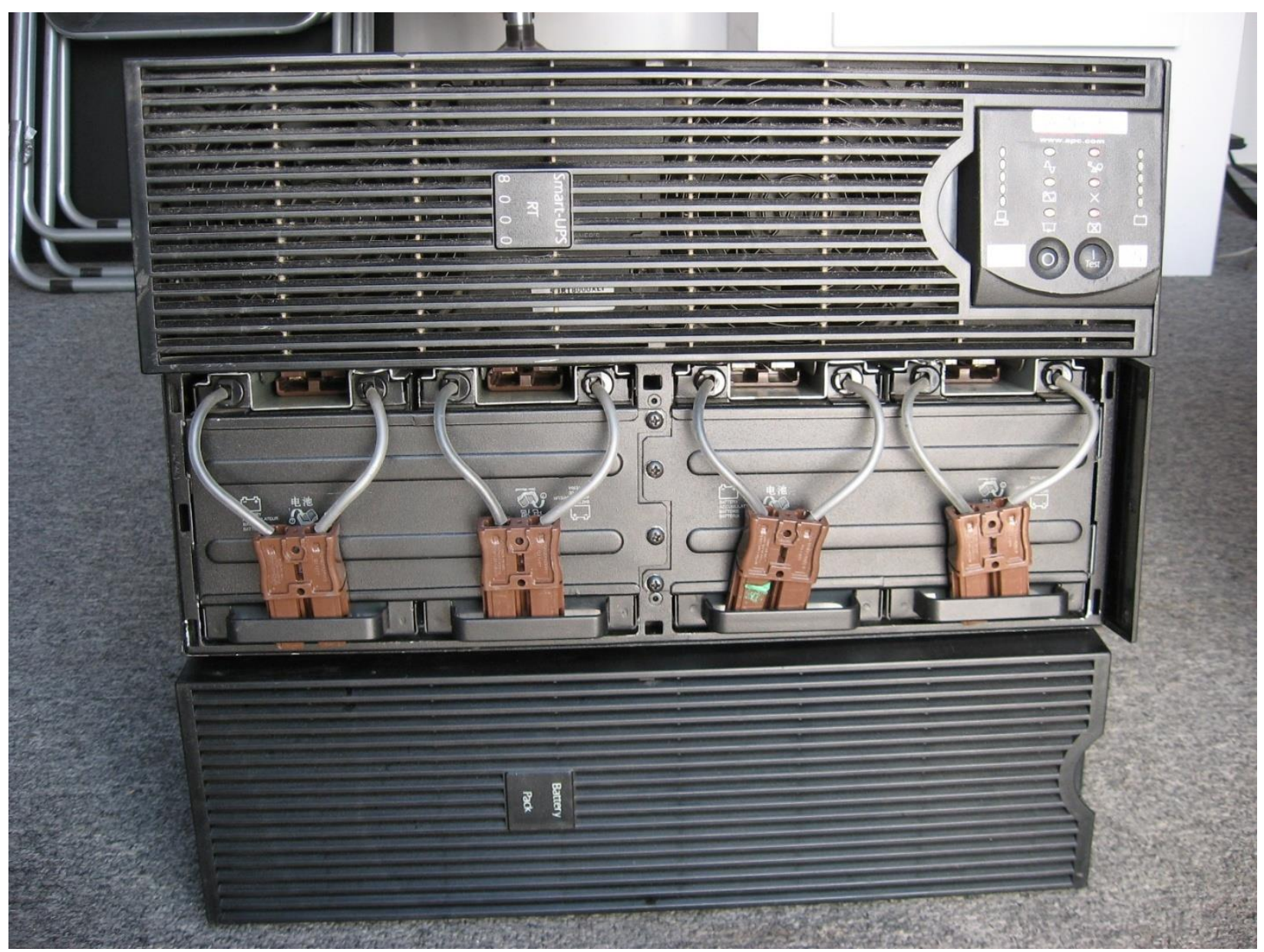

Figure 38. The house UPS is shown with the front panel removed and the batteries unplugged. 


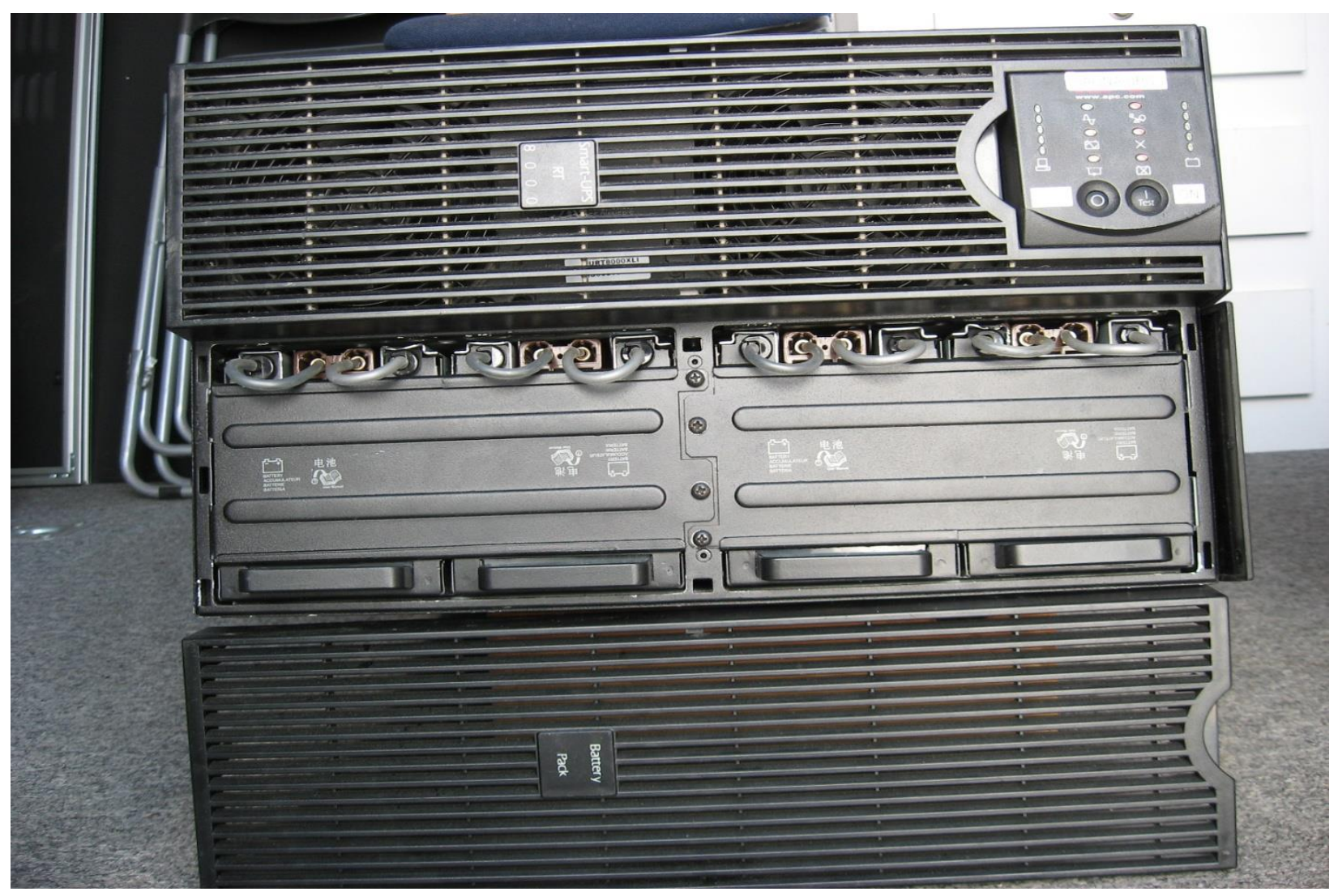

Figure 39. The house UPS is shown with the front panel removed and the internal batteries connected.

6. Turn on the TXL UPS. This is done by pressing on the pushbutton switch on the front of the UPS (Figure 40) until you hear two beeps. It is the right button labeled ON. The light-emitting diodes (LEDs) on the front should light up when you are successful. The UPS will produce a recurring beep notifying that it is operating on battery power. This will continue until the system is operating on utility power.

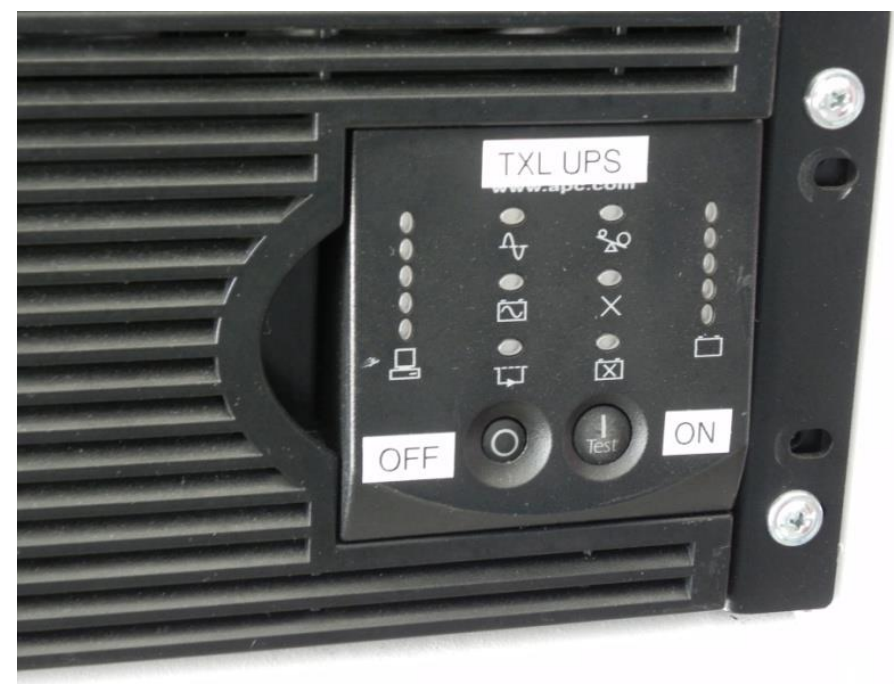

Figure 40. The uninterruptable power supply for the TXL is located in the SAUNA rack. 
7. “Clean" power should come on.

8. Retrieve the master electrical activation key from the oxygen monitor, leaving the monitor in the ON position when removing the key.

9. Insert the master electrical activation key into the TXL master control panel on the left side - the Line Power Activation switch. Turn the key to the ON position (Figure 41).

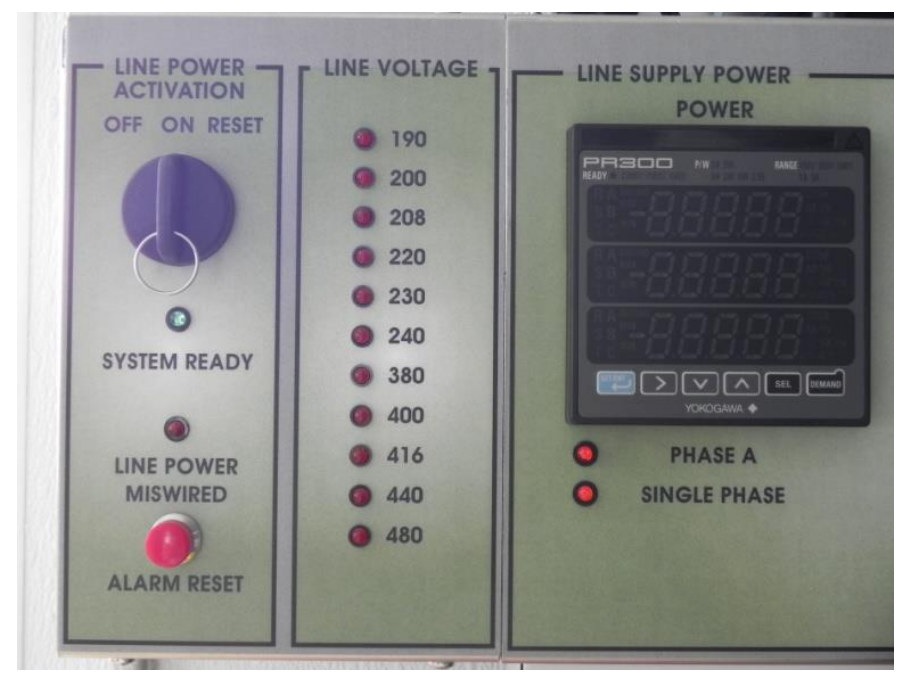

Figure 41. The master electrical activation key is inserted on in the Line Power Activation switch on the TXL master control panel.

10. The system will monitor the utility voltage and set the power relays within 15 seconds after activation. If the system is wired properly, the power meters will indicate voltage and current available, and the Line Voltage LED will indicate the incoming voltage settings. Verify that a line voltage has been selected by noting that a line voltage LED is illuminated.

\section{The Line Power Miswired LED should not be illuminated.}

12. Only if the previous two steps are successful, proceed to turn the generator automatic control module to the automatic position (Figure 42). This is done by pressing the "Auto Gen" button, then pressing "Enter." This allows the generator to automatically turn on in case of a power failure. Move the Emergency Back-up Light travel switch to the normal position. This switch is located on the bottom of the Emergency Back-up Light. Go to IV.I. Procedure. 


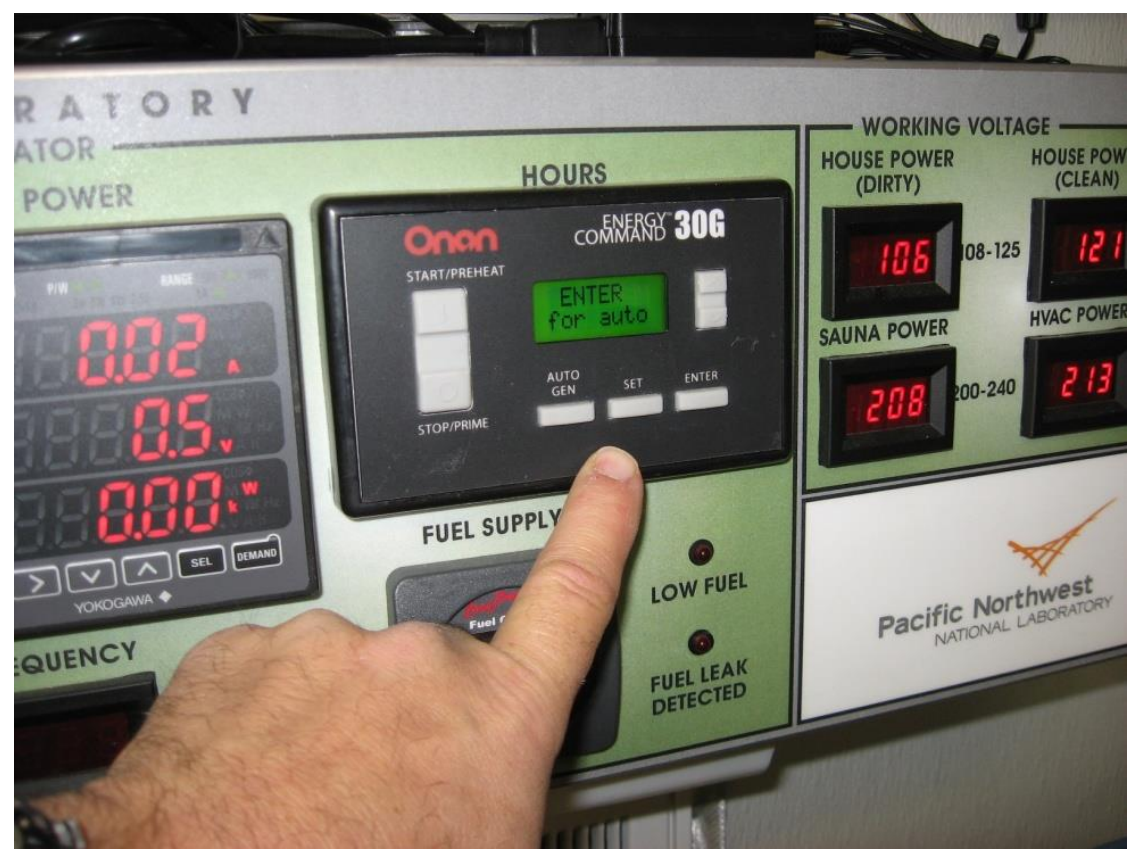

Figure 42. Turn the diesel generator automatic control module on.

13. If the miswired LED is illuminated, a problem with the utility wiring exists.

14. Check the power meters on the control panel (Figure 43) to assess which phase is wired improperly. For a single phase system, a single voltage value should appear on the Phase A meter. Phase B and Phase $\mathrm{C}$ may show a voltage value, but not one of the excepted values (190-480). For a three-phase system, three voltage values should be seen on the phase meters. If more information is needed, power up the house computer located in the SAUNA rack.

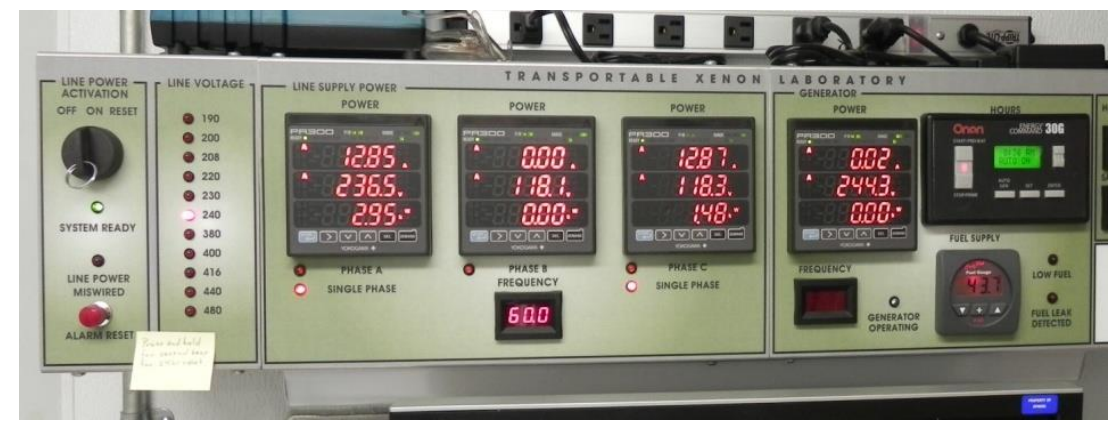

Figure 43. Check the power meters to assess which phase is wired improperly.

15. Once the house computer is on, open the voltage monitoring program from the computer desktop. This program gives an actual reading of all phases, and will let the operator know which phases are errant (voltage is 0 ), and which wires to check.

16. Turn the control panel off with the key switch, and turn the house UPS off by pressing the left button on the front of the UPS. Go back to, and perform steps beginning with IV.G Procedure.

\section{END OF PROCEDURE IV.H}





\section{Procedure for Filling the Diesel Fuel Tank}

\section{BACKGROUND}

The generator acts as backup power so it should be fueled before turning the power on. The generator has a 100-gallon fuel tank and runs on diesel fuel.

1. Unlock the padlock (using the same key as J-hook padlocks on the TXL key ring) and set it aside.

2. Open the fuel fill cap in preparation for filling the tank.

3. If a local diesel delivery truck with a delivery hose is available, fill the tank using standard procedures for filling tanks.

4. If the fuel is delivered in drums, unbolt the fuel transfer pump mounting bracket from the tank frame by removing the bolts shown in Figure 44.

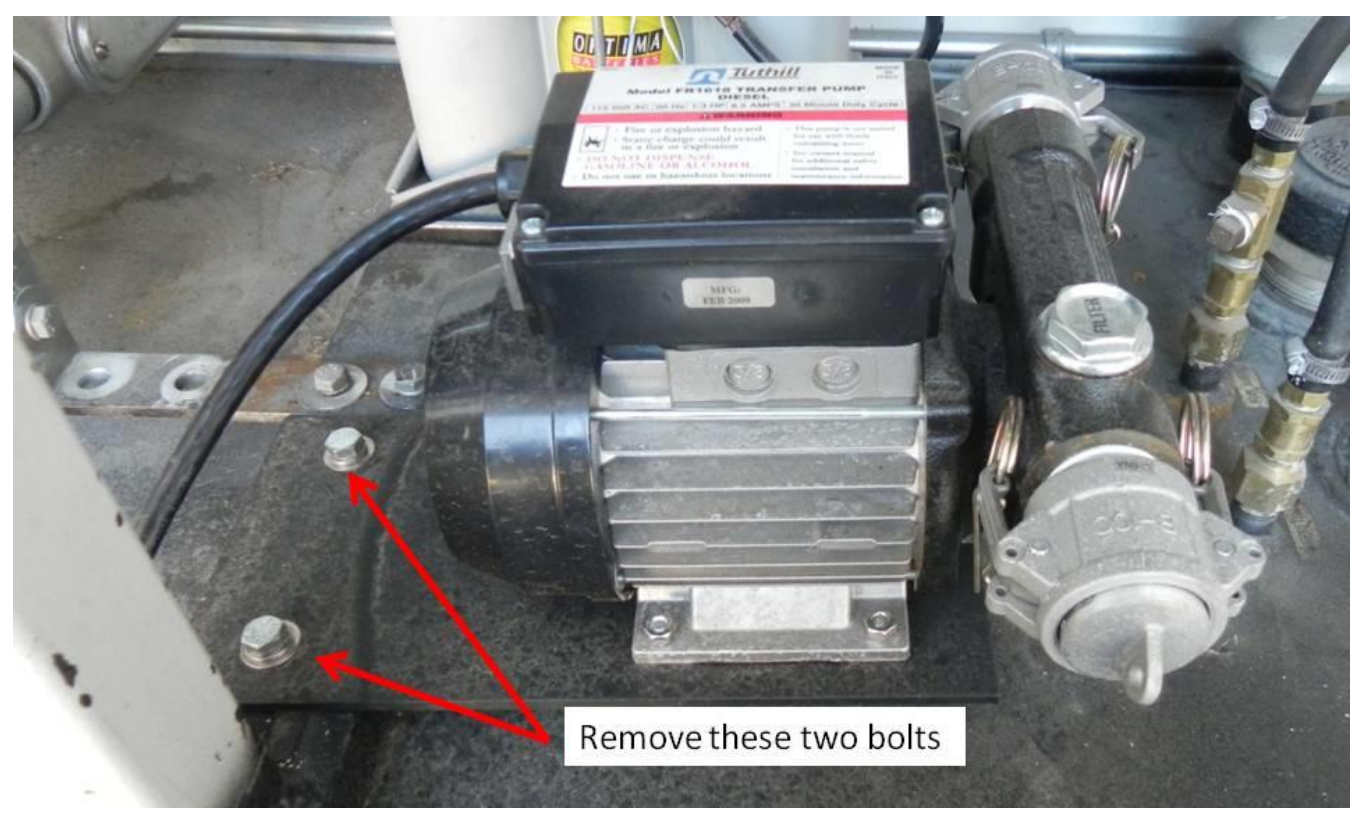

Figure 44. Remove these two bolts to remove fuel pump.

5. Note the fuel pumping direction of the pump (Figure 45). Connect the hoses to the quick disconnect fittings on the pump. 


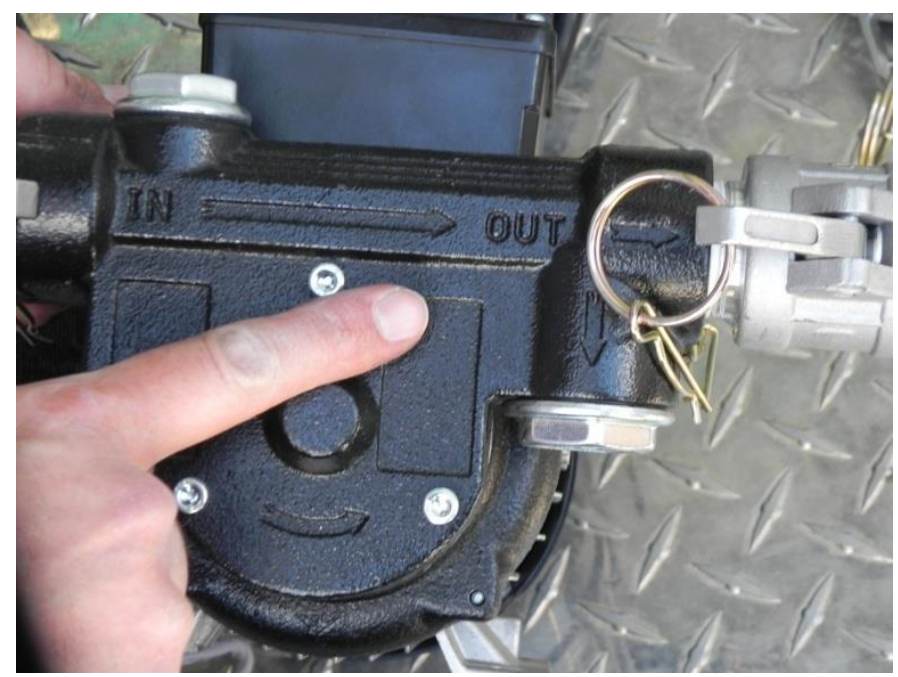

Figure 45. The pumping direction is noted on the fuel transfer pump.

6. Retrieve fuel transfer hoses from the Jacks/Leveling Fixtures/AC Cord shipping box stored on the rear deck.

7. Place the inlet hose into the fuel drum and the discharge hose into the 100-gallon fuel tank.

8. Remove the end caps on the non-quick release ends of the fuel transfer hoses and set aside.

9. Turn on fuel transfer pump by plugging it into the "dirty" convenience outlet located on the wall of the rear deck if utility power is available, or an extension cord plugged into a Clean Power Receptacle (UPS backed-up receptacle) within the TXL if utility power is not available.

10. Fill the tank until it is full. Watch the fuel level in the tank using a flashlight (located in the tool cabinet) to make sure not to overfill the tank.

11. Turn off the pump by unplugging it. Remove the hoses at the quick disconnect fittings and drain the remaining fuel into the tank and drum respectively.

12. Replace end caps on the non-quick release ends of the fuel transfer hoses.

13. Wipe up any spilled fuel and hoses with paper towels or another absorbent material. Dispose of towels in accordance with local regulations.

14. Store the fuel transfer hoses in the shipping container.

15. Replace the pump onto the fuel tank frame and bolt into place.

16. Close the fuel filler cap and secure the padlock.

END OF PROCEDURE IV.I 


\section{J. Procedure for Removing the Shipping Mounts for the SAUNA Translation Frame}

\section{BACKGROUND}

The TXL houses a sophisticated SAUNA system to allow monitoring of local environmental xenon concentrations. Because of the limited space, the engineers mounted the SAUNA system into a vibration-isolated frame that moves across the width of the container. During routine operation, the SAUNA frame is in the left position and when needed can be driven to the right side to allow easy access to the rear of the instrumentation for maintenance. The frame is positioned in the center and securely anchored to the container floor and ceiling during shipping.

The TXL is designed for long-term unattended operation of the SAUNA system. The TXL records AC power performance, standby power and fuel status, local weather observations, HVAC performance, and daily automated reporting of SAUNA observations.

SAUNA will be set up and operated only by SAUNA-trained operators.

The SAUNA translation frame consists of two major components: the SAUNA equipment rack and the SAUNA translation base. The equipment rack is attached to the translation base with four vibration isolators. During shipping, the translation base is secured to the TXL floor with three bottom mounting brackets. The equipment rack is secured to the left inside wall with two vibration isolation assemblies to prevent the rack from swaying (Figure 46).

CAUTION! Tripping hazards and head injury are possible. Proceed with caution. This procedure involves raising fixtures above a person's head, and requires two people to carry it out. The upper vibration spring and tie rod assembly weigh approximately 35 pounds. Hard hat use is required. 


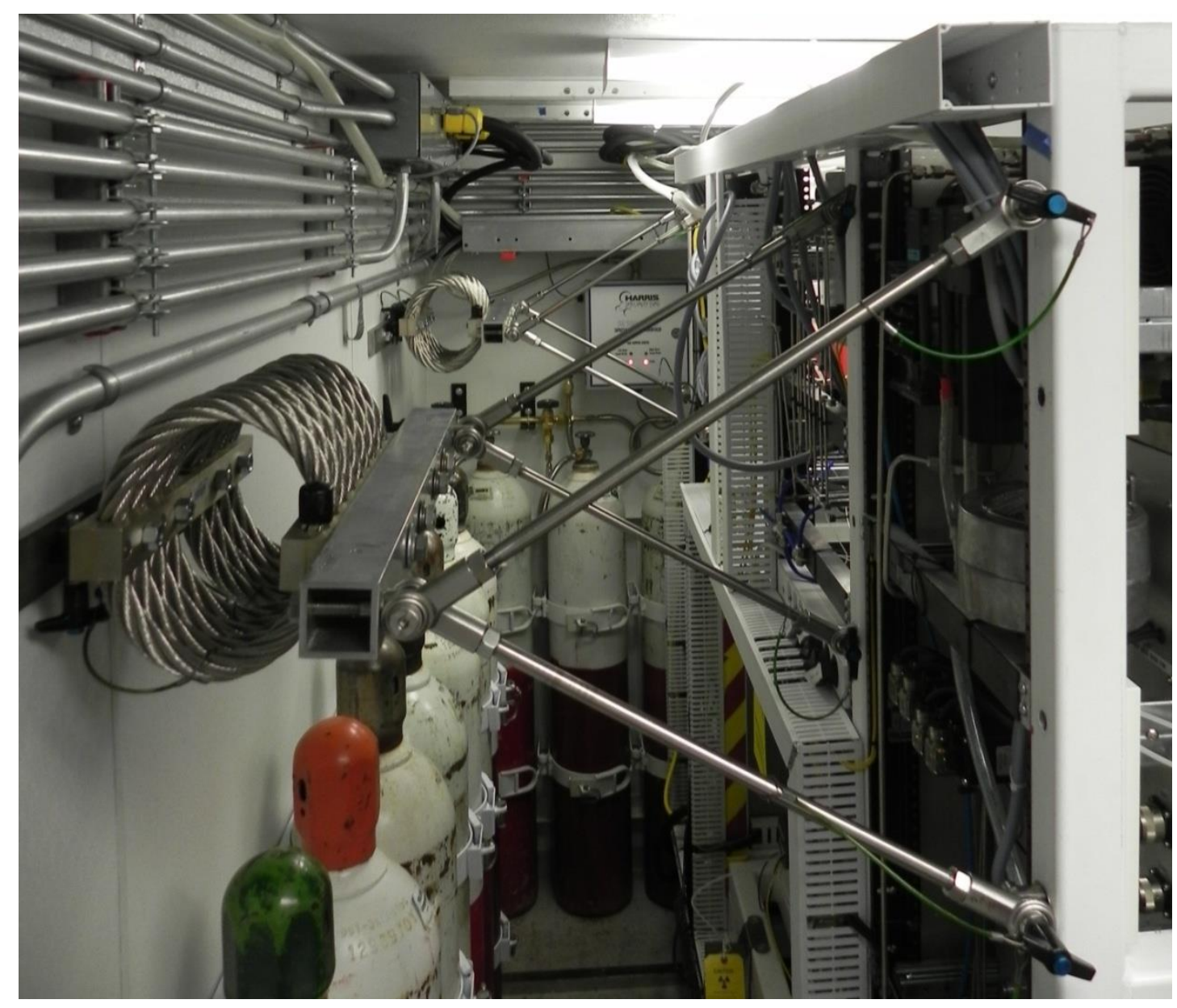

Figure 46. The upper vibration isolation assemblies prevent the equipment rack from swaying.

1. Place the Jacks/Leveling Fixtures/AC Cord shipping box on the left side of the rear deck. Position the box such that there is approximately 6 in. $(15 \mathrm{~cm})$ of clearance between the fuel tank and the shipping box. Be sure that the box hinges are facing the left door so that the box lid can be opened easily if needed. Secure the lid to the case with the integrated locks.

2. Relocate excess dunnage from staging area and place it between shipping box and fuel tank.

3. If the tool cabinet is locked, unlock it with the tool cabinet key.

4. Verify that there are no obstructions between the SAUNA rack and the right wall.

5. Insert the SAUNA rack transport motor key into control switch (Figure 47). Do not turn the switch. 


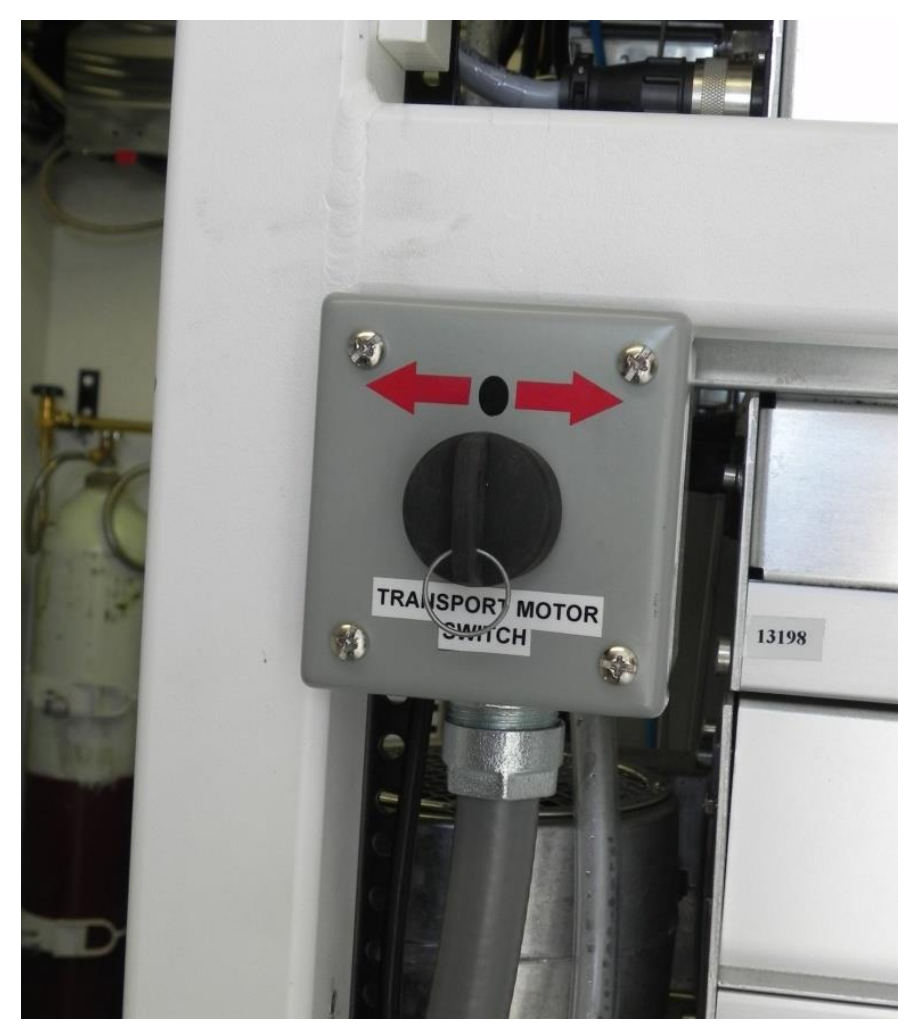

Figure 47. Key is inserted in the SAUNA rack transport motor.

6. Put on hard hats for the remaining steps in this procedure. The hard hats are stored on coat hooks located on the right inner wall of the TXL.

7. Using the socket wrench located in the tool cabinet, unbolt three bottom mounting brackets (Figure 48) located on the floor behind the SAUNA rack on the left side of the laboratory. Each bracket is secured to the translation base and the TXL floor with seven bolts and washers. Place the bolts and washers into the red metal storage box (labeled SAUNA Shipping Bolts \#1 and \#2). Set the box aside.

8. Move the three bottom mounting brackets and the red metal storage boxes outside on the rear storage deck in preparation for storage. 


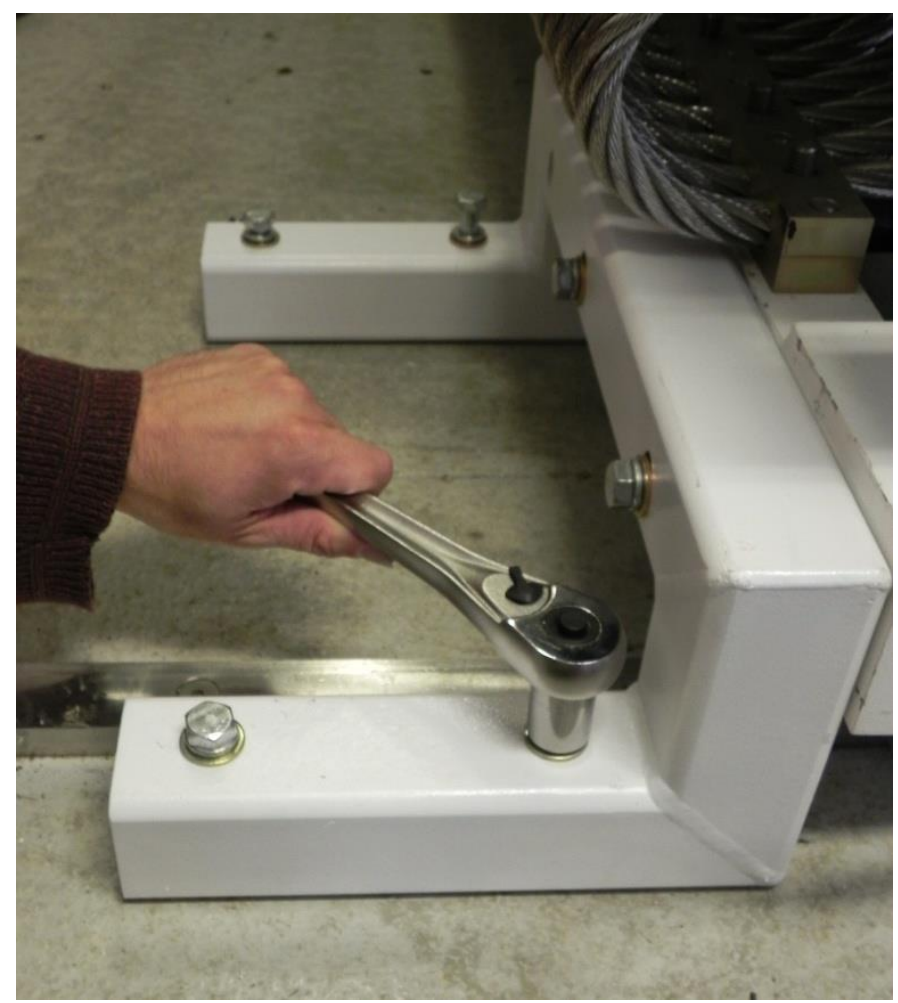

Figure 48. Unbolting the bottom-mounted bracket.

\section{Removal of Upper Vibration Mounting Fixtures}

Steps 9 through 15 will be performed by two people. One person will support the vibration isolation assembly, while the second person manipulates the attachment hardware and SAUNA rack transport motor.

9. Starting with the front vibration isolator assembly (the one closest to the tool cabinet), remove the lower two T-handle pins connecting the isolators to the SAUNA frame (Figure 49). Removing the T-handle pins is a two-handed task. Allow the lower connecting arms to hang freely. 


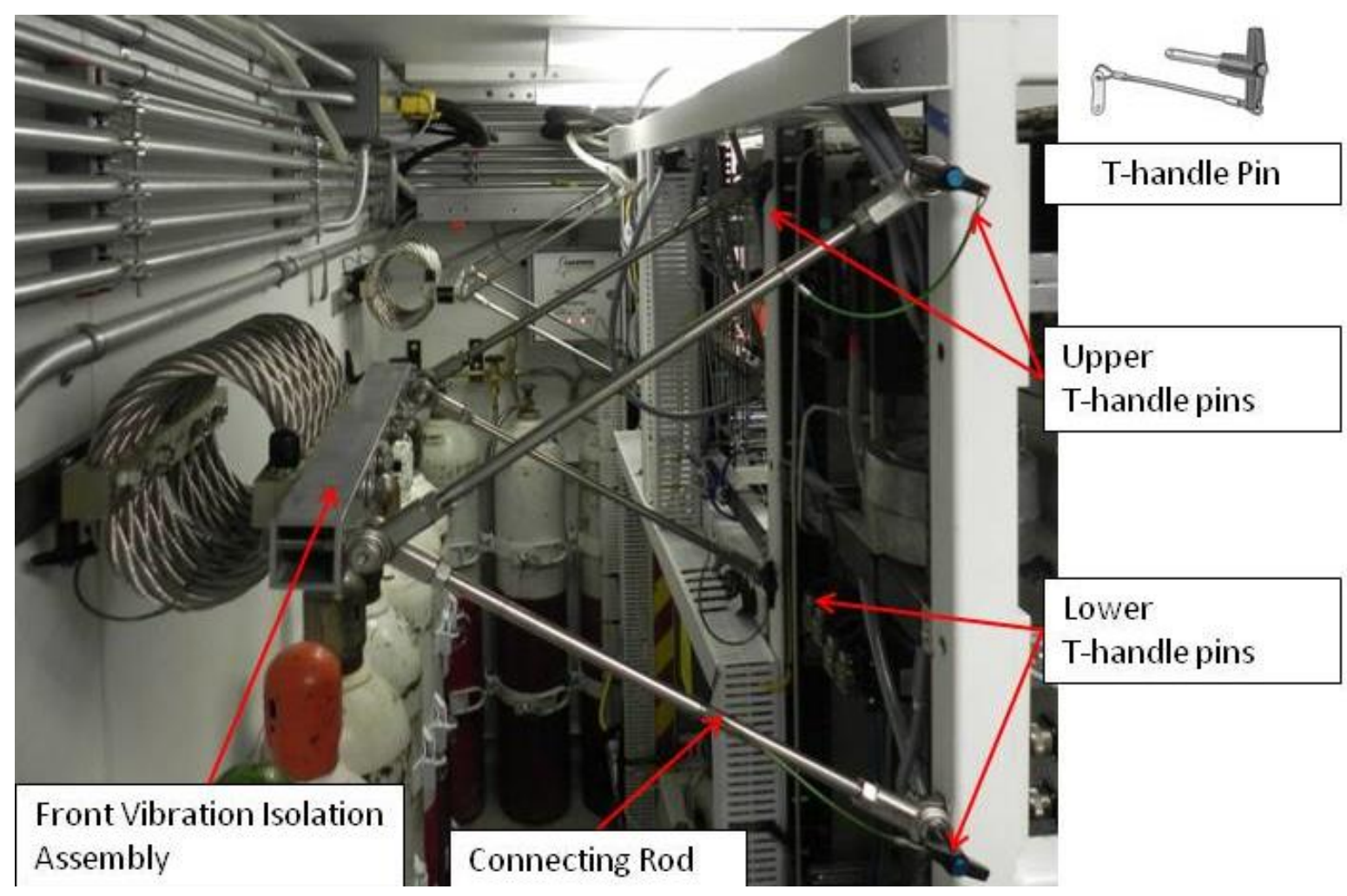

Figure 49. Components of the upper vibration isolation assembly are labeled.

10. Remove the upper connecting arms in a like maner and allow the arm labeled " $A$ " to hang freely. The labels are stamped on the rod ends and the corresponding attachment point on the SAUNA frame. NOTE: The upper arm that is labeled " $D$ " can not be lowered because of the SAUNA instrumentation. Using the T-handle pin, secure the rod temporarily to the holes in the $\mathrm{C}$-channel located on the ceiling. Ensure that the T-handle is securely engaged in the C-channel hole (Figure 50).

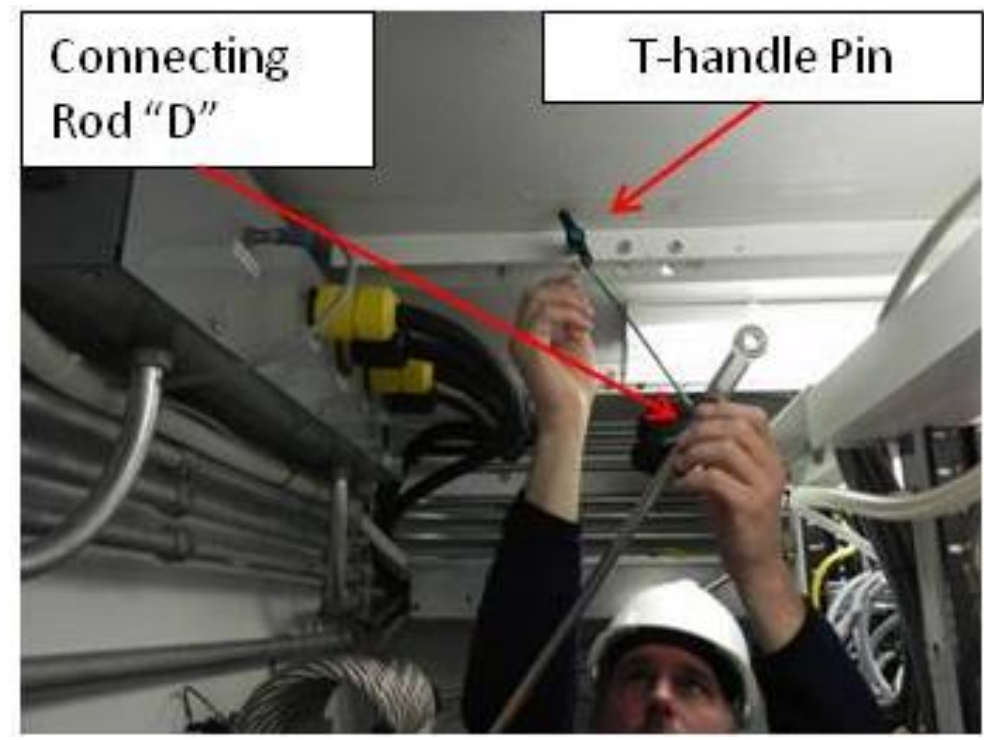

Figure 50. Secure the rod marked " $D$ " temporarily to the holes in the ceiling mounted C-channel. 
11. Move to the rear vibration isolation assembly. Remove the lower two T-handle pins connecting the isolators to the SAUNA frame. Removing the T-handle pins is a two-handed task. Allow the lower connecting arms to hang freely.

12. Remove the upper connecting arms. Allow the arm labeled " $D$ " to hang freely. The label is stamped on the rod end and the corresponding attachment point on the SAUNA frame. NOTE: The upper arm that is labeled " $A$ " can not be lowered because of the SAUNA instrumentation. Using the T-handle pin, secure the rod temporarily to the holes in the C-channel located on the ceiling. Ensure that the T-handle is securely engaged in the C-channel hole.

13. Turn the key in the SAUNA rack transport motor clockwise to move the rack near the right-hand wall. Stop the rack translation approximately 6 in. $(15 \mathrm{~cm})$ from the wall by returning the key to the center position.

14. One person will support the front vibration isolation assembly, while the second person removes the four T-handle pins securing the front vibration assembly to the left wall. Lower the assembly to the TXL floor.

15. Repeat step 13 to remove the remaining vibration isolation assembly.

16. Replace all T-handle pins into rod ends.

17. Move the vibration isolation assemblies outside the rear storage deck in preparation for storage.

18. Place the empty Dunnage/SAUNA Shipping Brackets shipping box on top of the Jacks/Leveling Fixtures/AC Cord shipping box on the left side of the rear storage deck. Make sure it can be opened and accessed. Leave approximately 6 in. $(15 \mathrm{~cm})$ between the fuel tank and shipping box for excess dunage. Open the lid fully. Load the three bottom mounting brackets into the shipping box as shown in Figure 51.

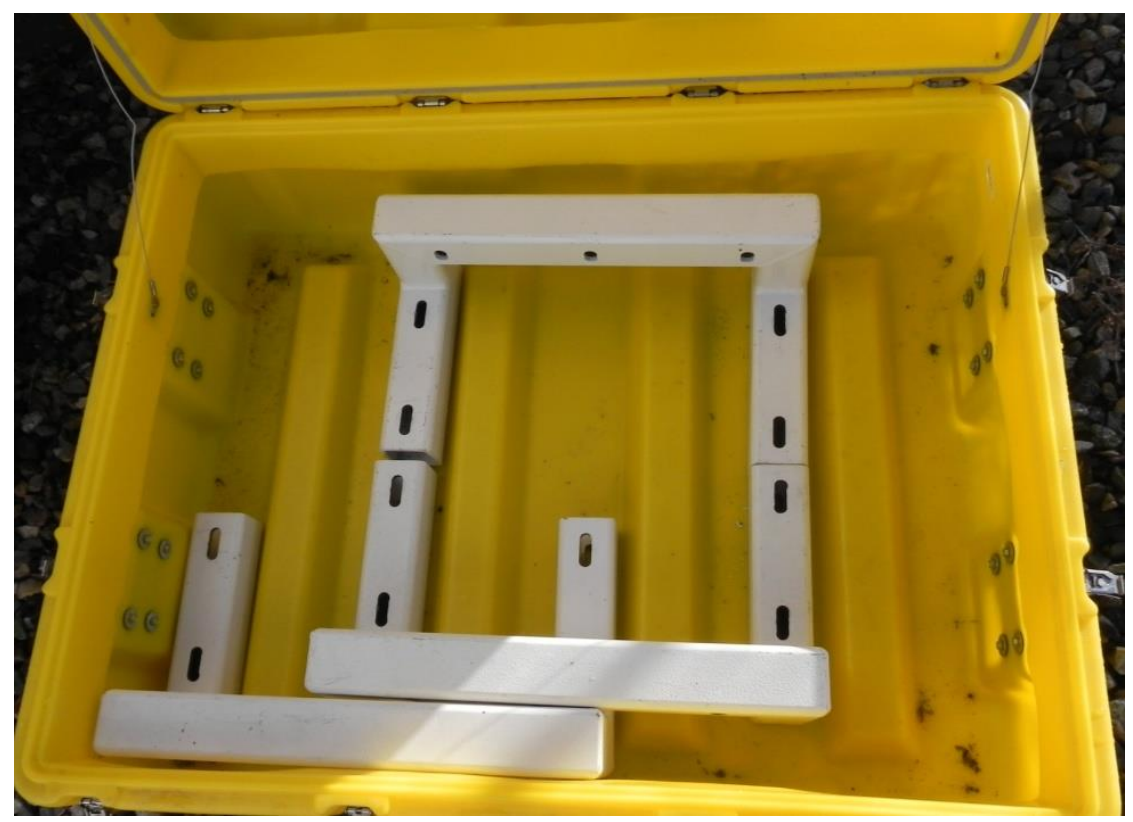

Figure 51. Three bottom mounting brackets are positioned in shipping box. 
19. Load the isolator assmemblies into the same shipping box. The connecting rods are connected to the base spring assembly by ball joints. Position the connecting rods as shown in Figure 52 to allow both vibration isloator assemblies to be placed into the shipping box. Fold the connecting arms in to the stowage postion as shown in Figure 53.

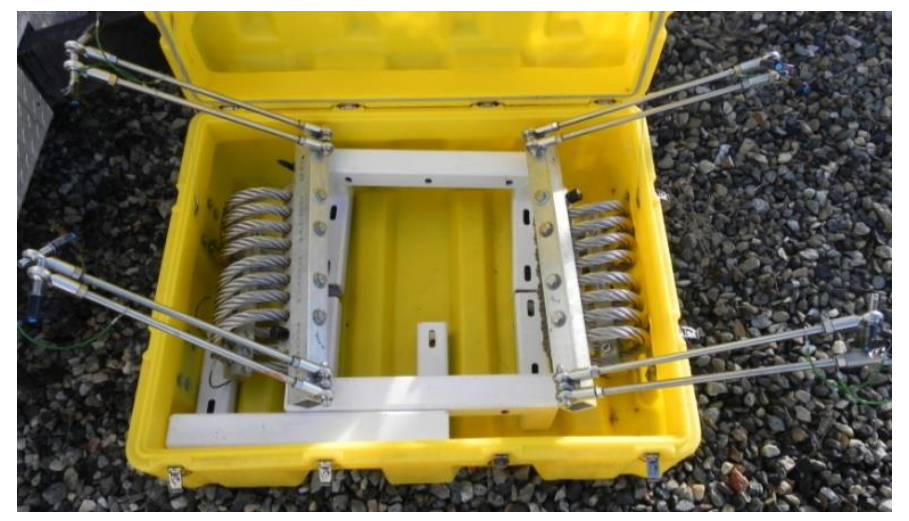

Figure 52. The vibration isolation assemblies are loaded in shipping box.

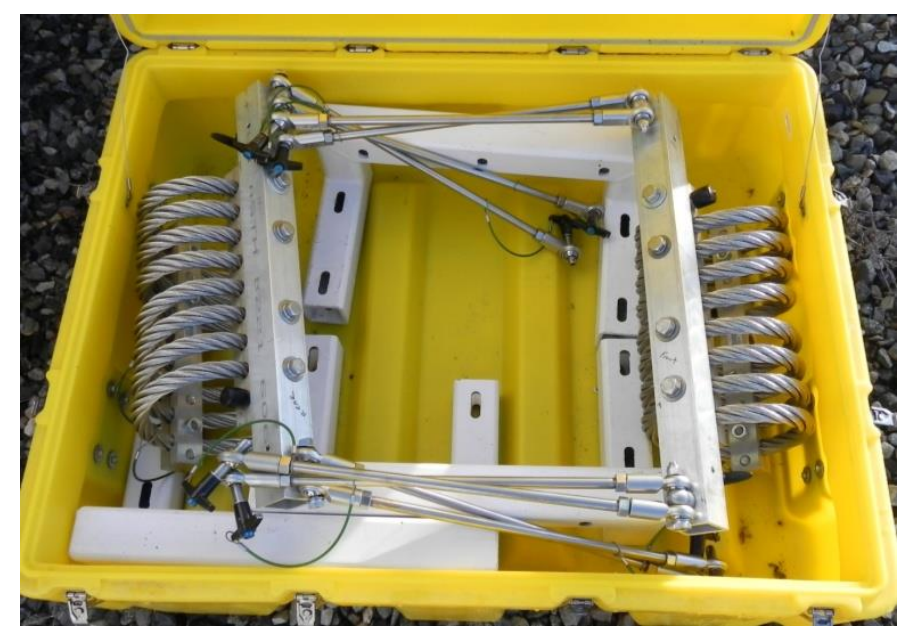

Figure 53. The connecting rods of the vibration isolator assembly are folded in when stowed.

20. Load the bagged shipping tie-down straps, red metal storage boxes, monitor shipping foam blocks, and bungee cords to secure computer monitor into the Dunnage/SAUNA Shipping Brackets shipping box (Figure 54). 


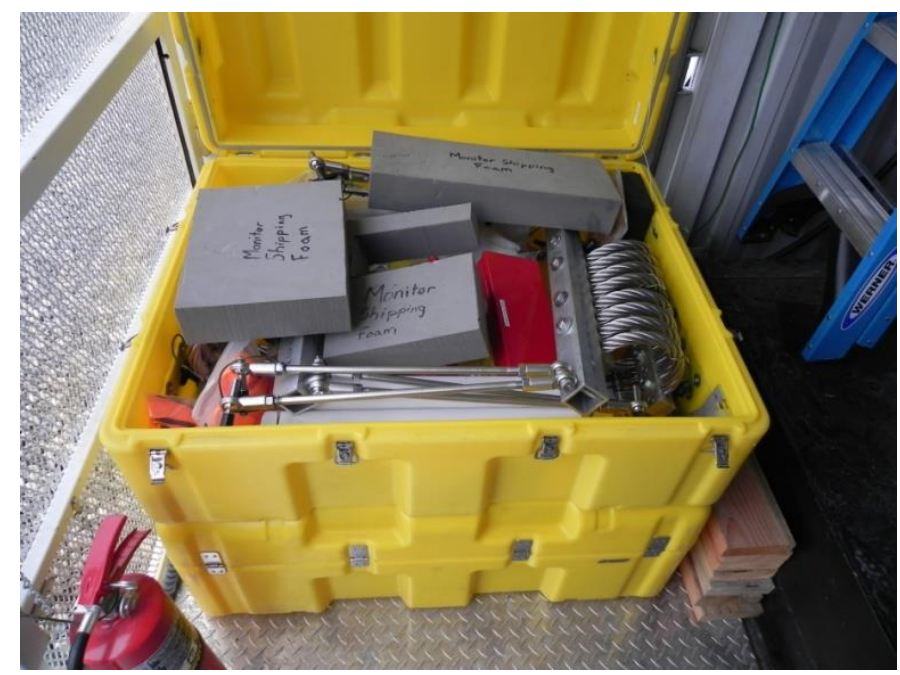

Figure 54. The vibration isolation assemblies are packed into a shipping box along with shipping tiedown straps, red metal storage boxes, foam, and bungee cords.

\section{Readying the Sauna for Use}

21. Remove detector lid brackets (Figure 55), store studs with plates and nuts in the red metal box labeled SAUNA Detector Shipping Brackets.

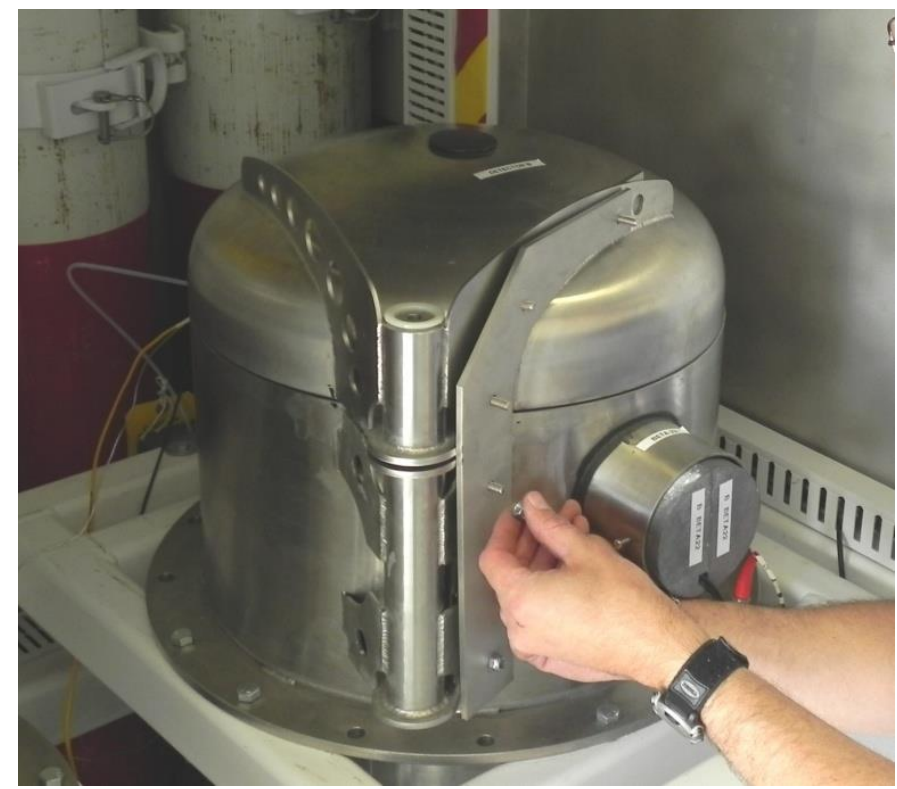

Figure 55. Removing the SAUNA detector lid brackets.

22. Store the red metal boxes and L-shaped detector brackets in the Dunnage/SAUNA Shipping Brackets shipping box. Close and secure shipping box lid.

23. Place the water condensation drain tube into the hole exposed by the bung (Figure 56). The tube is shipped coiled and cable-tied to the SAUNA frame. The tube should penetrate the hole 1.5 to 2.0 in. $(3.8$ to $5.0 \mathrm{~cm})$. 


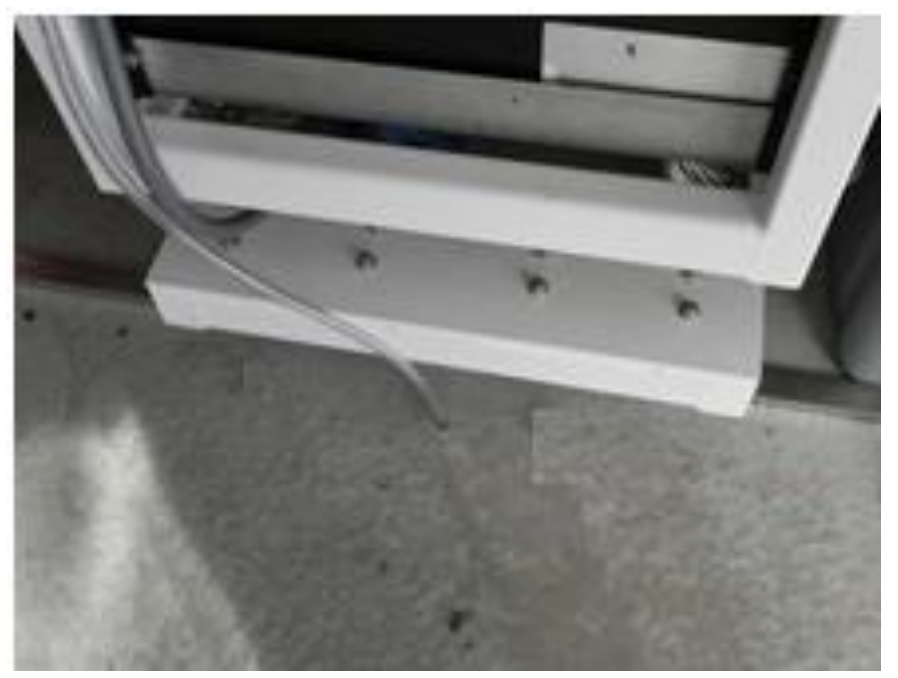

Figure 56. The water condensation tube is inserted through a hole in the floor.

24. Insert 16, 3/8-in. set screws into shipping anchor tapped holes in the floor to prevent insects from entering the laboratory from the underside of the TXL. The set screws are located in a zippered bag within the Shipping Tie Bolt metal box.

\section{END OF PROCEDURE IV.J}





\section{K. Procedure for Removing Shipping Containers from Inside TXL and Stowing Them on the Rear Deck}

1. Remove fire extinguisher from rear deck wall, and set outside temporarily.

2. The Dunnage/SAUNA Shipping Brackets, and Jacks/Leveling Fixtures/AC Cord shipping boxes and excess dunnage were stored while performing Procedure J.

3. Place the Spare Parts shipping box on top of the "Dunnage/SAUNA Shipping Brackets."

4. After the detector has been installed in proceedure Q, the Detector shipping box is stored on top of the Spare Parts shipping box.

5. Store the ladder next to the left hand wall as shown in Figure 57.

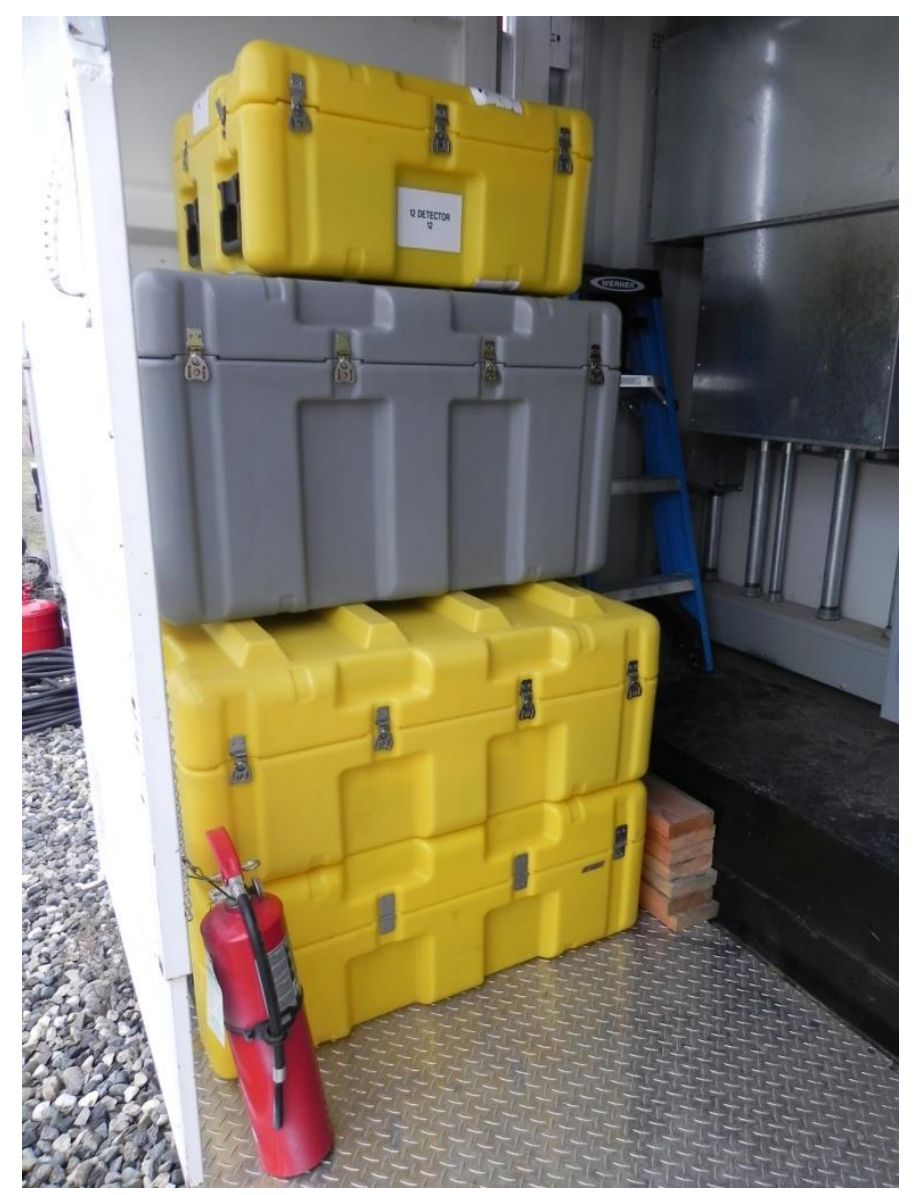

Figure 57. Final storage configuration of shipping boxes stowed on rear deck.

6. Place fire extinguisher on far right side of rear deck. Attach safety lanyard around the top of the extinguisher (Figure 58). Never obstruct the fire extinguisher. 


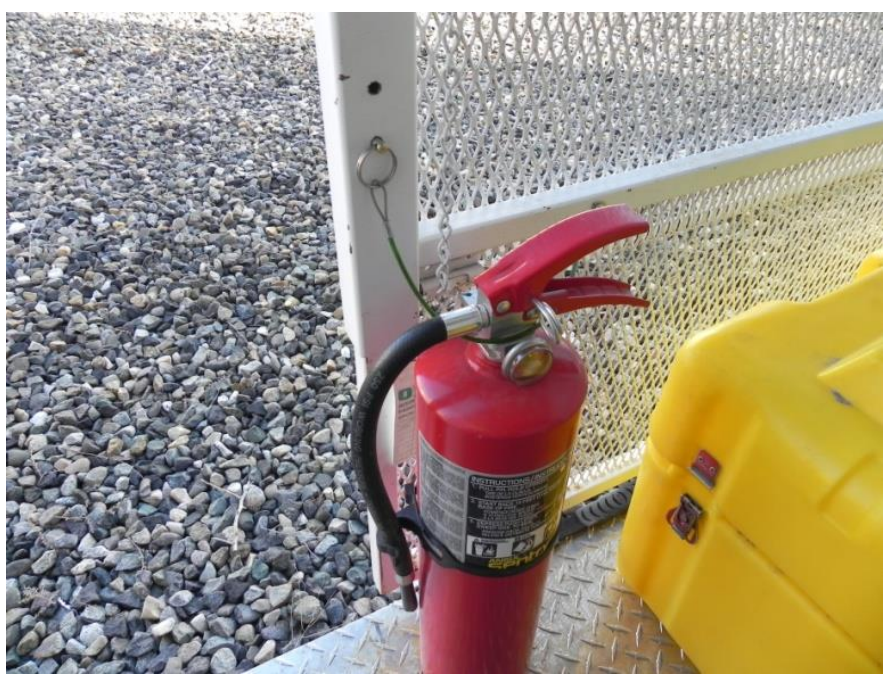

Figure 58. Secure fire extinguisher with safety lanyard.

\section{NOTE}

Do not store anything in front of the master power switch or the transformers. When TXL is operating, people must be able to access the master power switch, and the transformers must have no obstructions to free-flowing cooling air. See Figure 59 for the positions of the master power switch, the transformers and the stowed shipping boxes.

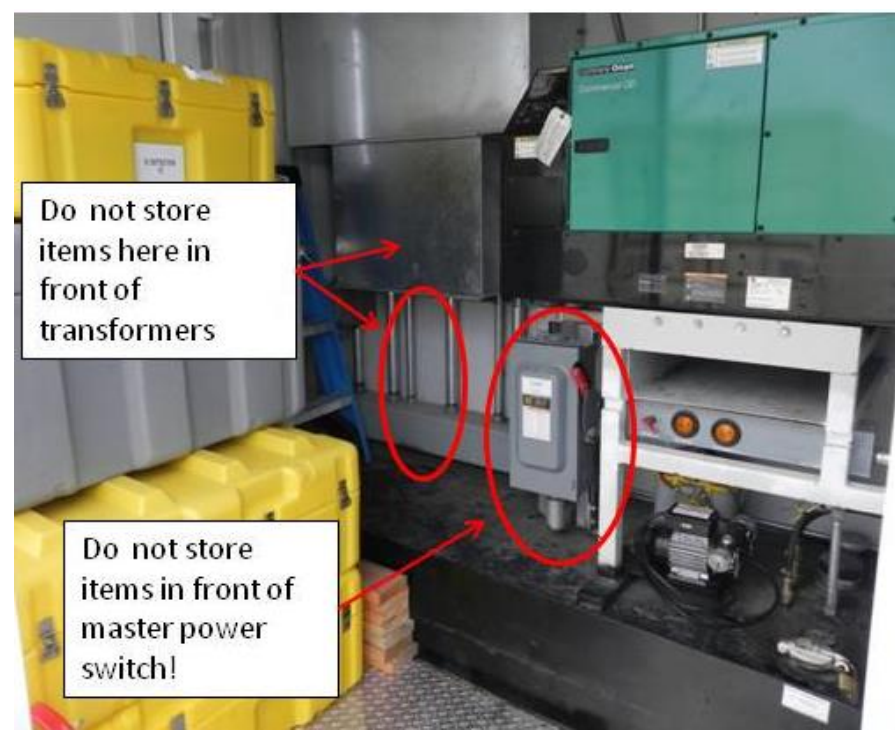

Figure 59. Do not obstruct the master power switch or transformers at the rear of the TXL.

\section{END OF PROCEDURE IV.K}




\section{Procedure for Setting Up the Helium Cylinders for SAUNA Use}

\section{SAFETY NOTE}

The oxygen sensor (TOX Gard II) alarm is audible inside the TXL, but not outside. For personnel outside TXL, pay attention to the warning light. If the oxygen sensor alarms, there is a helium leak. EVACUATE THE LABORATORY. Leave the laboratory door open.

Go to Procedure IV.M for procedure to check for a helium leak.

This procedure will be performed only if the red light of the oxygen sensor for the TXL is off.

The helium supply is provided by a bank of five helium cylinders located on the rear wall of TXL. The helium supply is configured with two separate banks of cylinders, one bank with two cylinders and another bank with three cylinders. The cylinders within each bank are connected to a header with a flexible pigtail hose, and can be individually isolated from the header via an isolation valve. Each header is connected to the automated switch-over manifold and regulator. The switch-over manifold and regulator are controlled by the gas manifold controller (Figure 60). Seven spare helium cylinders are mounted to the left wall of the TX (Figure 61).

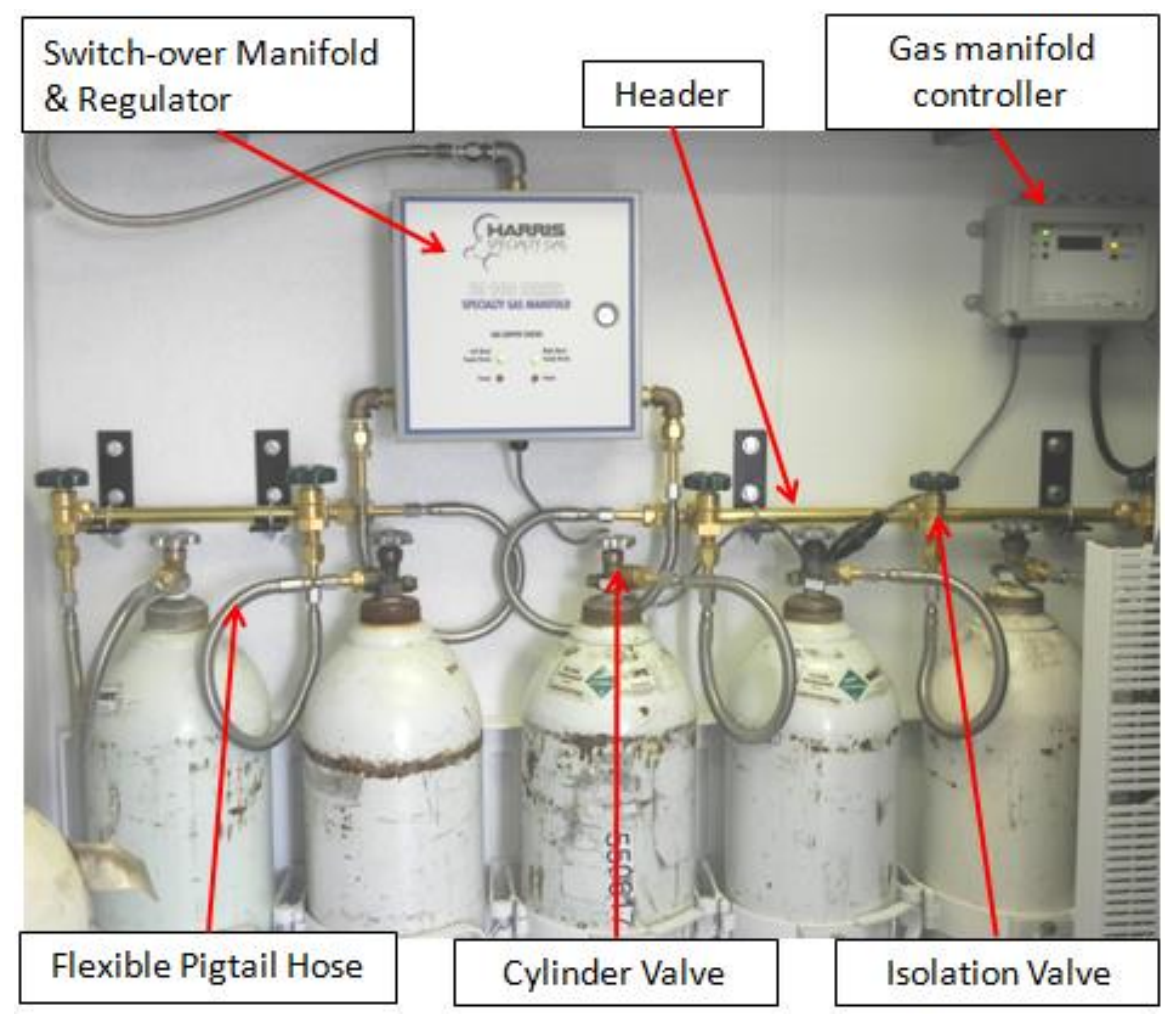

Figure 60. The helium supply is provided by five helium cylinders configured in two separate banks. The controlling components are shown in the figure. The fifth isolation valve is partially obstructed and at the extreme right of the figure. 


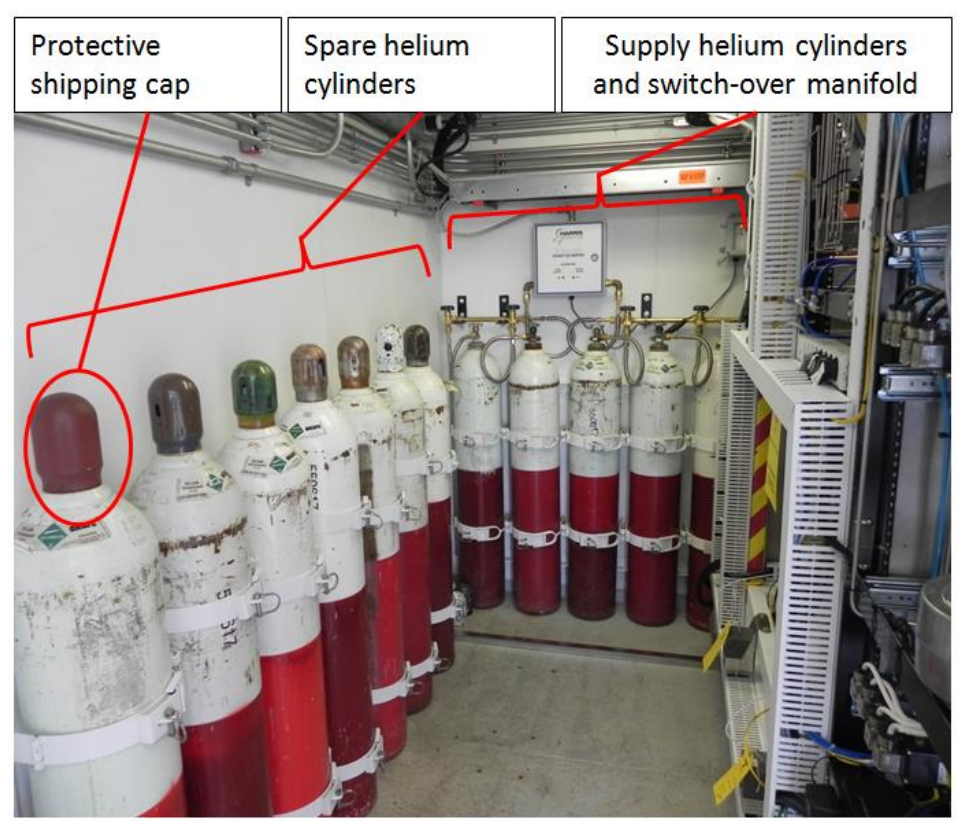

Figure 61. The helium distribution system and spare helium cylinders are mounted on the rear and left walls of the TXL.

1. The TXL is initially shipped with full helium tanks. Signs indicating the status of each cylinder are stored in the Dunnage shipping box. Retreive the signs and hang them on the cylinders to indicate the status. The signs have the word Full on one side and Empty on the other.

2. Ensure that power is on to the gas manifold controller (lights are on). The gas mainifold power cord should be plugged into the back of the TXL UPS. If the controller is not on, make sure that it is plugged in, the UPS breaker for that circuit is on, and that the TXL UPS is on. Figure 62 shows the gas manifold controller, which is located on the center of the back wall of the TXL (opposite the pedestrian access door).

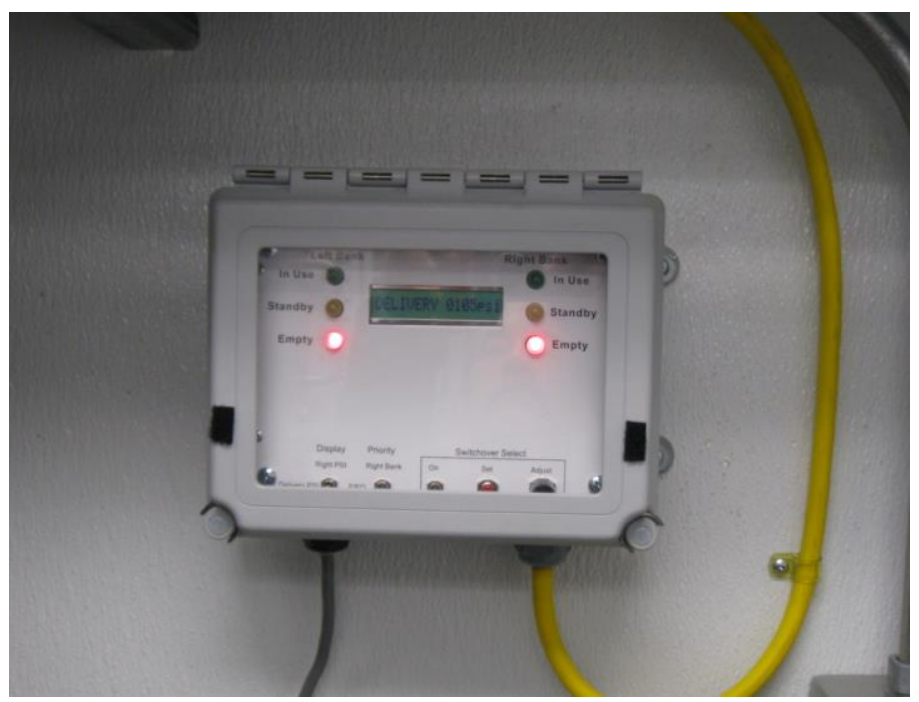

Figure 62. The gas manifold controller is located inside the TXL opposite the pedestrian access door. In this photo, the lights on the controller indicate that both banks of helium cylinders are empty. 
3. Ensure that the cylinders are securely mounted to cylinder racks with latches and locking pins provided (Figure 63).

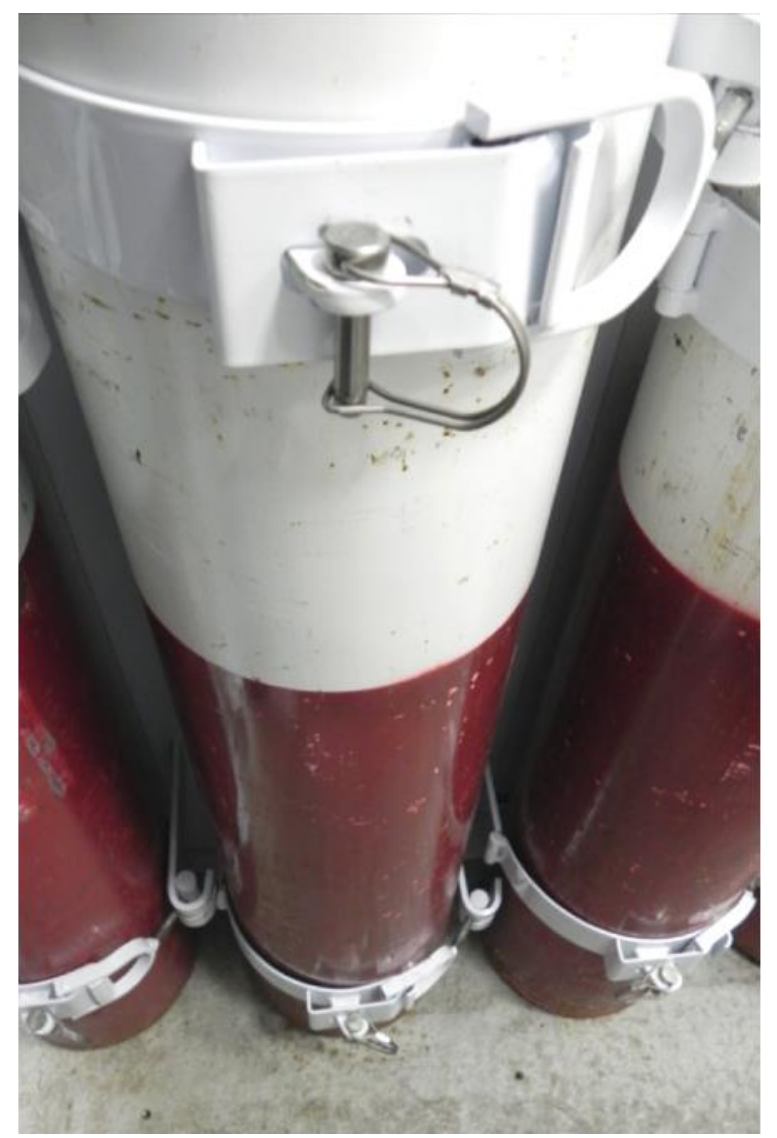

Figure 63. Ensure that helium cylinders are secured with safety pins at all times except when replacing a cylinder.

\section{CRITICAL: Close all five isolation valves (Figure 60).}

5. Remove the protective caps from five supply helium tanks. Place these protective caps on the floor in the corner between the supply and storage helium racks.

6. Inspect all cylinder connections for dirt, oil, or other contamination. If any is found, wipe off the dirt with a clean rag, or the remove the cylinder from service and replace it with a full cylinder from a designated helium supplier. See Procedure IV.N for replacing cylinders.

7. Connect all five cylinders to the flexible pigtail hose (pigtail) taking precautions not to kink the flexible pigtail. The flexible pigtail hose has a minimum bend radius of 4 in. $(10 \mathrm{~cm})$.

8. Start with the right side cylinder bank, with the cylinders secured within the cylinder racks. The right bank is also the default bank; it will supply helium gas if all power is lost to system. Slightly open each cylinder valve slowly to let the system pressurize from the cylinder to isolation valve.

9. Check for leaks at the pigtail hose and cylinder connection, as well as the isolation valve connection with Snoop® (or equivalent liquid leak detector solution) located in Drawer 1 of the 
tool cabinet. Once the pigtail hoses have been pressurized, slowly open the isolation valves completely to pressurize the header.

10. Fully open the cylinder valves for the helium cylinders connected to the right header.

11. Check for leaks at the hose and cylinder connection as well as the header connection with Snoop®.

12. With the headers pressurized, the right side of the switch-over manifold and regulator will be pressurized. The right side red status light on the manifold controller will change to green (Figure 64).

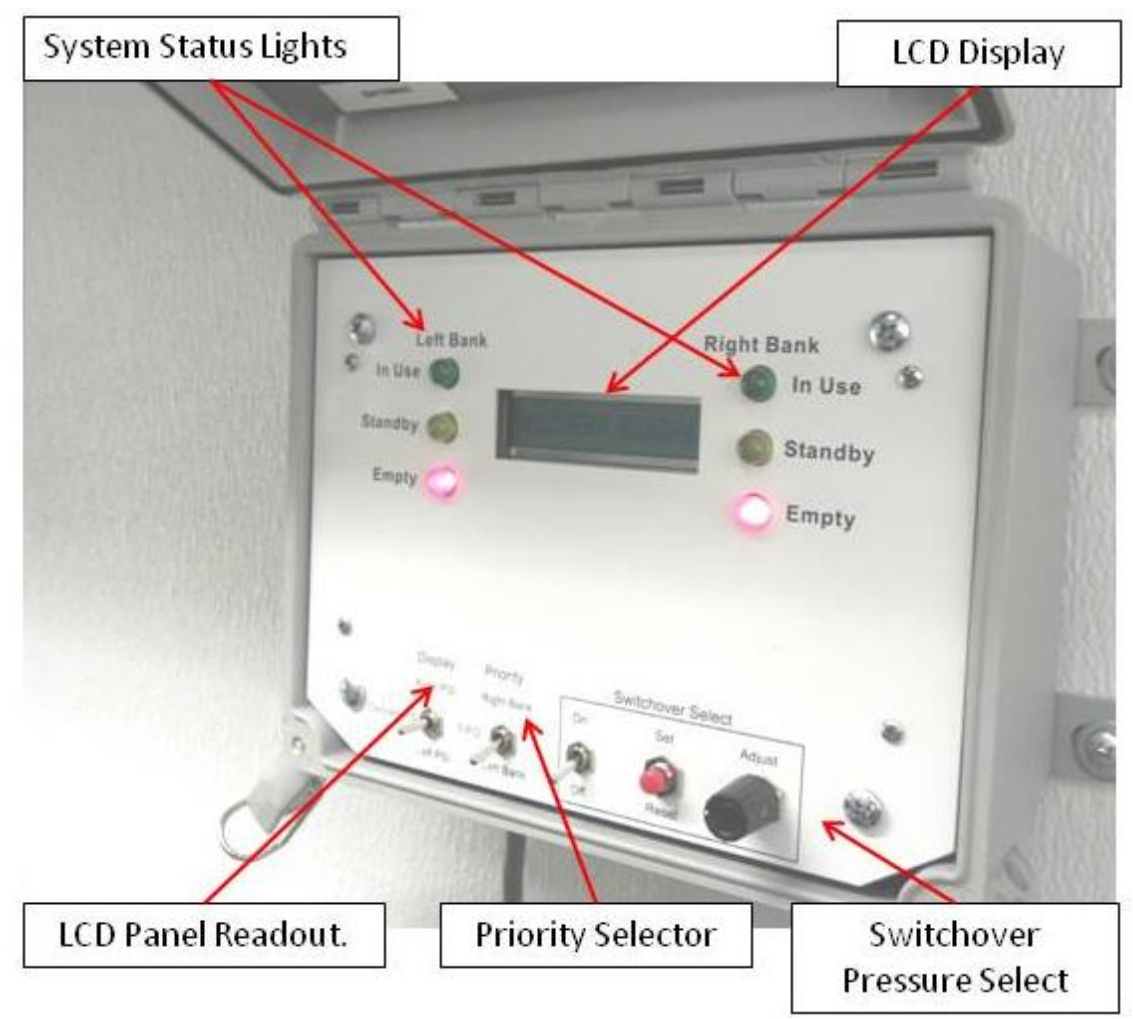

Figure 64. The displays and controls on the gas manifold controller are identified.

13. Go to the left side cylinder bank. Repeat Steps 7 through 12. The left side red status light on the manifold controller will change to amber.

14. With the Priority Selector switch set in FIFO mode (the factory setting), the bank with the green indicator light will be the cylinder bank in use. The opposite cylinder bank (amber light on) will start as the reserve bank. The cylinder banks will alternate between in-use and standby reserve as each bank is depleted and replenished with new cylinders.

\section{Adjust the crossover pressure to $150 \mathrm{psig}$}

15. Press SET (RESET).

16. Set the Switchover Pressure Select ON/OFF switch to ON. The red and green LEDs will flash for a short while. 
17. On the LCD Panel Readout switch select RIGHT BANK.

18. Looking at the LCD Display, adjust the desired switchover pressure set point by turning the Switchover Pressure Select ADJUSTMENT knob. Turn clockwise to increase the switchover pressure setting or counterclockwise to decrease the switchover pressure setting. Set the pressure to 150 PSIG.

19. Once you have verified the desired switchover pressure setting, press the Switchover Pressure Select SET(RESET) button. This action stores the switchover pressure for the right bank.

20. Move the Display Pressure Select switch to the left position. Verify the setting on the LCD panel, or adjust to desired switchover pressure setting.

21. Once you have verified the desired setting, press the Switchover Pressure Select SET(RESET) button, Both right and left switchover pressure set points are now stored in memory.

22. Set the Switchover Pressure Select ON/OFF switch to OFF.

The gas manifold is now operating and the automated switch over function is activated. Once a bank of helium is consumed, the gas manifold will automatically switch over to the reserve tank. When this occurs, the depleted cylinder bank is indicated by the red status light for that cylinder bank. Refer to Procedure IV.N to replace the depleted cylinders with full ones.

\section{END OF PROCEDURE IV.L}





\section{Procedure for Detecting a Helium Leak}

\section{SAFETY NOTE}

Refer to the daily log for consumption rate of helium. If the rate suddenly increases or the oxygen monitor alarm is active, there is likely a helium leak in the TXL. In the event that a helium leak occurs, the leak must be located and repaired. Open and latch the pedestrian access door in the open position. Leave door in the open position until the leak has been resolved. If at any time the ToxGard II oxygen monitor alarms, vacate the laboratory until it stops.

1. Remove the "Snoop ${ }^{\circledR}$ " (or equivalent liquid leak detector solution) from the tool cabinet.

2. With the helium system is pressurized, start at the helium cylinders and apply a stream of Snoop ${ }^{\circledR}$ to each pressurized connection. There are numerous connections within the helium system. A pressurized connection is defined by any threaded or compression fitting between the helium cylinder and the SAUNA system.

3. Formation of foamy bubbles at the connection indicated a leak is present at that connection. It may take several minutes for a small leak to produce bubbles.
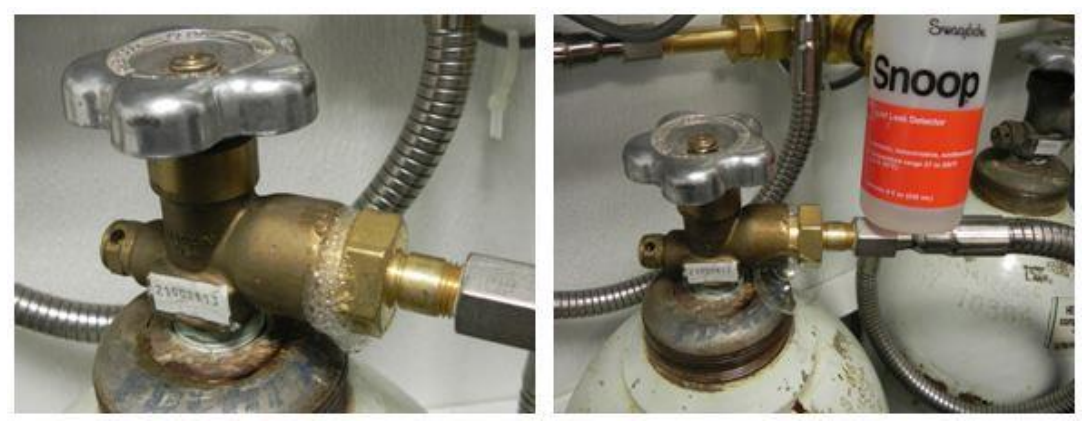

Figure 65. The formation of bubbles indicates a leak is present in this fitting.

4. Tighten fitting with the appropriate wrench for the fitting. Wrenches are located in the tool cabinet. Reapply Snoop ${ }^{\circledR}$ to determine if the leak has been stopped.

5. Continue inspecting each of the pressurized helium distribution lines and connections leading to the SAUNA system.

6. If the leak has not been detected in the supply/distribution lines to the SAUNA system, the leak is most likely within the SAUNA II system.

7. If you are not a certified SAUNA operator, do not attempt to detect or resolve a SAUNA system helium leak.

8. Turn off the helium cylinder valves and the isolation valves.

9. Contact the PNNL technical contact for the deployment for further instruction. If no one at PNNL can be reached in a timely manner, contact PNNL Operations Control Center at +01(509)375-2400. Identify yourself as a Transportable Xenon Laboratory (TXL) system operator. Request to speak with Robert Thompson, Ted Bowyer, or Harry Miley.

\section{END OF PROCEDURE IV.M}





\section{N. Procedure for Replacing Helium Cylinders}

When one bank of helium tanks is empty, the gas manifold controller will automatically switch the SAUNA helium supply to the full bank. The gas manifold controller's illuminated LED lights will switch from green to red indicating the helium bank is empty.

1. Determine if the left or right bank of helium cylinders are empty by looking at the gas manifold LED status lights. Red indicates empty (Figure 66).

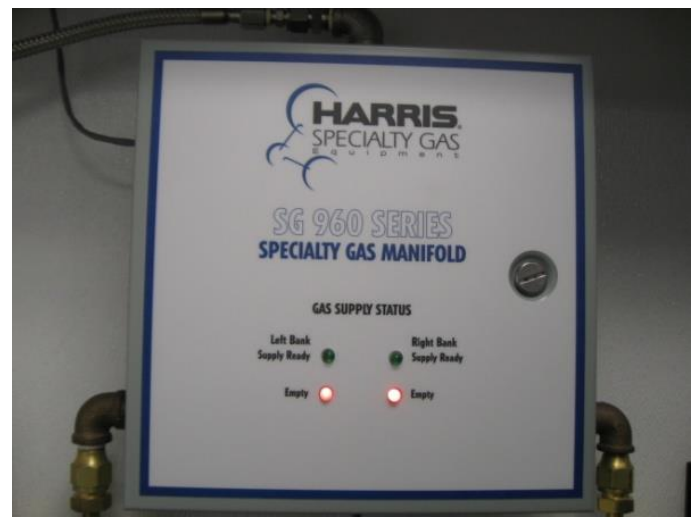

Figure 66. The gas manifold indicates both banks of helium cylinders are empty.

2. Move the SAUNA rack to the right or left as needed to access the empty cylinders.

3. Close all isolation valves and cylinder valves on the empty bank of cylinders. Refer to Figure 67 for the locations of valves.

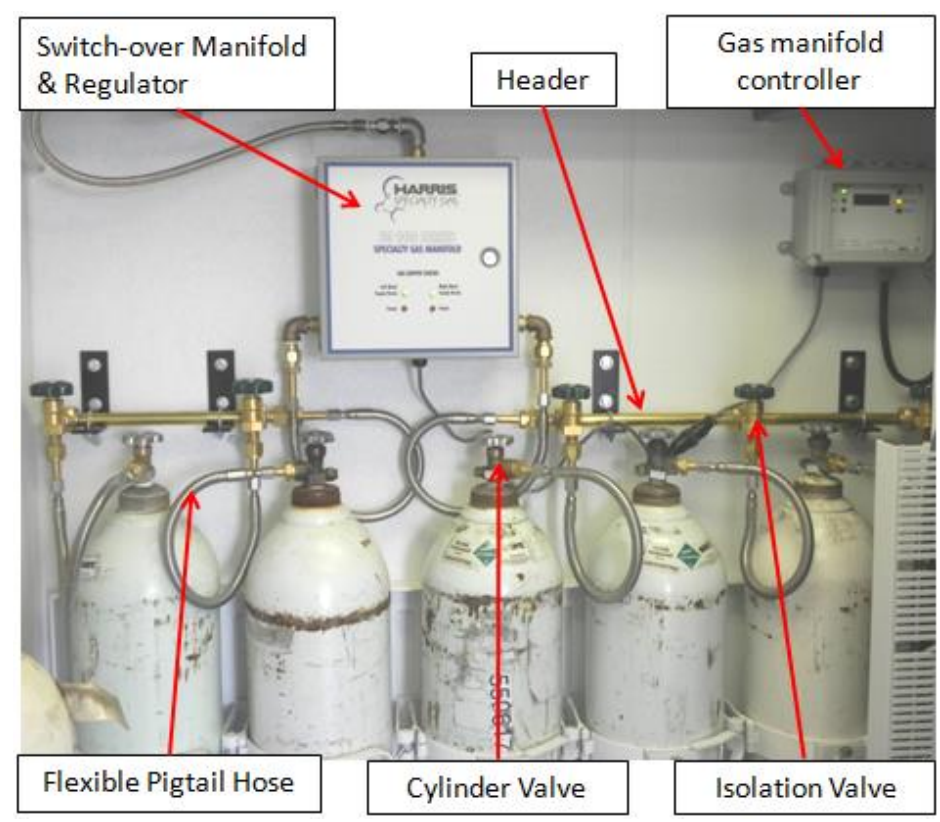

Figure 67. Before replacing helium cylinders, close the isolation and cylinder valves.

4. Remove the flexible pigtail hose from the cylinders taking precautions not to kink the flexible pigtail hose. The flexible pigtail hose has a minimum bend radius of 4 in. $(10 \mathrm{~cm})$. 
5. Replace protective caps on the empty helium tanks.

\section{SAFETY NOTE}

Never unsecure a helium cylinder from the storage rack or move a helium cylinder without the protective cap in place (Figure 68). Serious injury or death will occur if a cylinder is knocked over without the protective cap on.

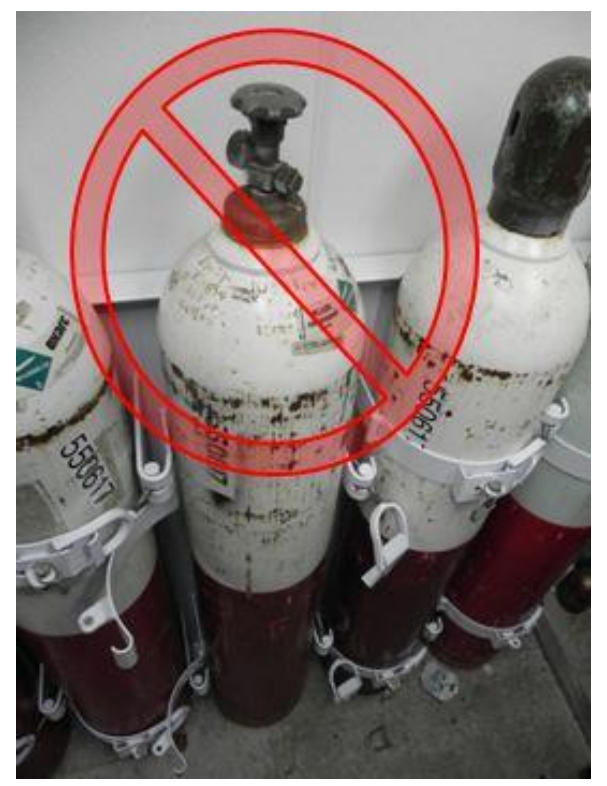

Figure 68. Never unsecure a helium cylinder from the storage rack or move a helium cylinder without the protective cap in place.

6. Remove the safety pins from the helium rack bands and open the retaining bands on the empty cylinder.

7. Roll the empty cylinder out of the manifold rack and out of the way. Have one person hold the cylinder to prevent it from tipping over.

8. Remove the Full status sign from the selected cylinder within the storage rack as set aside.

9. Retrieve a full cylinder from the storage rack and roll it into place in the empty manifold rack.

10. Fasten the two retaining bands and secure the retaining bands with the safety pin.

11. Roll the empty helium cylinder to the open location in the storage helium rack and secure it.

12. Replace the status sign on the empty cylinder with the word Empty showing.

13. Repeat Steps 2-13 for each empty cylinder.

14. Refer to Procedure L, Steps 4-12 for connecting the new cylinders to the manifold.

15. When replacing empty cylinders in the storage rack with full ones, release and resecure the cylinders as described in Steps 5-9. Place the Full status sign on each new cylinder.

\section{END OF PROCEDURE IV.N}




\section{O. Procedure for Erecting the Weather Mast}

The weather mast is mounted to the left container door when facing the front of the container.

1. Remove the black rubber cap from the SAUNA air sample inlet (Figure 69).

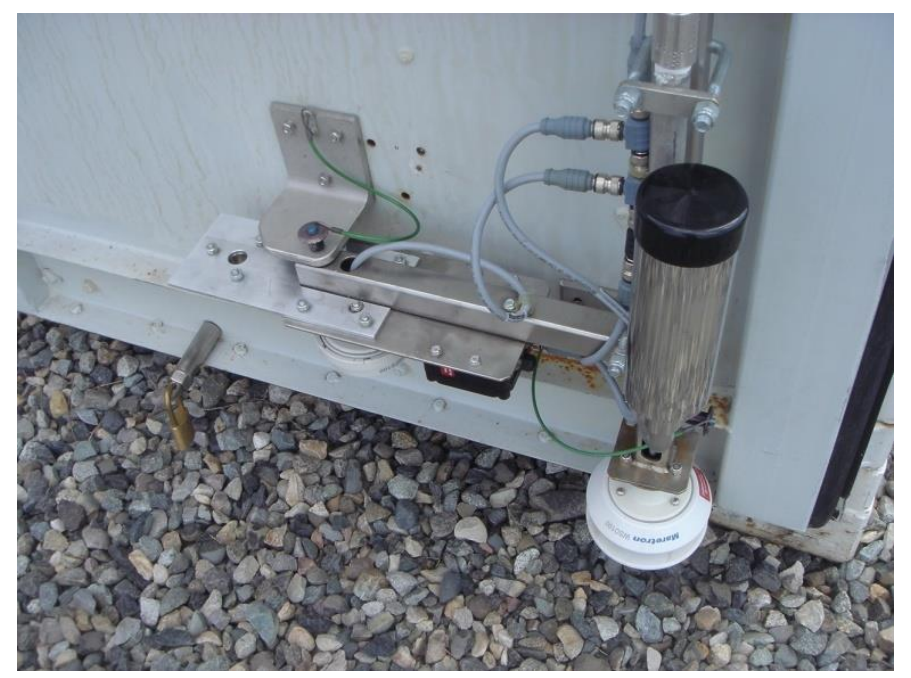

Figure 69. The black cap covers the air sample inlet during shipping.

2. Store the cap in the tool cabinet inside the laboratory.

3. Remove the 3 spring-loaded pins ( 2 pins on the bottom and 1 at the top of the door) from the mounting fixtures (Figure 70).

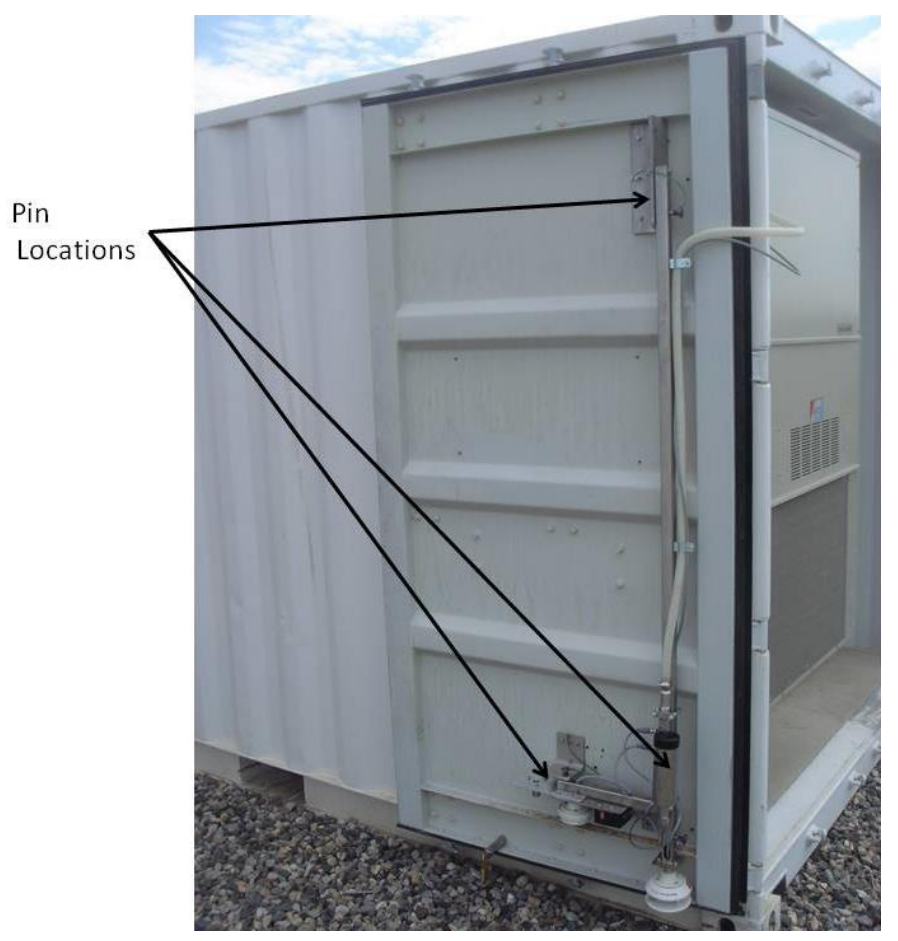

Figure 70. Remove the spring-loaded pins from the mounting locations. 
4. Place ladder to the right of the weather mast with one person standing two-thirds distance up the ladder.

5. The person on the ground walks the mast (raising it) to the person on the ladder.

6. The person on the ladder completes raising the mast to the full vertical position and locks it into place with the spring loaded pin (Figures 71 and 72).

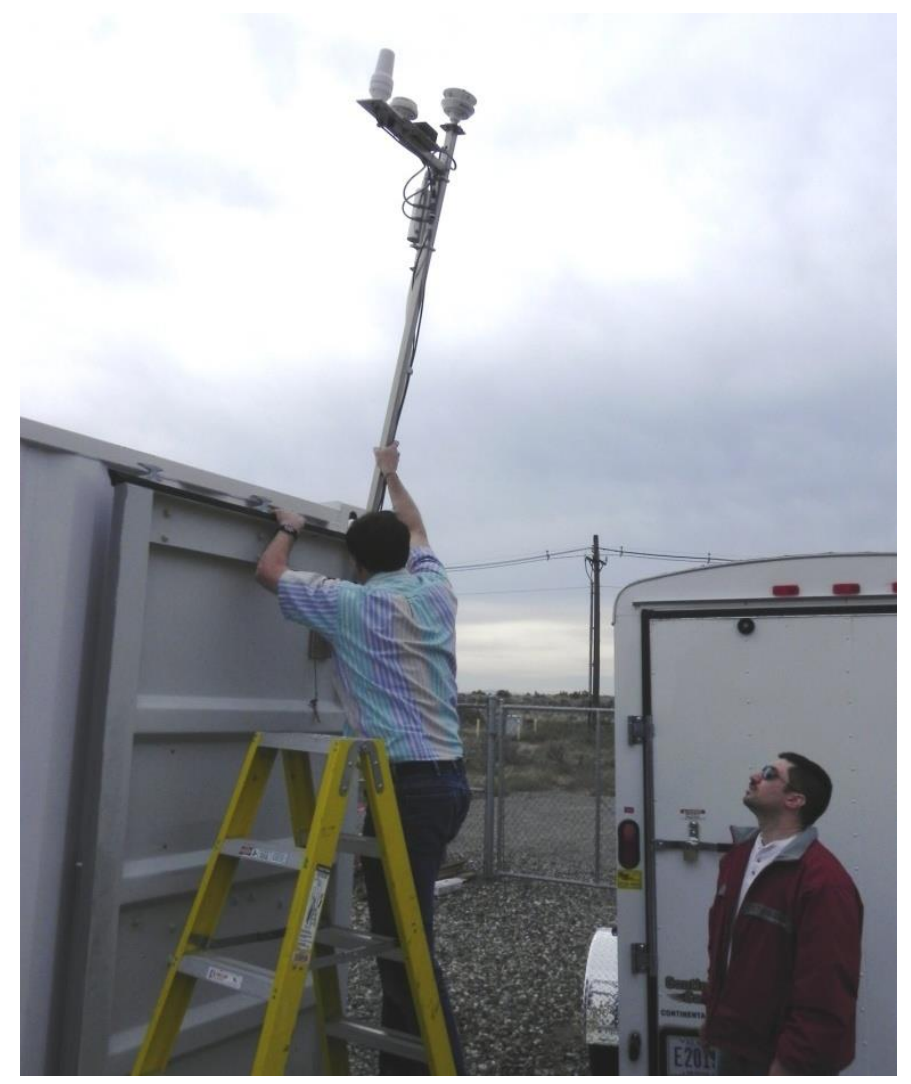

Figure 71. Raise the weather mast. 


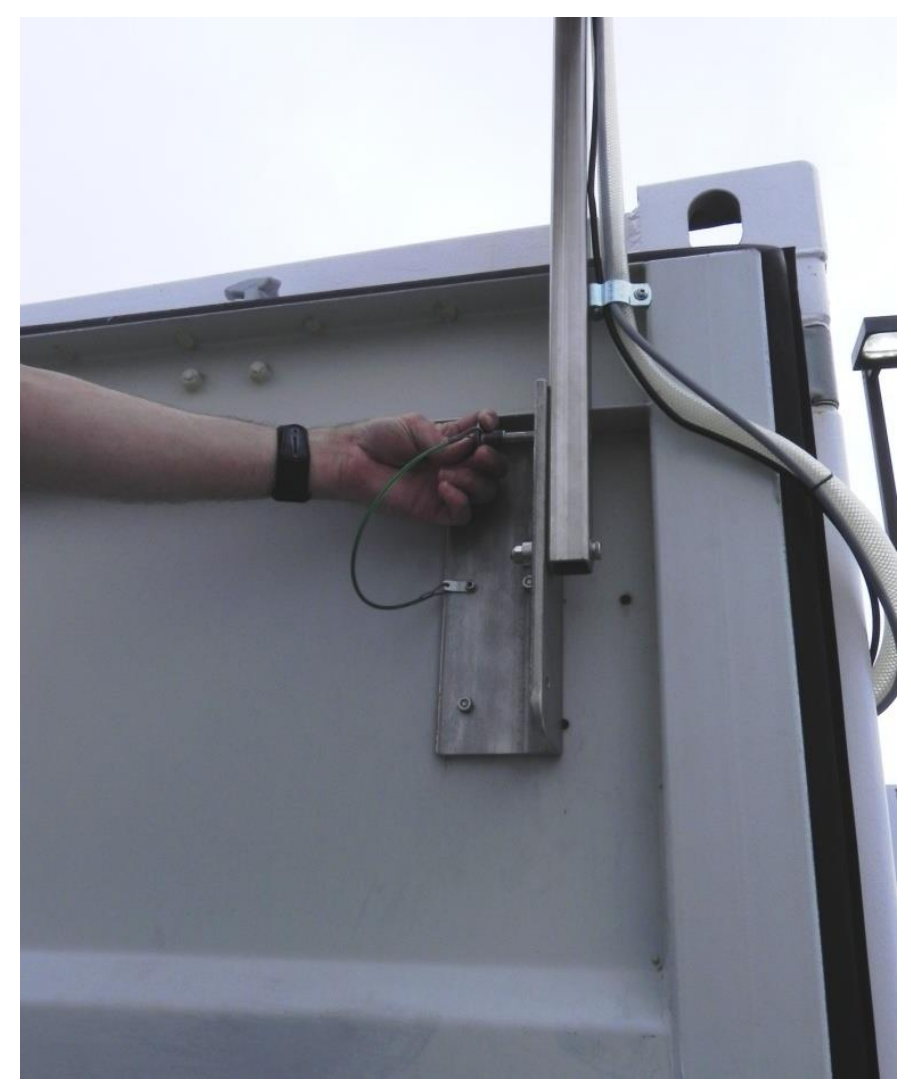

Figure 72. Replace the pins in the mounting holes to secure the weather mast in the deployed position.

7. Replace lower pins into mounting fixture holes (Figure 73).

8. Stow the ladder on the rear deck.

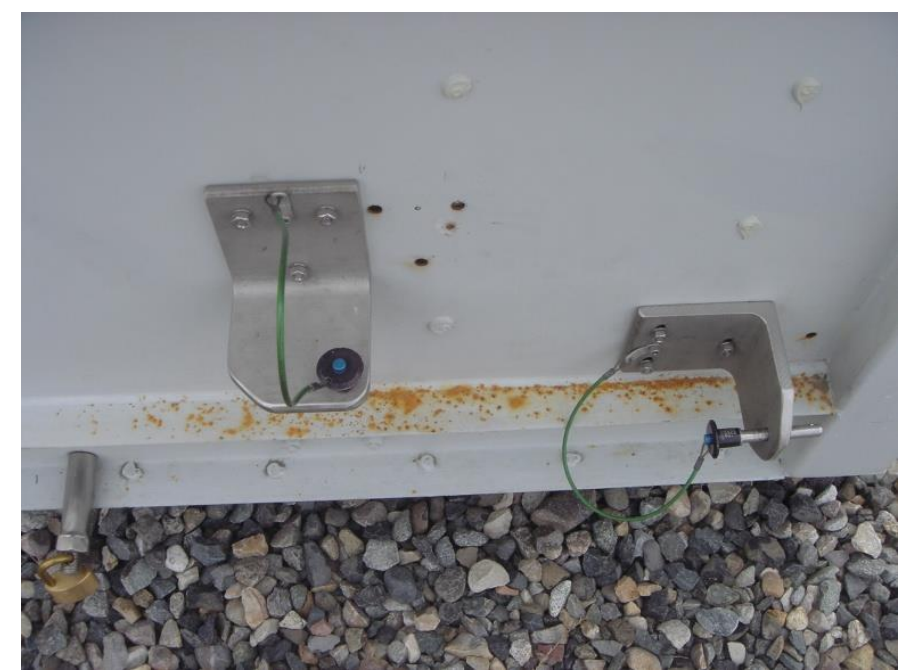

Figure 73. Insert the pins into the lower mounting fixture holes.

END OF PROCEDURE IV.O 



\section{P. Procedure for Powering Up the SAUNA}

1. Connect the internal batteries to the SAUNA uninterruptable power supply (UPS) located in the left side of the SAUNA rack (Figures 74 and 75).

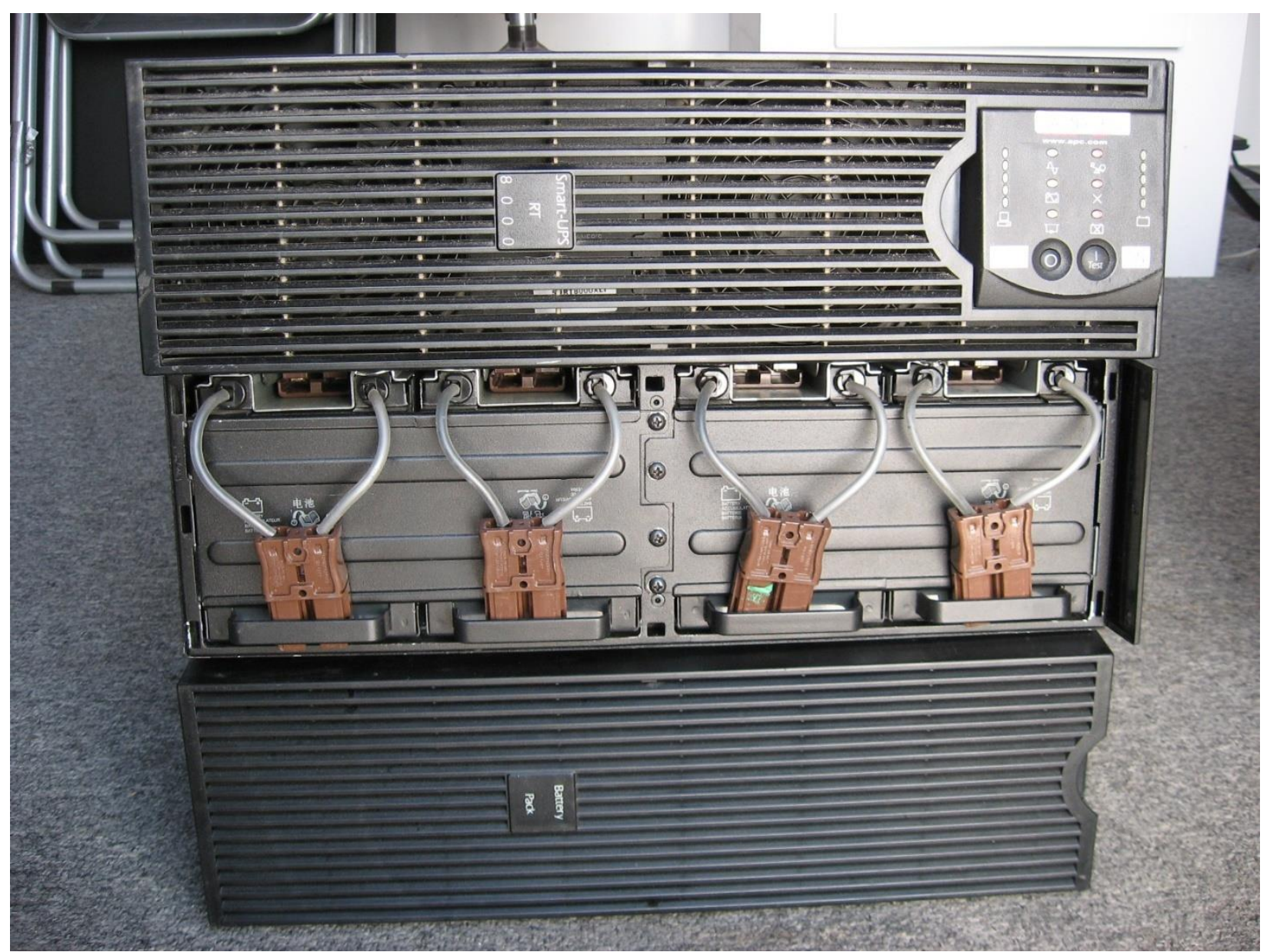

Figure 74. The UPS is shown with the front panel removed and the batteries unplugged. 


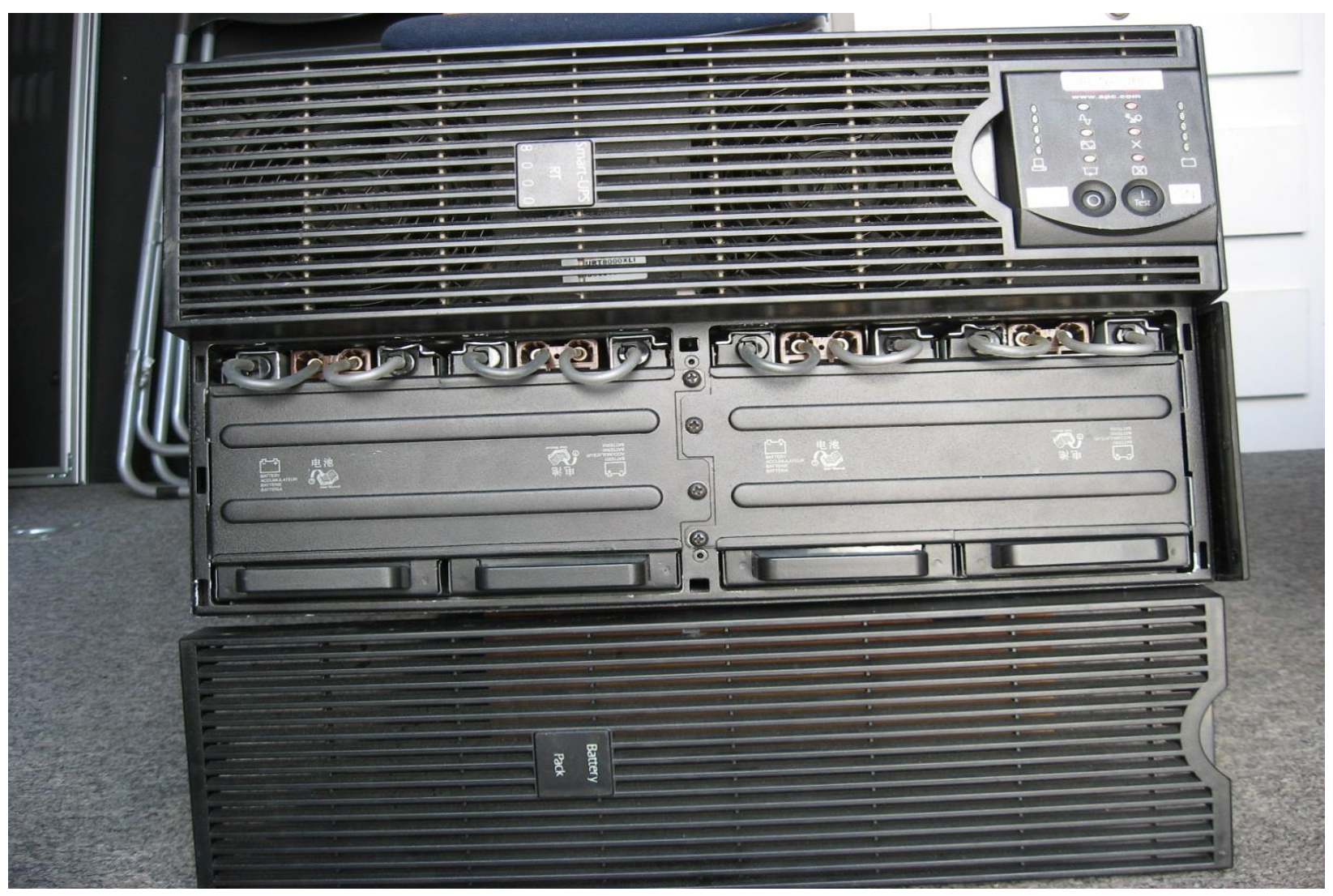

Figure 75. The UPS is shown with the front panel removed and the internal batteries connected.

2. Turn on the SAUNA uninterruptable power supply (UPS, shown in Figure 76), located in the left side of the SAUNA rack. This is done by pressing on the pushbutton switch on the front of the UPS until you hear two beeps. It is the right button labeled ON. The LEDs on the front should light up when you are successful.

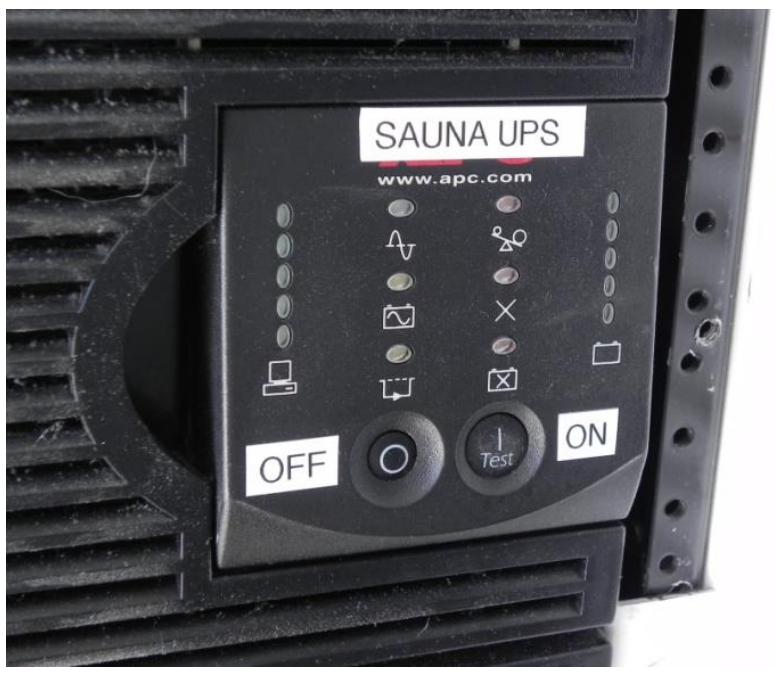

Figure 76. Turn on the SAUNA UPS by pushing the ON button. 
3. Retrieve the keyboard, mouse, and satellite phone handset from Drawer 4 of the tool cabinet. Plug the keyboard and mouse into the keyboard video monitor (KVM) extender mounted on the workbench. Plug the satellite phone handset into the satellite phone base unit.

4. Use the KVM switch to select the SAUNA computer, labeled SOH (Figure 77). The KVM is used to display the desired computer on the monitor.

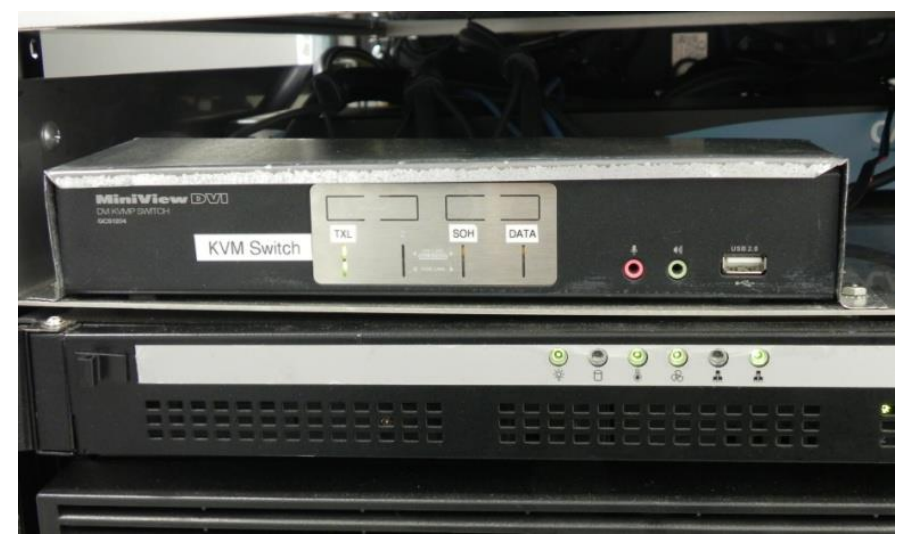

Figure 77. Use the KVM switch to select the SAUNA computer, labeled SOH.

5. The State of Health SAUNA program is available on computer desktop. Turn on both the State of Health and PH.D. computers. The State of Health computer requires no action on the part of the operator. Switch the KVM to the DATA position.

6. Click OK when the computer prompts with the User Warning Notice. This is a Federal computer system and is the property of the United States Government. It is for authorized use only. Users (authorized or unauthorized) have no explicit or implicit expectations of privacy. Any or all users of this system and all files on this system may be intercepted, monitored, recorded, copied, audited, inspected and disclosed to authorized Site, Department of Energy, and law enforcement personnel, as well as authorized officials of other agencies, both domestic and foreign. By using this system, the user consents to such interception, monitoring, recording, copying, auditing, inspection, and disclosure at the discretion of authorized Site or Department of Energy personnel. Unauthorized or improper use of this system may result in administrative disciplinary action and civil and criminal penalties. By continuing to use this system you indicate your awareness of and consent to these terms and conditions of use. LOG OFF IMMEDIATELY if you do not agree to the conditions stated in this warning.

7. Further steps related to the operation and start up of the SAUNA system are covered in Section 2 of the Gamma Data SAUNA II Operation Guide.

END OF PROCEDURE IV.P 



\section{Q. Procedure to Begin Operation of SAUNA}

Only SAUNA-trained operators start up the SAUNA system according to the procedures in the Gamma Data SAUNA II Operation Guide stored in Drawer 3 of the tool cabinet.

The lead and copper shields and protective gear (gloves, gowns, etc.) are stored in the bottom drawer of the tool cabinet.

The detectors are stored in their own shipping box that has been staged outside the TXL during Procedure IV.B. After installing the detectors into the SAUNA system, store the Detector shipping box on the rear deck on top of the Spare Parts shipping box.

END OF PROCEDURE IV.Q 



\section{Shut Down Procedure}





\section{A. Procedure for Powering Down the SAUNA}

These steps will be performed by SAUNA-trained operator(s) only.

1. Power down SAUNA system according to the Gamma Data SAUNA II Operation Guide stored in Drawer 3 of the tool cabinet.

2. Prepare SAUNA system for shipping according to the Gamma Data SAUNA II Operation Guide.

END OF PROCEDURE V.A 



\section{B. Procedure for Powering Down the TXL Computer}

1. Use keyboard video monitor (KVM) switch to select TXL computer (Figure 78).

2. Exit from running programs.

3. Turn off the house computer (located in the left side of the SAUNA rack).

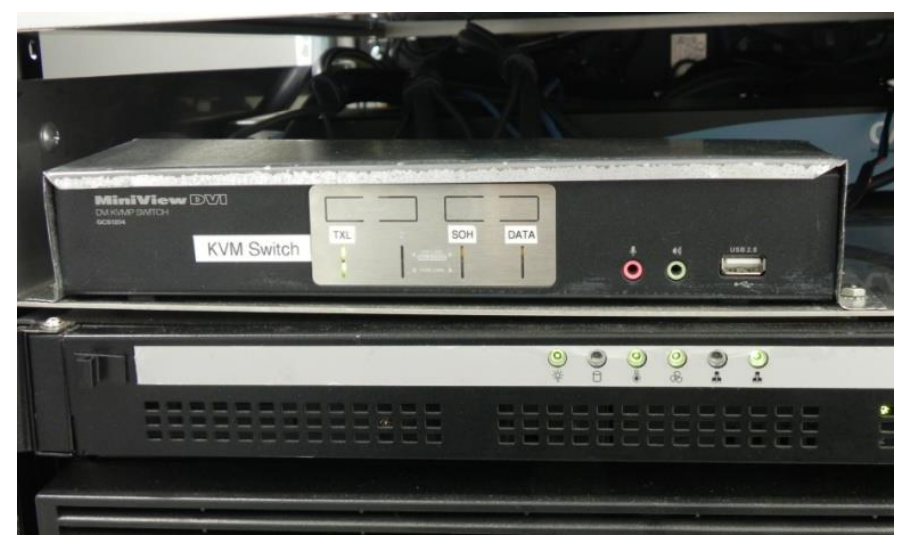

Figure 78. The KVM Switch is mounted above the house computer. Access to the computer power switch is located behind the silver fold-down door.

END OF PROCEDURE V.B 



\section{Procedure for Stowing the Weather Mast}

The weather mast is mounted to the left container door when facing the front of the container.

1. Retrieve the ladder from the rear deck.

2. One person climbs the ladder, and the other person stands ready to receive the mast as it is lowered.

3. Remove lower pins from the mounting fixture holes.

4. The person on the ladder lowers the mast to the person on the ground, who walks the mast to its stowed (shipping) position (Figure 79).

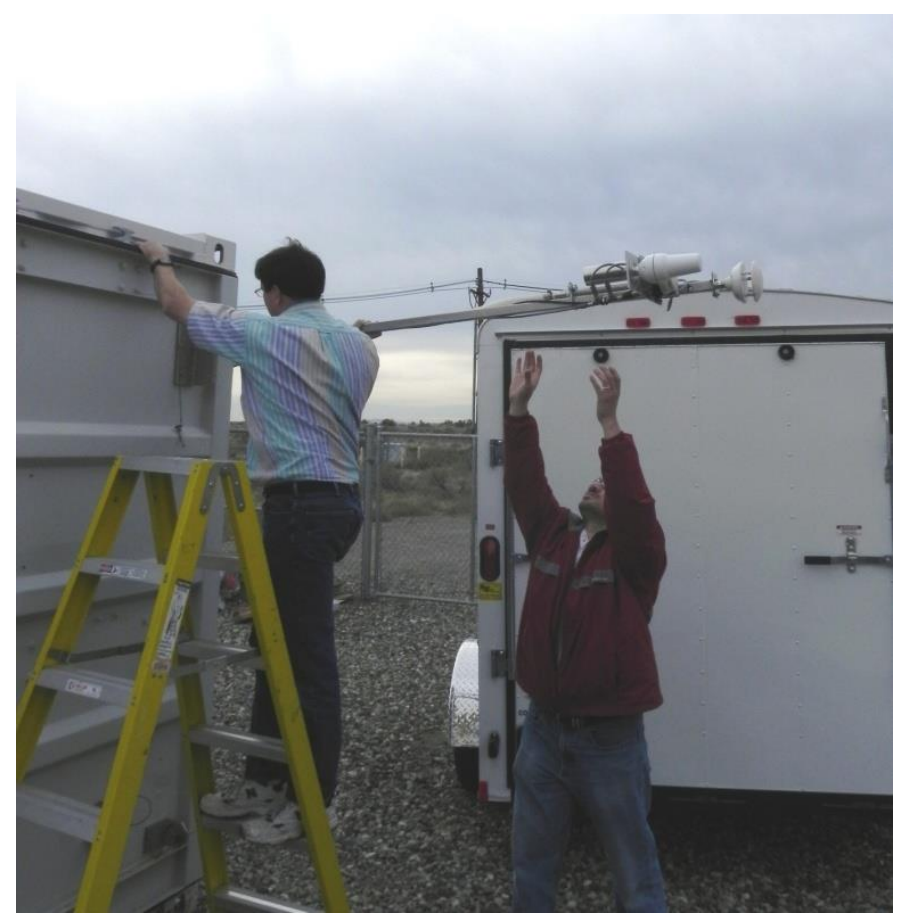

Figure 79. Two people lower the weather mast.

5. Lock the mast into is shipping configuration with the 3 spring-loaded pins (Figure 80). 


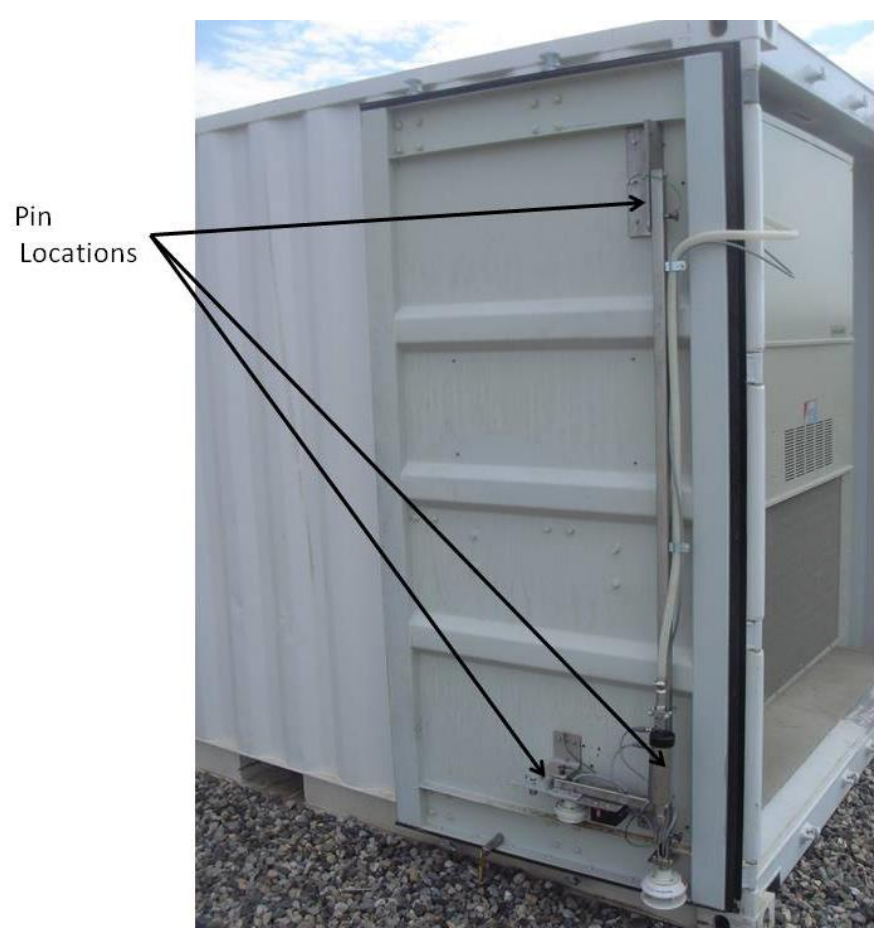

Figure 80. Secure the weather mast in its shipping configuration using the three pins.

6. Retrieve the black rubber cap for the SAUNA air sample inlet from the tool cabinet inside the laboratory.

7. Place the cap on the air sample inlet (Figure 81).

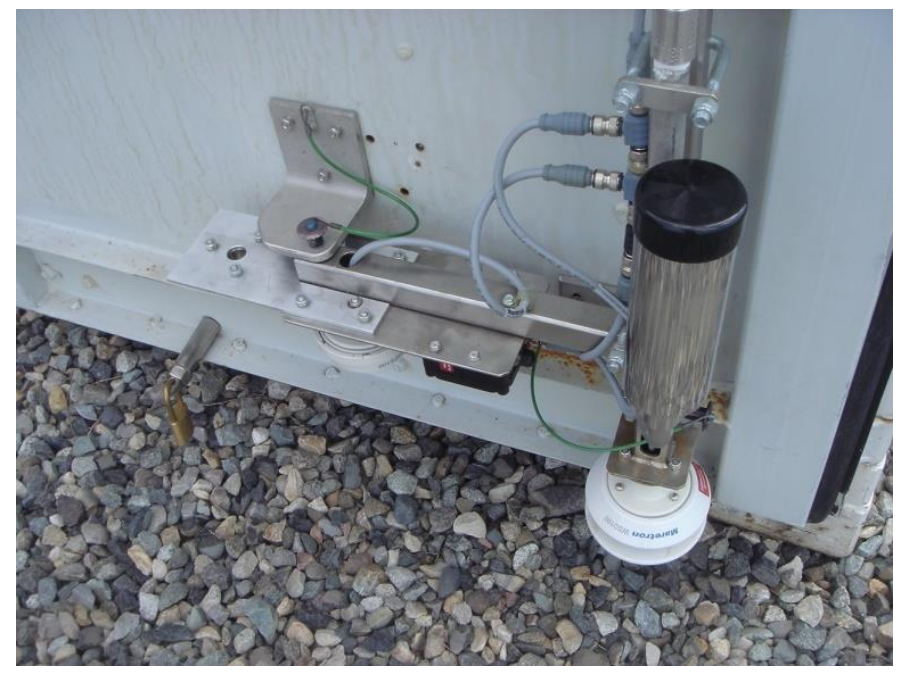

Figure 81. The black cap covers the air sample inlet during shipping.

END OF PROCEDURE V.C 


\section{Procedure for Shutting Off and Securing Helium Cylinders}

\section{SAFETY NOTE}

If at any time the ToxGard II oxygen monitor alarms, evacuate the laboratory until it stops. Lock the personnel door in the open position to allow helium to vent from the TXL

1. Open and latch the personnel door in the open position.

2. Refer to Figure 82 for the component of the helium distribution system.

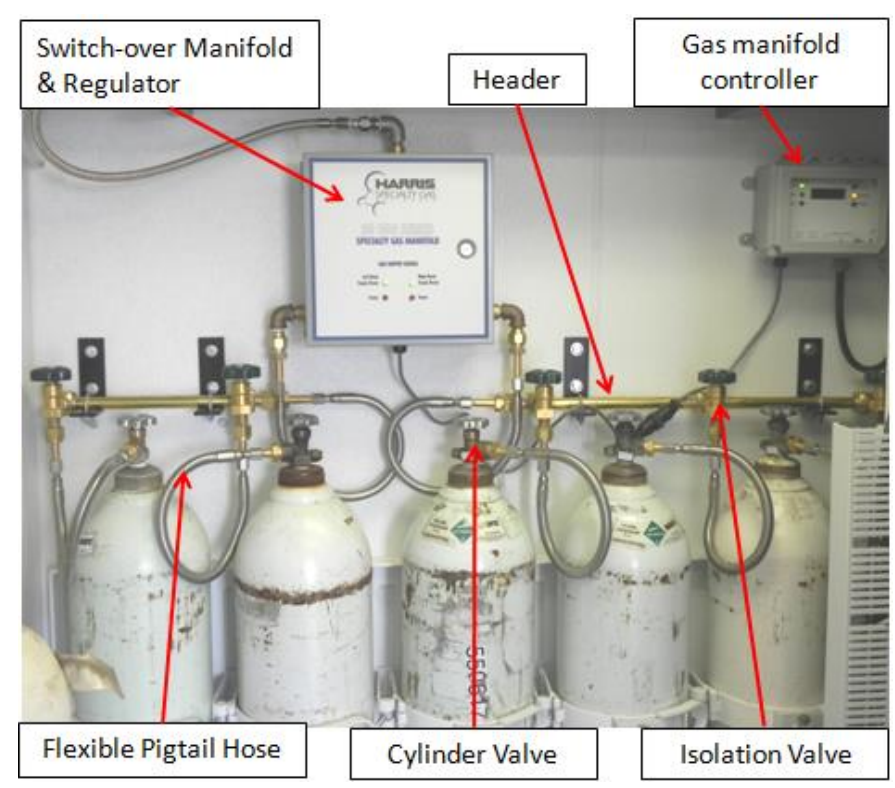

Figure 82. Note the components of the helium distribution system to follow Shut Down Procedure V.D.

3. Close isolation valves and the helium cylinder valves.

4. Disconnect flexible pigtail hoses from helium cylinders.

5. Wire tie the pigtail hoses to the cylinder rack with wire ties located in the tool cabinet.

6. Put protective caps over the helium cylinders. Protective caps for the supply helium cylinders are stored on the floor between the supply and storage helium racks.

7. Check the cylinder rack clamps to make sure they will keep the helium cylinders in place during shipping. If rack clamps do not fit snuggly, shorten the length of the rack clamp. Release one clamp at a time and rotate the buckle clockwise to shorten the clamp length. Resecure the cylinder rack clamp.

8. Verify that the locking pins are securely in place on each cylinder in the supply and storage racks.

END OF PROCEDURE V.D 



\section{E. Procedure for Preparing the SAUNA for Shipping}

Steps 1 through 3 must be performed by a SAUNA-trained operator.

1. Remove detectors elements and lead from detector housing.

2. Store detectors in the Detector shipping box.

3. Store lead in bottom drawer of tool cabinet.

Steps 4 through 8 should be performed by the TXL shut-down personnel.

4. Remove shipping boxes from rear storage deck to allow access to the Dunnage/SAUNA Shipping Brackets shipping box. Stage boxes near the front of the container.

5. Retrieve the detector lid brackets, threaded stud plates, and nuts from the red box labeled SAUNA Detector Shipping Brackets.

6. Install five detector lid brackets on each side of the detector lids to lock them in place relative to the detector housing (Figures 83-85).

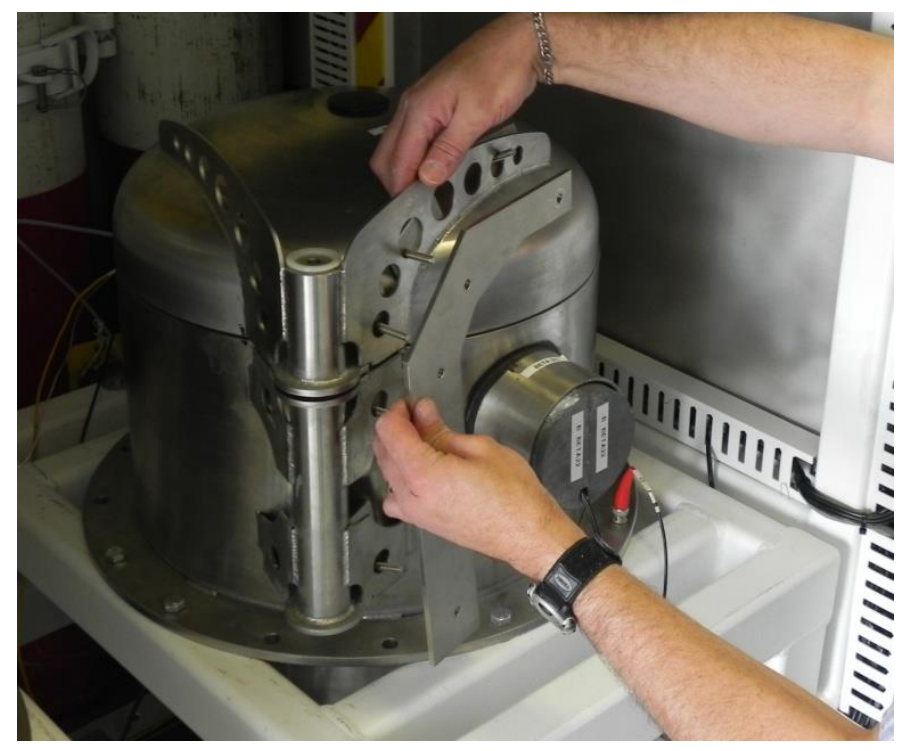

Figure 83. Insert stud plates through the holes on the detector lid hinge supports. 


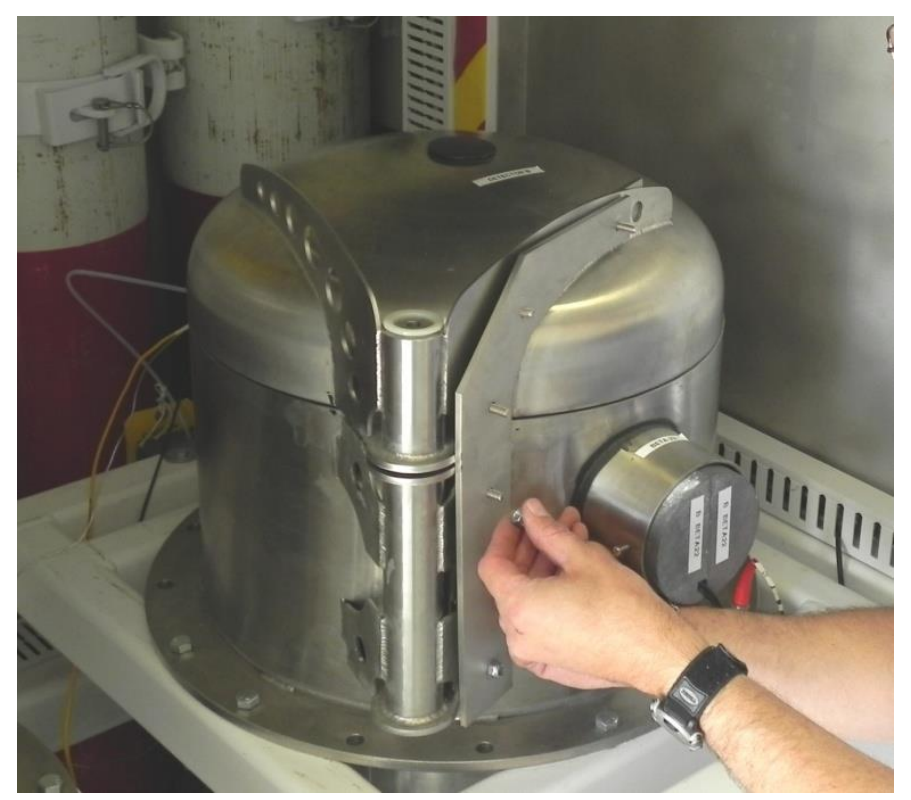

Figure 84. Guide studs through the holes in the detector lid bracket and secure with nylock nuts.

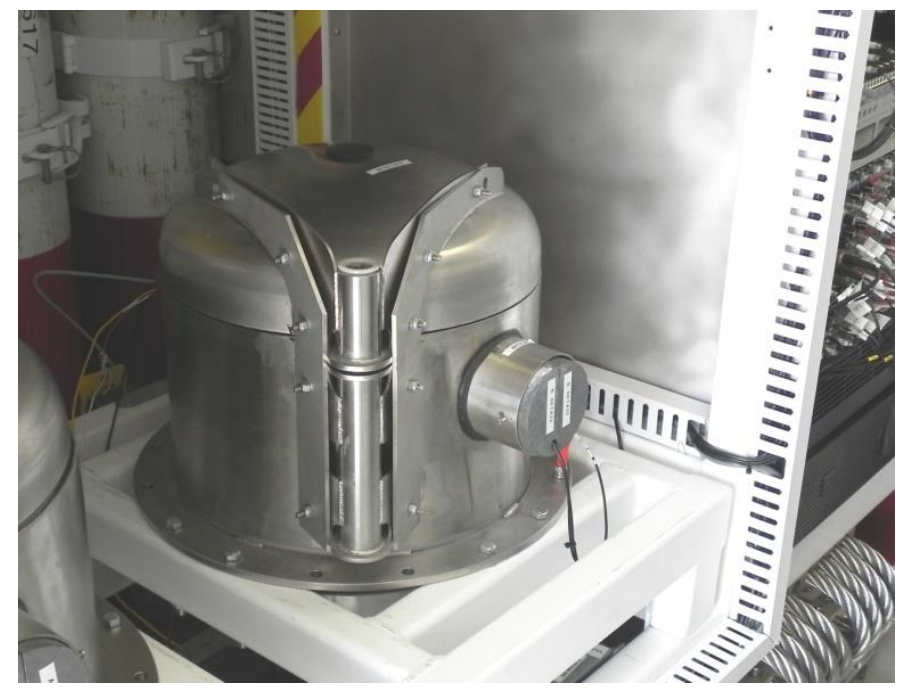

Figure 85. Detector is ready for shipping.

7. Remove condensation line from hole in floor and secure it to the SAUNA frame with a tie wrap (Figure 86). 


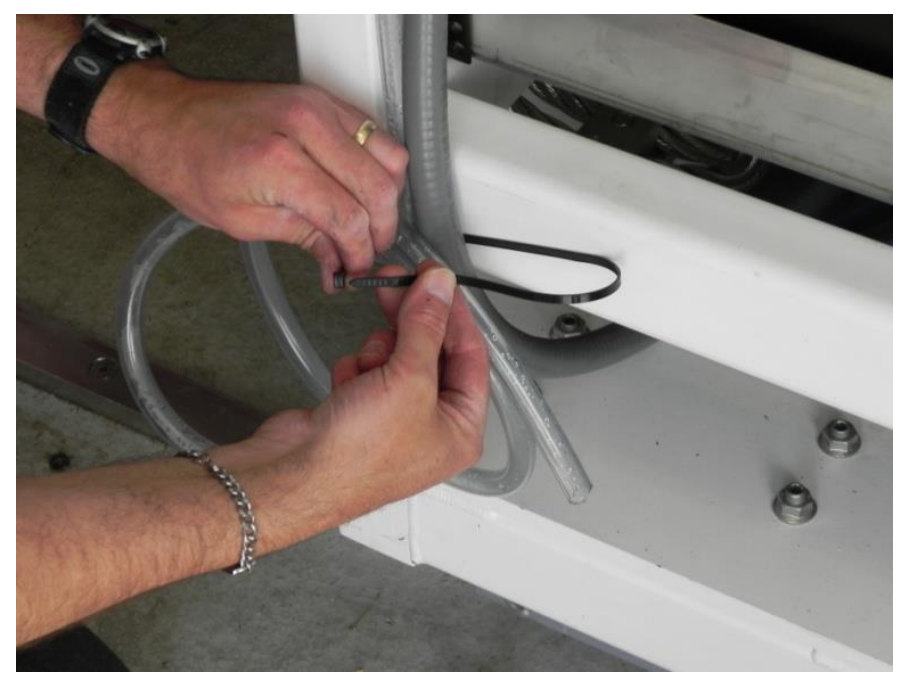

Figure 86. Secure the condensation line to the SAUNA frame with a tie wrap.

8. Retrieve the bung from the Jacks/Leveling Fixtures/AC Cord shipping box. Replace the bung in condensation hole in floor of TXL (Figure 87).

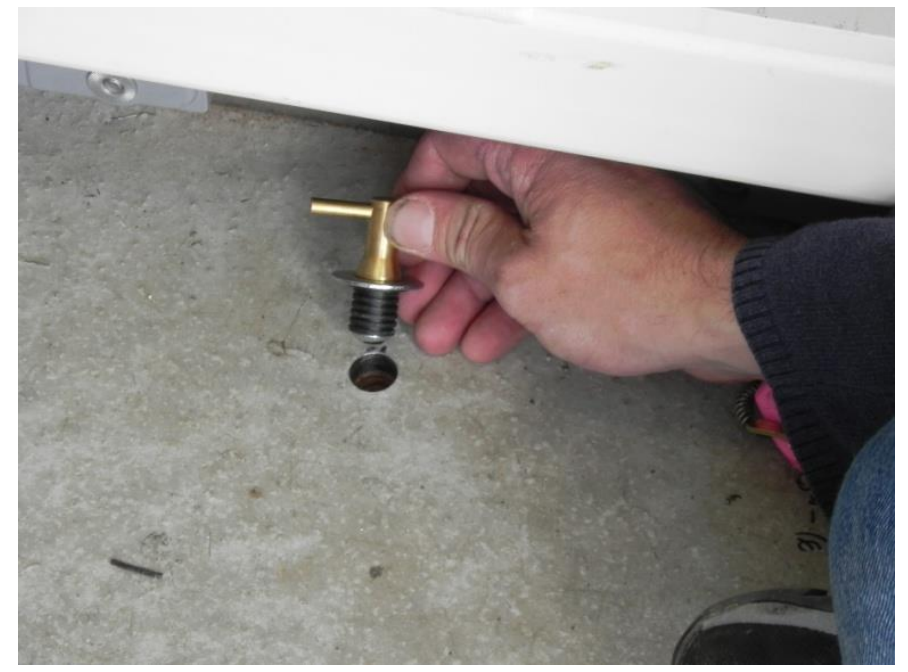

Figure 87. Insert the bung in the floor where the condensation tube was removed.

END OF PROCEDURE V.E 



\section{F. Procedure for Securing SAUNA Translation Frame for Shipping}

\section{BACKGROUND}

The SAUNA translation frame consists of two major components; a) the SAUNA equipment rack and b) the SAUNA translation base. The equipment rack is attached to the translation base with four vibration isolators. During shipping, the translation base is secured to the TXL floor with three bottom mounting brackets. The equipment rack is secured to the left inside wall with two vibration isolations to prevent the rack from swaying.

CAUTION! Tripping hazards and head injury are possible. Proceed with caution. This procedure involves raising fixtures above a person's head, and requires two people to carry it out. Figure 88 shows the vibration isolator assembly and identifies the components to be removed in this procedure. The upper vibration spring and tie rods weigh approximately 35 pounds. Hard hat use is required.

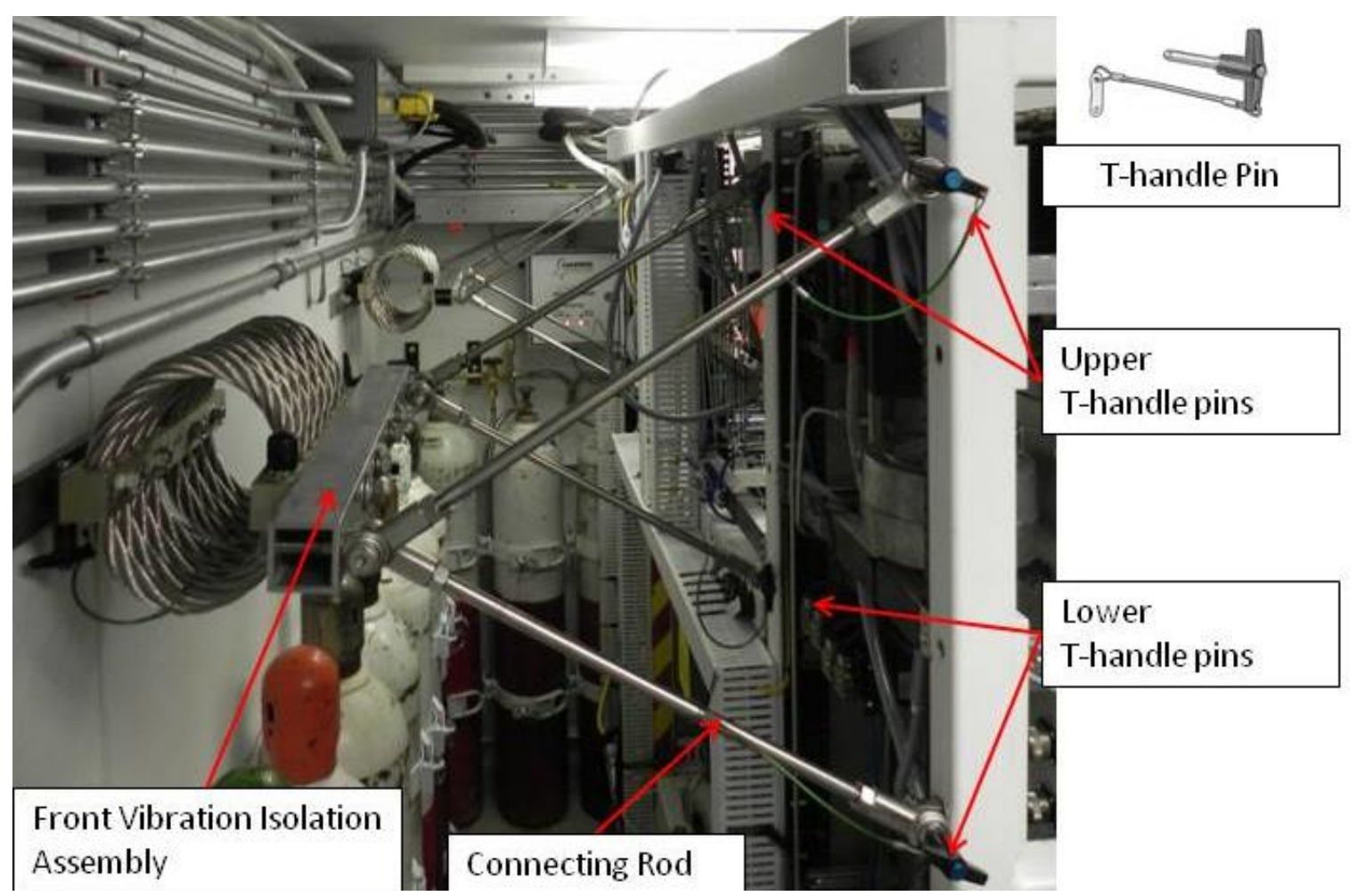

Figure 88. Vibration isolator assembly components are noted.

1. Retrieve the two upper vibration mounting fixtures, the three bottom-mounting brackets, and associated hardware (nuts, bolts, and washers) located in the red metal boxes labeled SAUNA Shipping Bolts \#1 \& \#2 and other items from the the Dunnage/SAUNA Shipping Brackets shipping box. Stage the hardware outside the TXL front door.

2. Verify that there are no obstructions between the SAUNA rack and the right wall. 
3. Turn the SAUNA rack transport motor key (Figure 89) in the clockwise position to move the rack near the right hand wall. Stop the rack translation approximately 6 in. $(15 \mathrm{~cm})$ from the wall.

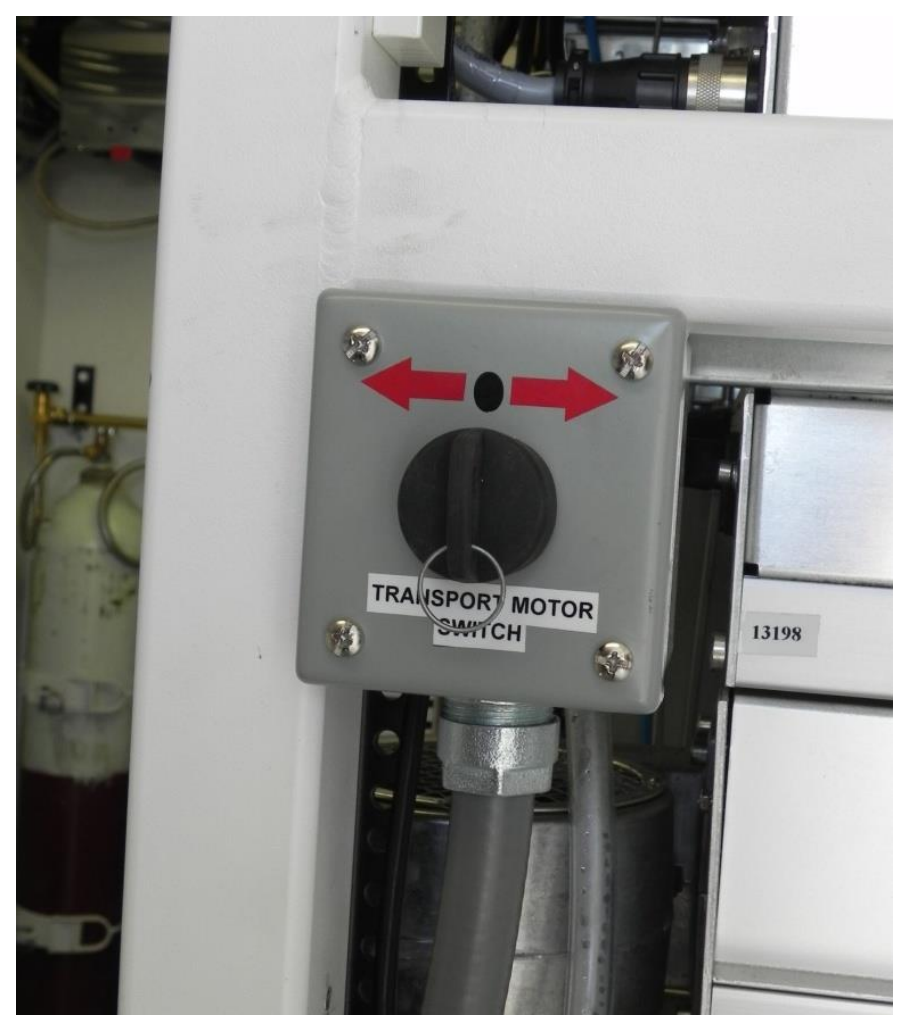

Figure 89. To move the SAUNA transport rack to the right, turn the key on the transport motor in the clockwise position.

4. Position the upper vibration islator assembly marked Rear Isolator Assembly, at the rear of the laboratory on the TXL floor. Notice the markings on the connecting rods are marked " $A$ "-" $D$." Orient the isolator assembly such that the connecting rods correspond to the " $A$ "- " $D$ " marking on the SAUNA rack. The labels are stamped on the rod ends and the corresponding attachment point on the SAUNA frame.

5. Remove all T-handle pins from the assembly and let them hang freely.

6. Lift the isloator assembly and position the assembly above the wall-mounted tie rod ends. With one person supporting the assembly, the other person inserts the four T-handle pins from the bottom securing the assembly to the wall mount. Ensure that the pins are fully engaged. Allow the connecting arms to hand free. Note: Pins can be inserted from the top or bottom (Figure 90). 


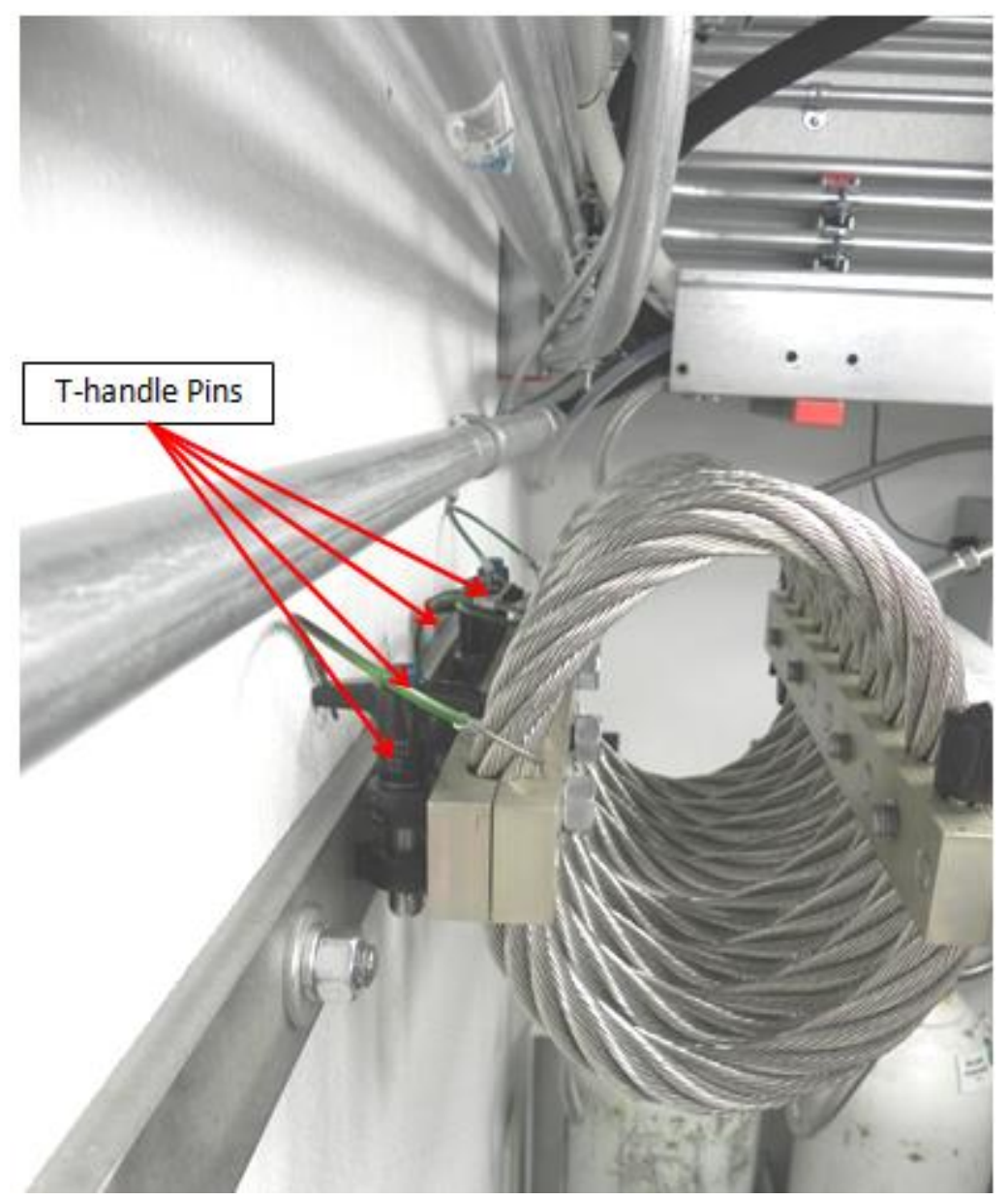

Figure 90. Vibration isolator assembly attached to the wall with T-handle pins.

7. Repeat Step 6 with the Front Isolator Assembly.

8. Raise the Front Isolator Assembly's connecting rod labeled " $D$ " and the Rear Isolator Assembly's connecting rod labeled " $A$ " and secure the rods temporaly to the holes in the C channel located on the ceiling using the T-handle pins. Ensure that the T-handles are securely engaged in the C channel hole (Figure 91). 


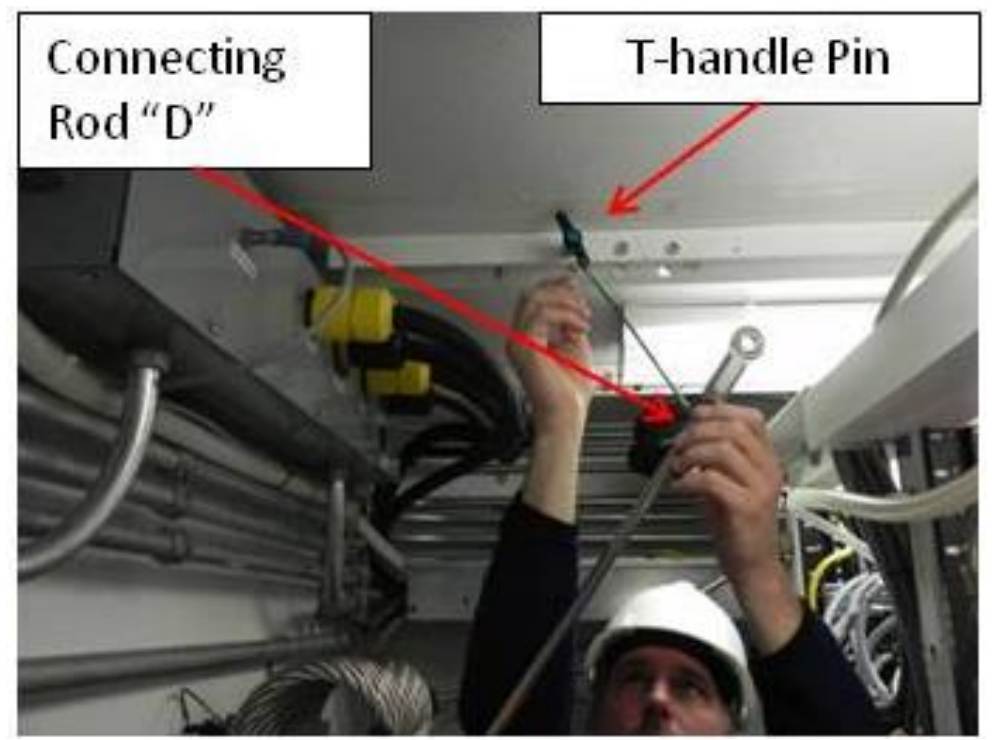

Figure 91. Secure the connecting rods marked " $D$ " and " $A$ " temporarily to the holes in the ceiling mounted C channel.

9. With one person at the front assembly and one at the rear assembly, turn the SAUNA rack transport motor key counter-clockwise position to postion the rack such that the Front Isolator Assembly's connecting rod " $A$ " is aligned with the corresponding tie rod end on the SAUNA rack. The correct spacing of the rack from the left wall is approximately $29.25 \mathrm{in} .(74.3 \mathrm{~cm})$. Stop the movement of the rack. Insert the T-handle pin as shown in Figure 92. This may take a few attempts to align the holes.

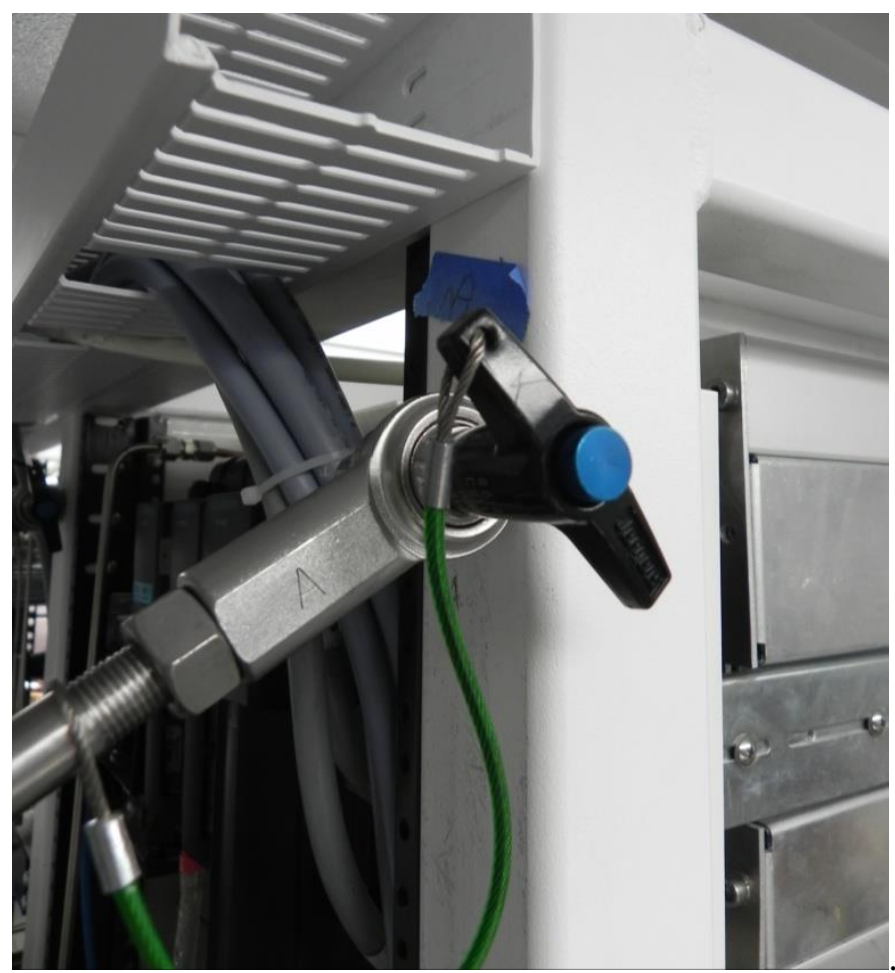

Figure 92. Align and secure the upper connecting rod to the SAUNA rack. 
10. Attach the three remaining connecting rods to the SAUNA rack.

11. Attach the four connecting rods of the Rear Isolator Assembly to the SAUNA rack in a similar manner.

\section{NOTE}

In the unlikely event that the connecting rods will not align, adjustments may be made to the length of the connecting rods, the jam nuts may be loosened, the rod ends screwed clockwise or counterclockwise as required. Once the adjustment is made, lock the jam nuts firmly into place.

12. The final installation of the upper vibration isolation assemblies is shown in Figure 93.

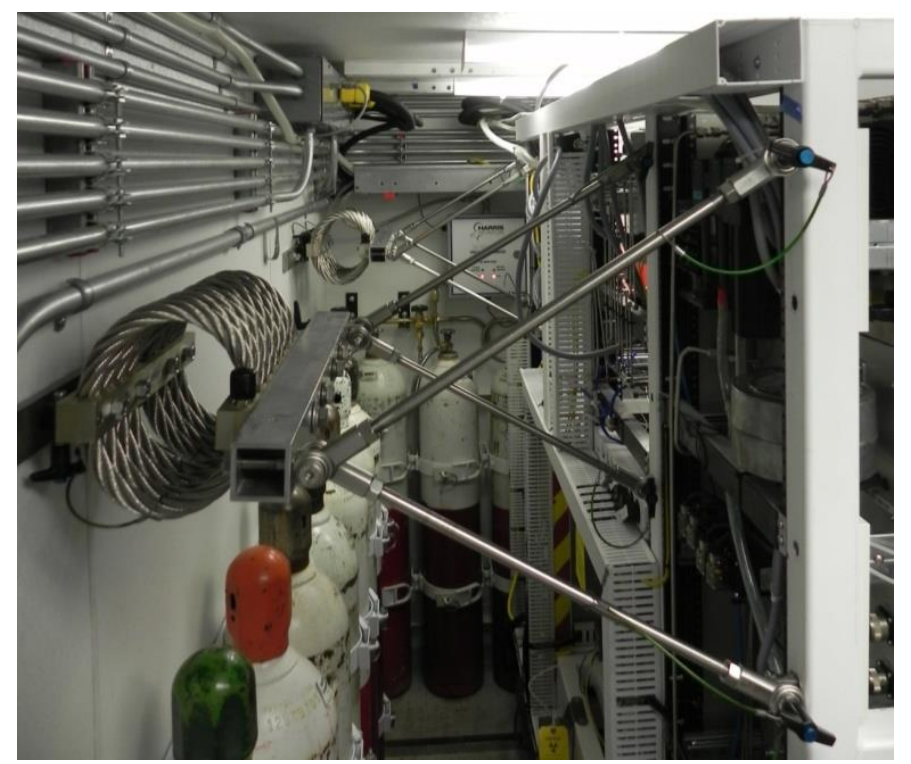

Figure 93. When properly installed, the upper vibration isolation assemblies look like this.

13. Using the socket wrench located in the tool cabinet, secure the three bottom mounting brackets (Figure 94) to the lower SAUNA translation base and the the floor. Each bracket is secured to the translation base and the TXL floor with seven bolts and washers. The bolts and washers are stored in the red metal storage box labeled SAUNA Shipping Bolts \#1 and \#2. 


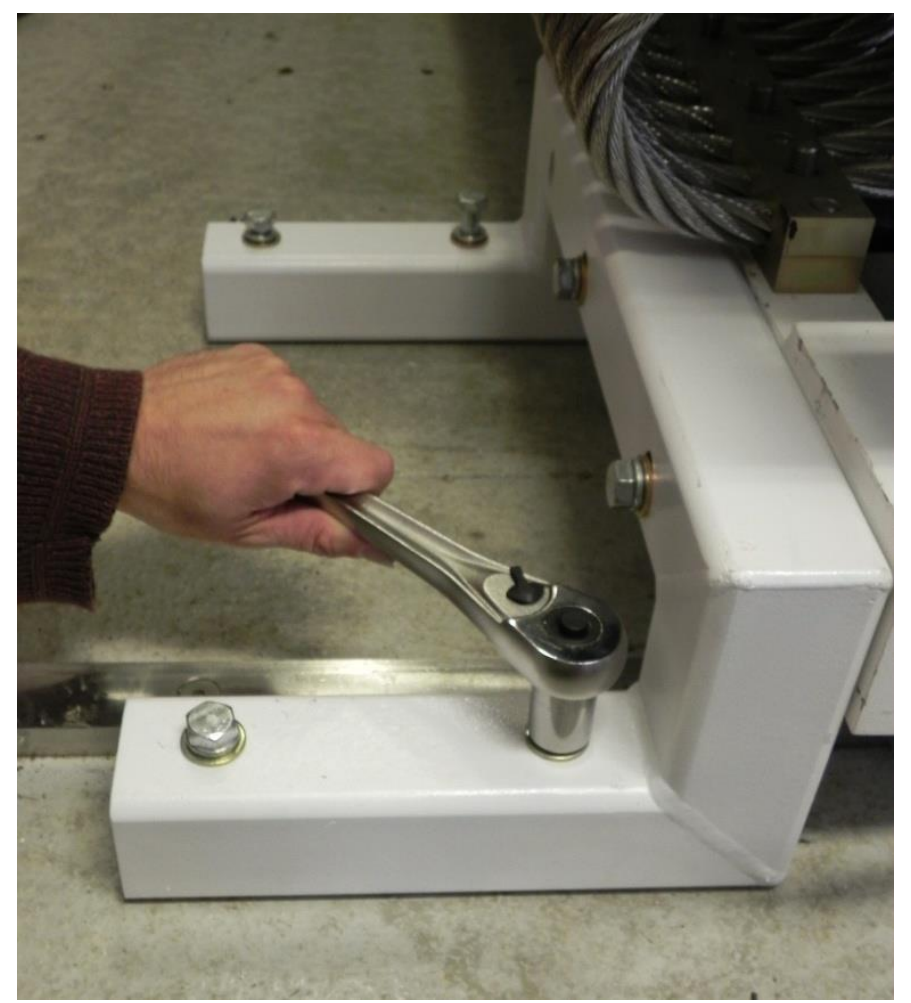

Figure 94. Secure the bottom-mounted bracket to the lower SAUNA translational base and the floor. END OF PROCEDURE V.F 


\section{G. Procedure for Draining the Diesel Fuel Tank}

\section{If fuel delivery truck retrieves fuel from the tank:}

1. Unlock the padlock (using keys on master ring, same key as J-hook locks) on the cap of the diesel fuel tank and set the lock aside.

2. Open the fuel fill cap.

3. Fuel truck retrieves fuel.

4. Replace cap.

5. Lock the padlock on the tank with the body of the padlock towards the inside of the rear deck (Figure 95).

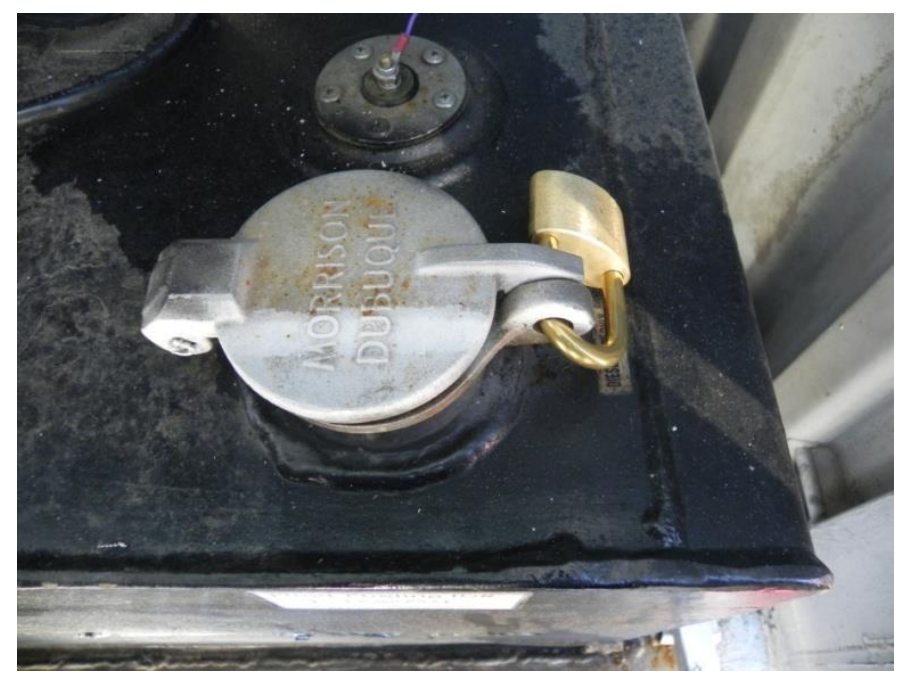

Figure 95. Lock the padlock on the tank cap with the body pointing toward the rear deck.

6. Wipe up any spilled fuel and hoses with paper towels or another absorbent material. Dispose of towels in accordance with local regulations.

\section{If personnel discharge the remaining diesel fuel to empty fuel drums:}

1. Unlock the padlock (from master key ring same key as J-hook locks) and set the lock aside.

2. Open the fuel fill cap.

3. Unbolt the fuel transfer pump from the tank frame (Figure 96). 


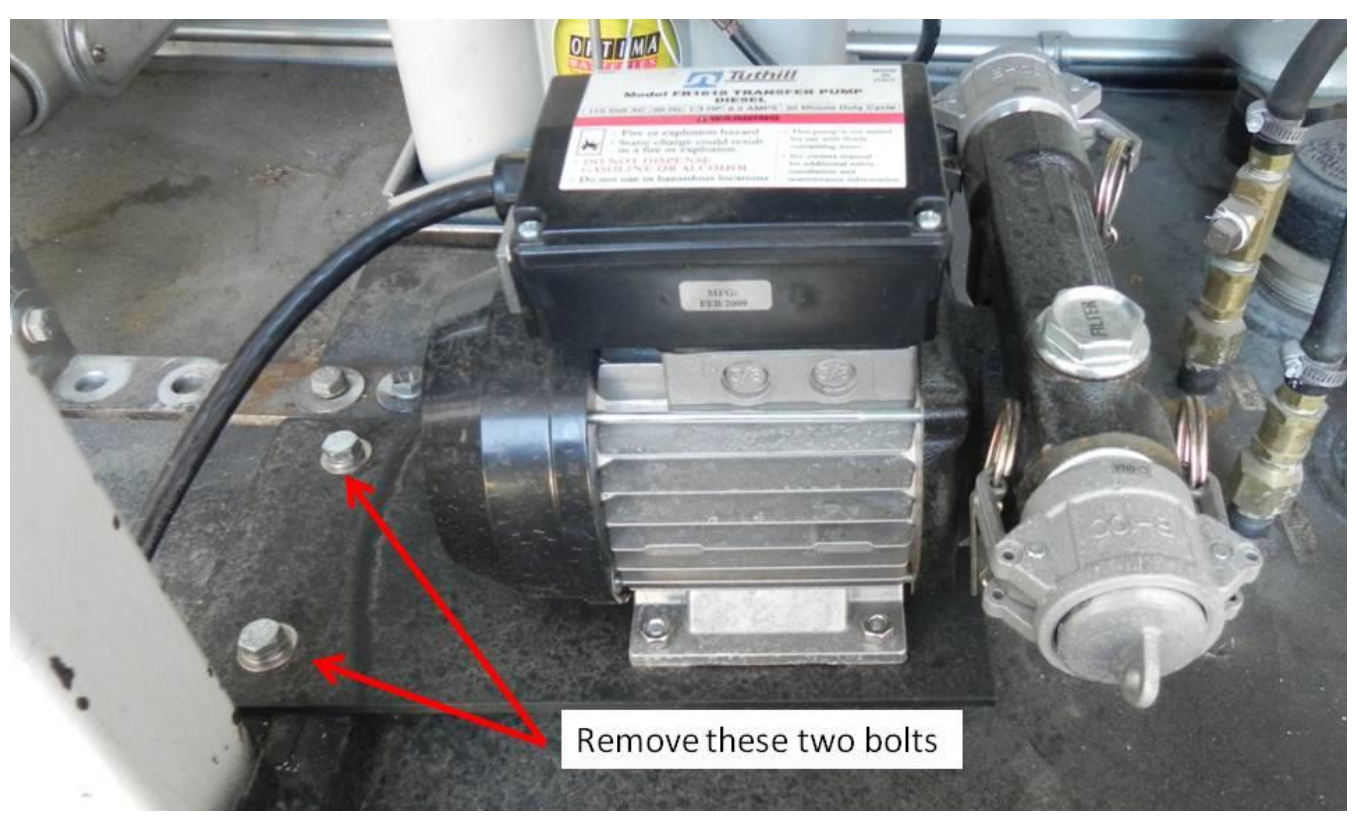

Figure 96. Unbolt the fuel transfer pump from the tank frame.

4. Note the fuel pumping direction of the pump (arrow indicates inlet and outlet ports, Figure 97).

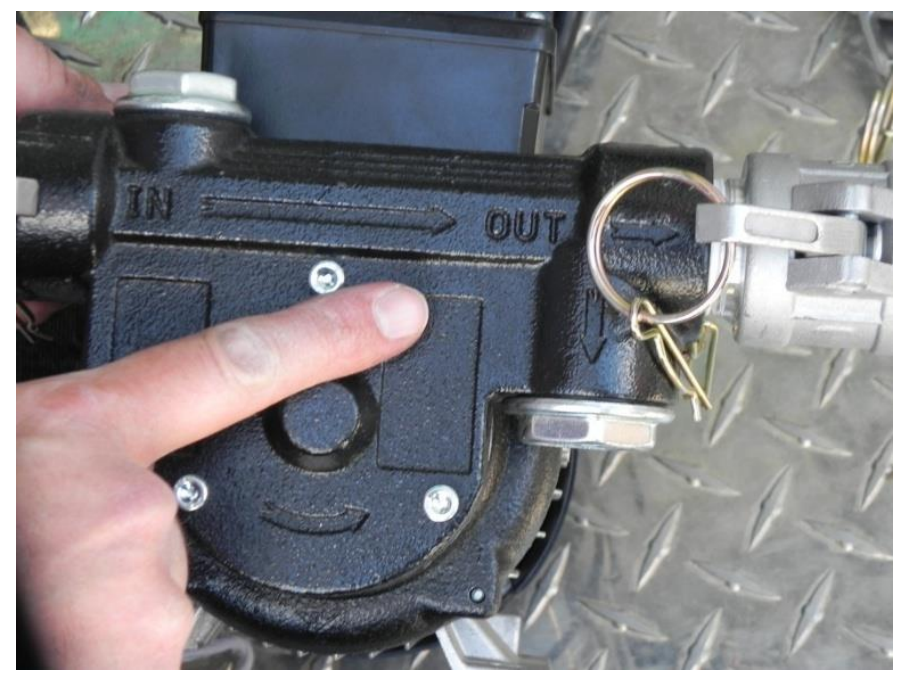

Figure 97. The pumping direction is noted on the fuel transfer pump.

5. Retrieve fuel transfer hoses from the Dunnage/SAUNA Shipping Brackets shipping box stored on the rear deck.

6. Connect the hoses to the quick disconnect fittings on the pump.

7. Remove the end caps on the non-quick release ends of the fuel transfer hoses and set aside.

8. Ensure that all Teflon pipe tape has been removed from the hose threads.

9. Place the inlet hose into the 100-gallon fuel tank and the discharge hose into the fuel drum.

10. Turn on fuel transfer pump by plugging it into the convenience AC outlet located on the wall of the rear deck. If the TXL is operating on generator power, ensure that the end of the hose placed 
in the tank is 2 in. $(5.1 \mathrm{~cm})$ above the bottom of the tank during the emptying process. Do not allow the generator to run the tank dry.

11. Drain fuel from the tank until the fuel level reaches the 2-in. $(5.1-\mathrm{cm})$ reserve fuel level. Be careful not to overfill drum(s).

12. If you have more fuel than one drum can contain, unplug the pump and withdraw the discharge hose when one drum nearly full and put the next empty drum in place, and replace the discharge hose in the empty drum and turn on the pump.

13. When the tank has been drained, turn off the fuel transfer pump by unplugging it from the convenience AC outlet.

14. Remove the hoses at the quick disconnect fittings and drain the remaining fuel into the drum.

15. Install the cap on the drum(s).

16. Place end caps on the non-quick release ends of the fuel transfer hoses. Use Teflon tape (from the tool cabinet) to wrap the threaded hose fittings and secure the threaded hose caps.

17. Wipe up any spilled fuel and hoses with paper towels or another absorbent material. Dispose of towels in accordance with local regulations.

18. Store the fuel transfer hoses in the shipping box.

19. Return fuel pump to shipping location and bolt into place.

20. Close fuel filler cap and secure with padlock with the body of the padlock towards the inside of the rear deck (Figure 95).

\section{END OF PROCEDURE V.G}





\section{H. Procedure for Powering Down the TXL}

1. Open personnel door and latch in the open position.

2. Turn off the TXL computer using normal Windows ${ }^{\circledR}$ shut-down procedure.

3. Remove monitor foam blocks and bungee cords from shipping box. Secure monitor for transport as shown in Figure 98.

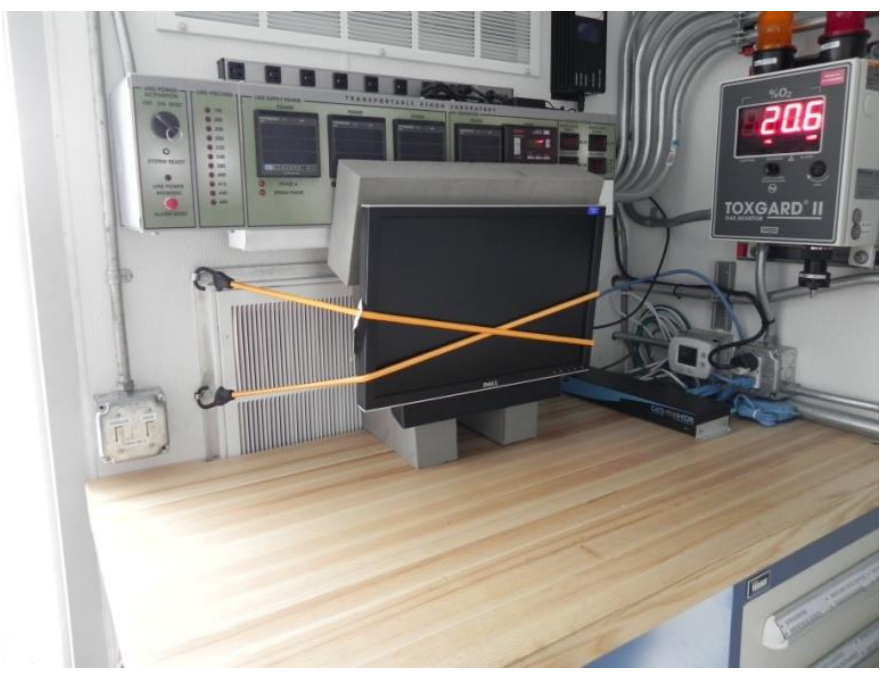

Figure 98. Secure monitor for transport with bungee cords and foam.

4. Unplug the satellite phone handset from base unit. Store handset in Drawer 4 of the tool cabinet.

5. Unplug the keyboard and mouse from the KVM extender and store them in Drawer 4 of the tool cabinet.

6. Set the generator automatic control unit on the control panel to the MANUAL position (Figure 99).

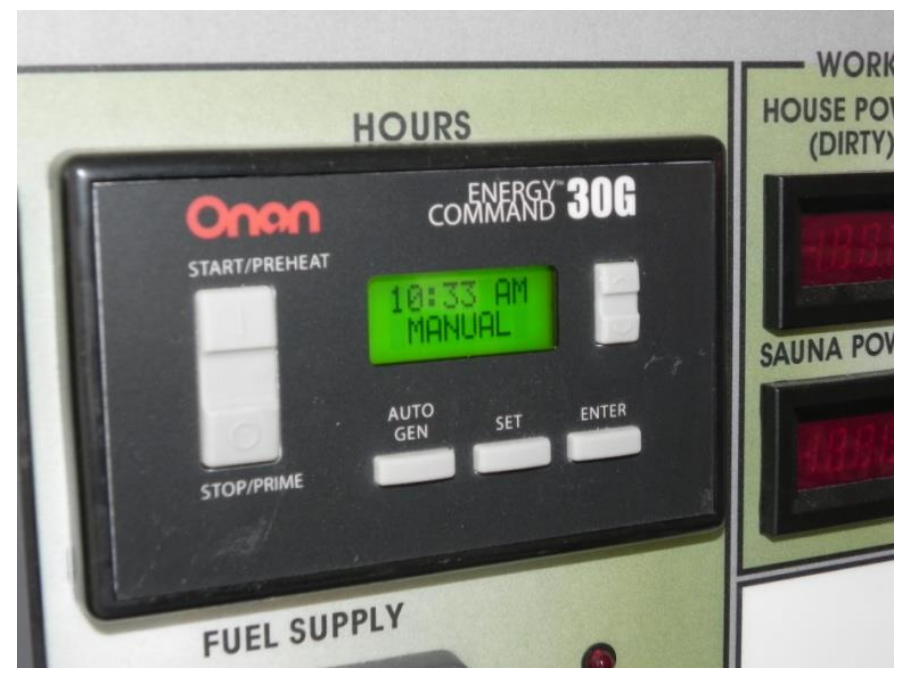

Figure 99. The generator automatic control unit is set to MANUAL. 
7. Turn off interior and deck light switches.

8. Turn the control panel off with the key switch (Figure 100).

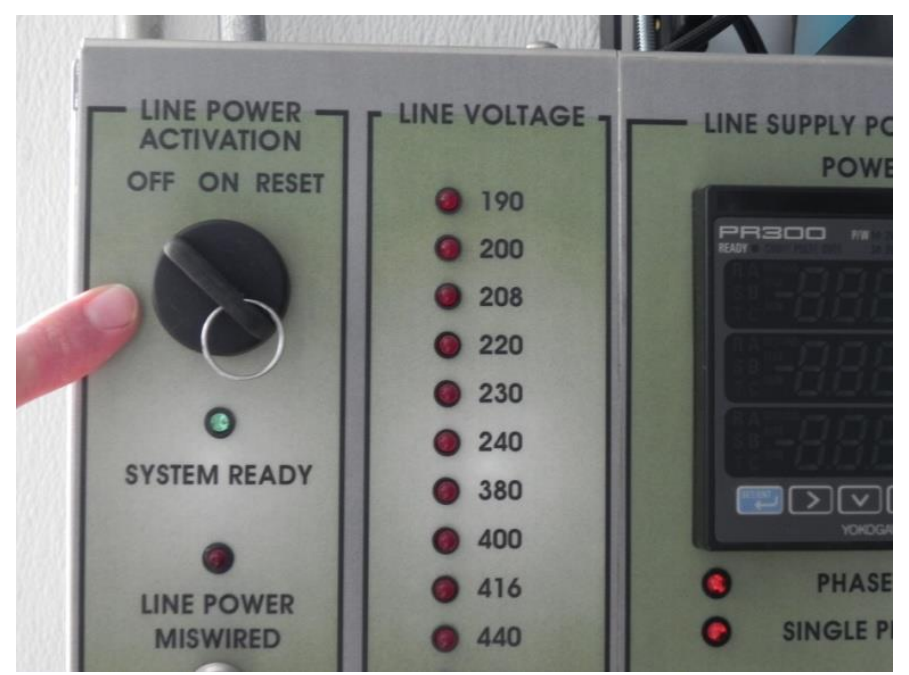

Figure 100. Control panel key is in the OFF position.

9. Turn the house UPS off by pressing the OFF (left) button on the front of the UPS (Figure 101). Continue pressing the button until the UPS beeps.

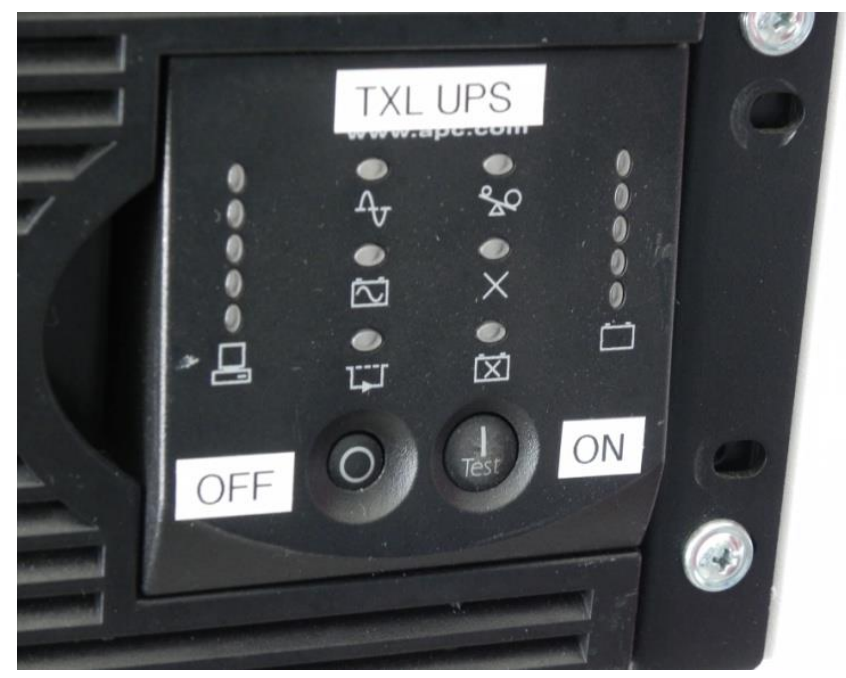

Figure 101. The TXL Uninterruptable Power Supply has the ON and OFF buttons labeled.

10. Remove key from the control panel, and put it in the external TOX Guard key switch to the right of pedestrian access door.

11. Remove the house UPS front panel (Figure 102) and disconnect the UPS batteries (Figure 103) for safe travel. Do the same for the SAUNA UPS. 


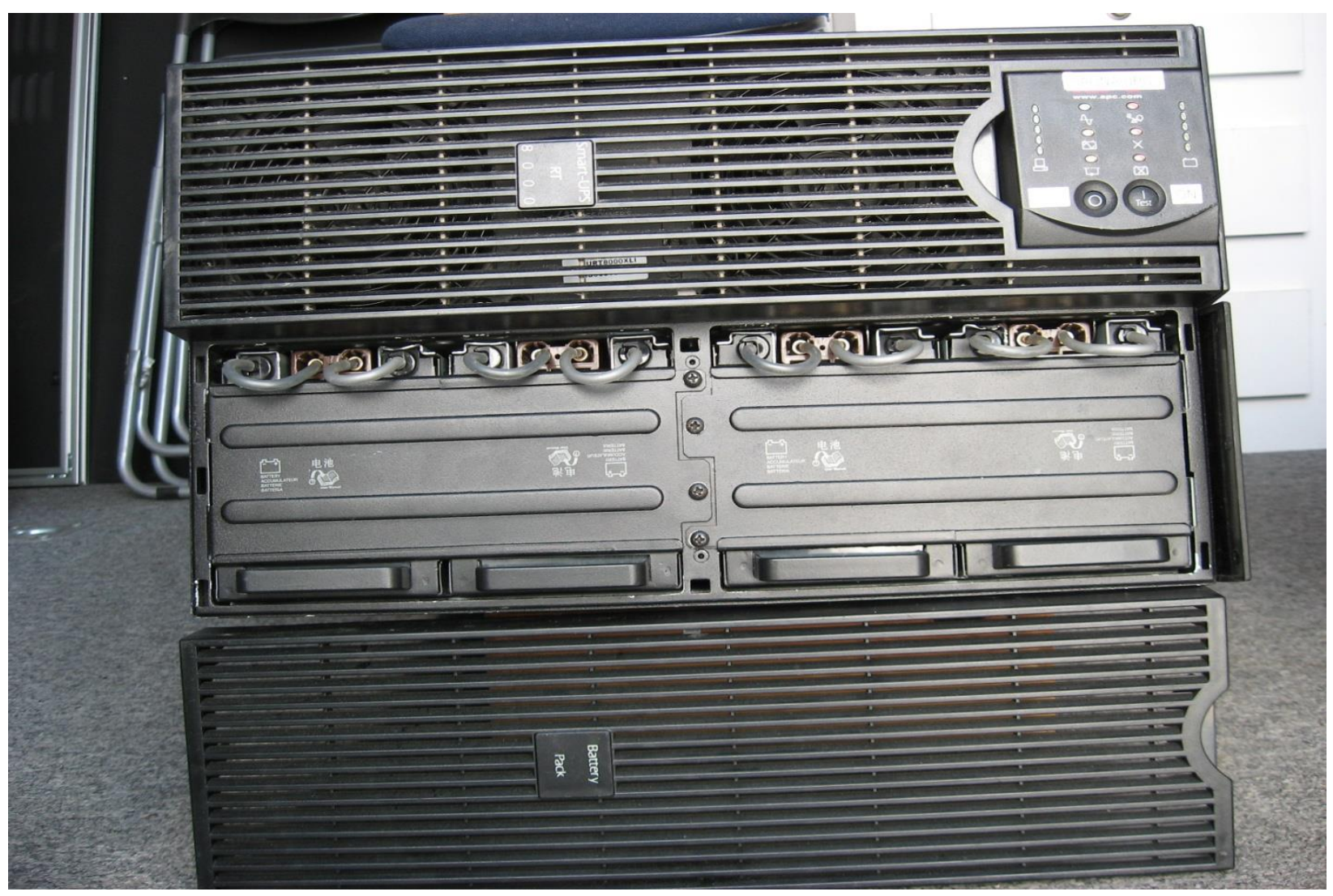

Figure 102. The house UPS is shown with the front panel removed and the internal batteries connected. 


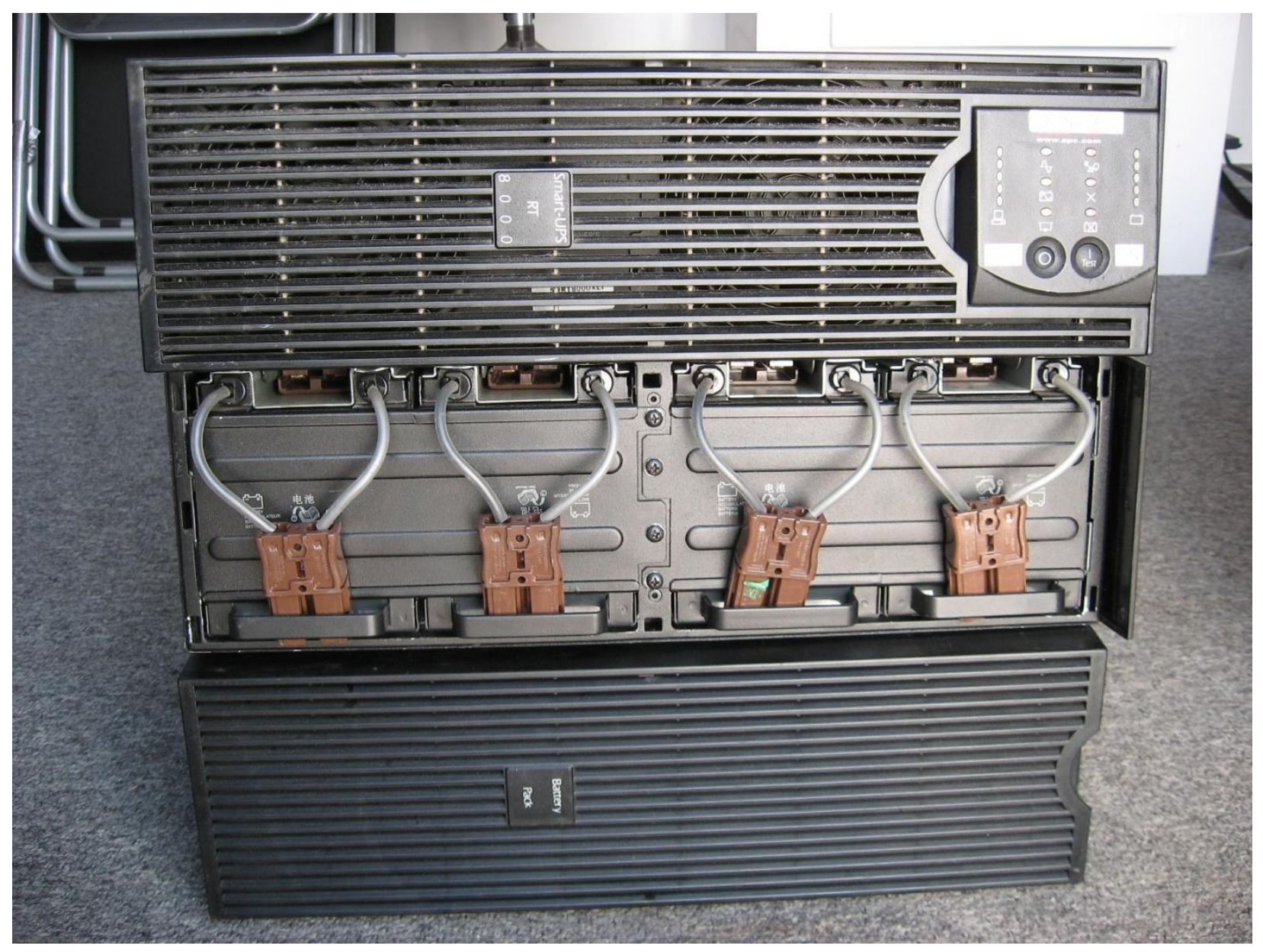

Figure 103. The house UPS is shown with the front panel removed and the batteries unplugged.

12. Switch the emergency light to the TRAVEL position.

13. Put main power switch located on the rear deck in OFF position (Figure 104). 


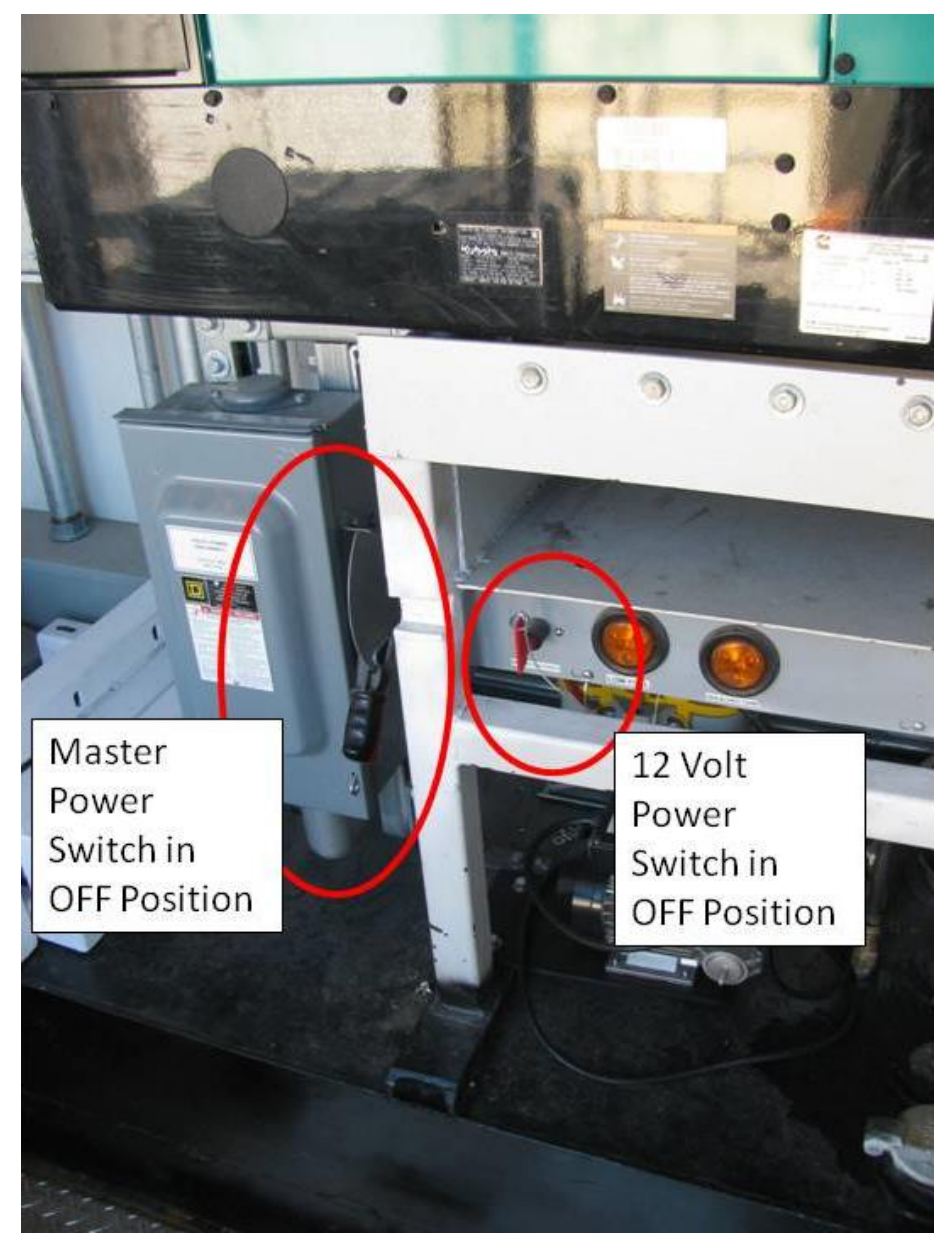

Figure 104. The power switch is in the OFF position.

14. Turn off 12 volt power switch located on rear deck (Figure 104).

15. Disconnect large power plug from receptacle (Figure 105). Lay plug on top of fuel tank. 


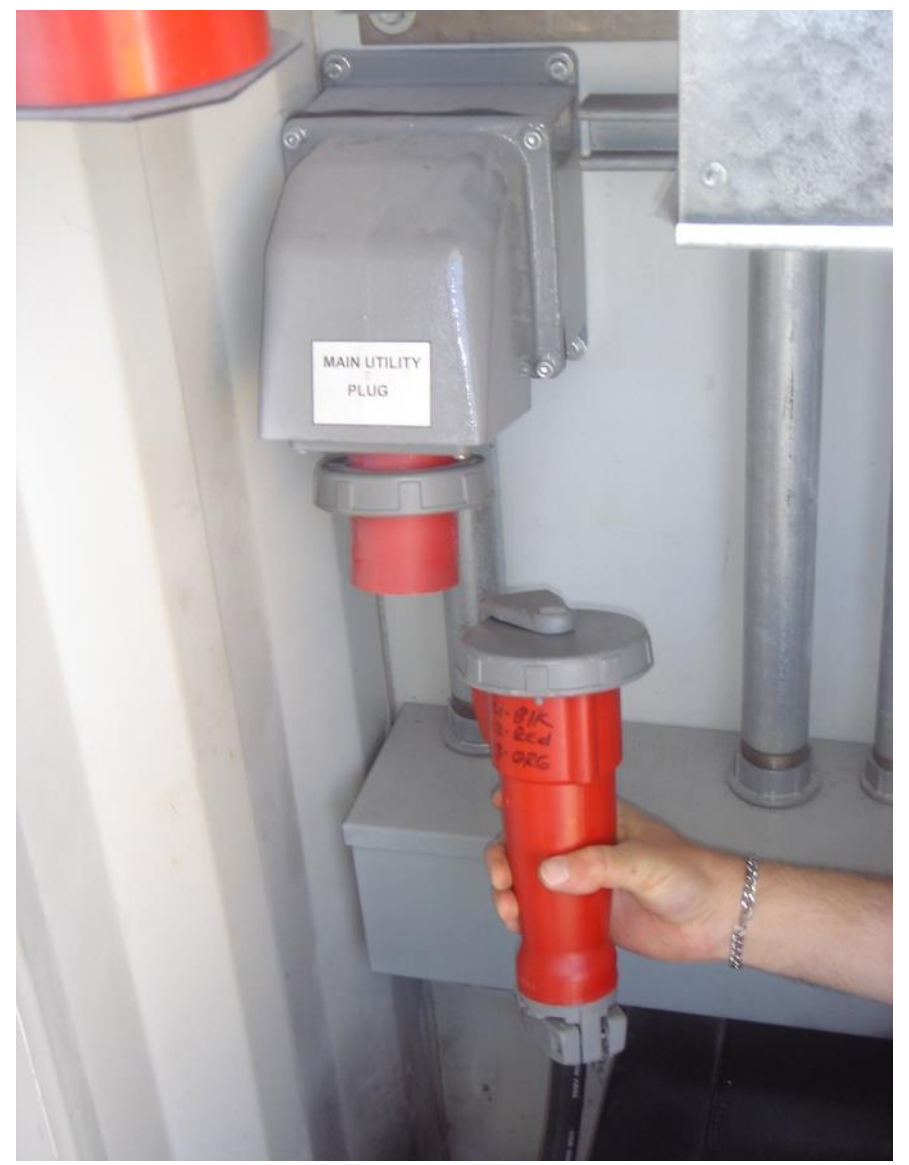

Figure 105. Disconnecting the power from the receptacle on the rear deck.

16. Turn off local utility power switch or breaker.

17. Disconnect cable from local utility power.

18. Disconnect green ground wire (if used) from utility ground.

19. Coil the green wire up and stage near left rear door.

END OF PROCEDURE V.H 


\section{Procedure for Removing the Generator Exhaust Diverter From the Tail Pipe}

1. Remove spring-loaded pin from exhaust diverter assembly (Figure 106).

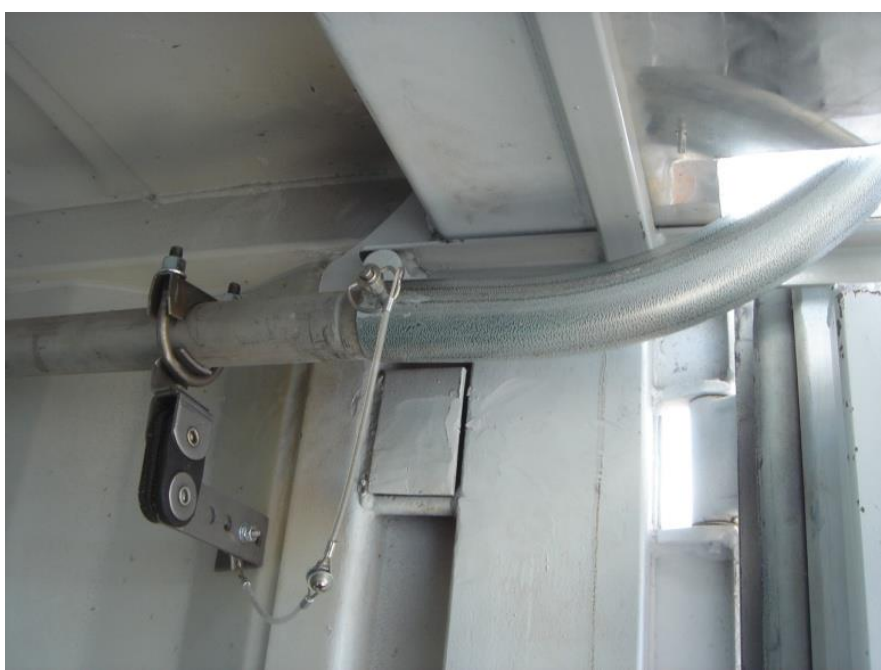

Figure 106. Exhaust diverter assembly.

2. Remove diverter from exhaust pipe and slide it out through the hole in the roof of the rear deck. Use the provided step ladder if needed.

3. Replace spring-loaded pin into hole in the exhaust pipe.

4. Store exhaust diverter assembly in Dunnage/SAUNA Shipping Brackets shipping case.

END OF PROCEDURE V.I 



\section{J. Procedure for Stowing the Rear Storage Area of TXL}

\section{SAFETY NOTE}

Be aware that winds may cause unsecured shipping doors and screen doors to open and close unexpectedly. If possible, stow the rear storage area in winds speeds less than 5 miles per hour (8 kilometers per hour).

1. Unlock cylindrical padlock securing rear deck screen doors.

2. Enter rear storage area.

3. Empty the storage area of any remaining shipping boxes, ladder, dunnage, etc. Replace the fire extinguisher into wall mounting rack and secure.

4. Unlatch the lower panel of the left screen door (Figure 107). and push it up, and latch it in the "up" position (Figure 108). Repeat for right door.

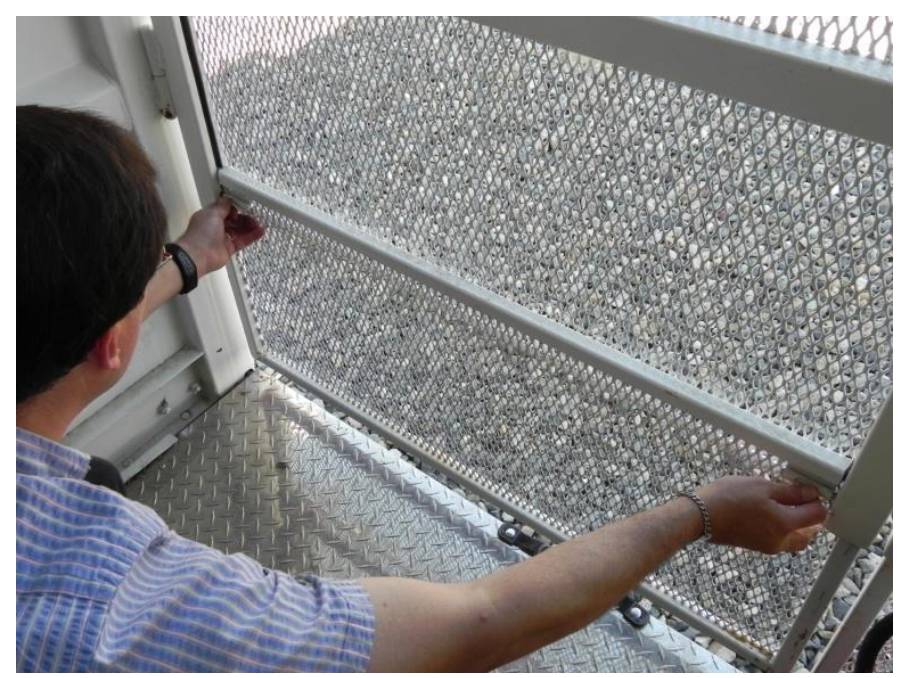

Figure 107. Unlatching the lower panel of the left screen door. 


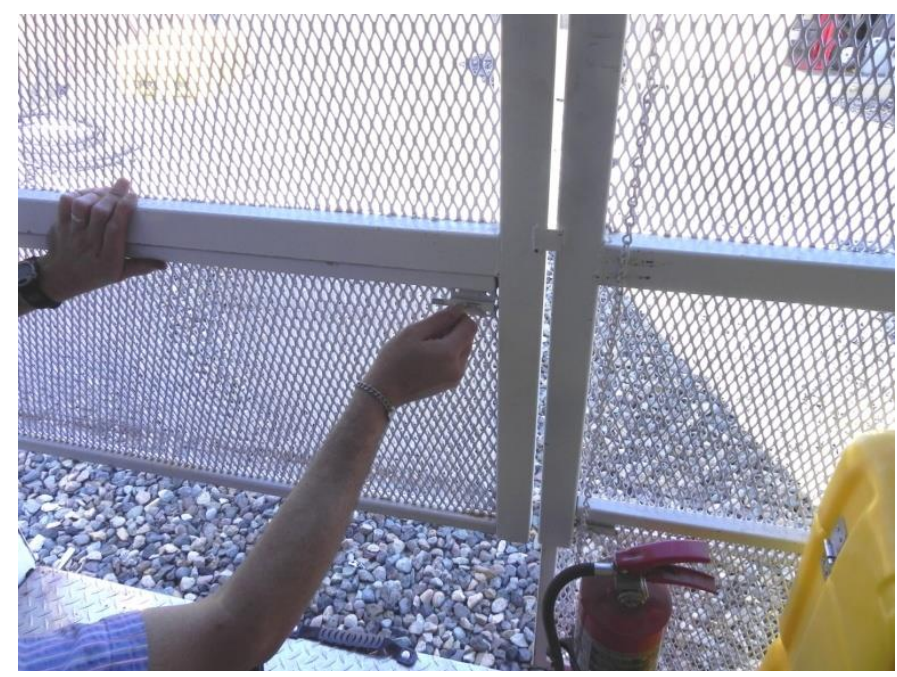

Figure 108. Pushing up the lower panel of the screen door, and latching it in the "up" position.

5. Open the D ring and remove chain. Return the D ring to a closed state. Use a ladder if needed (Figure 109).

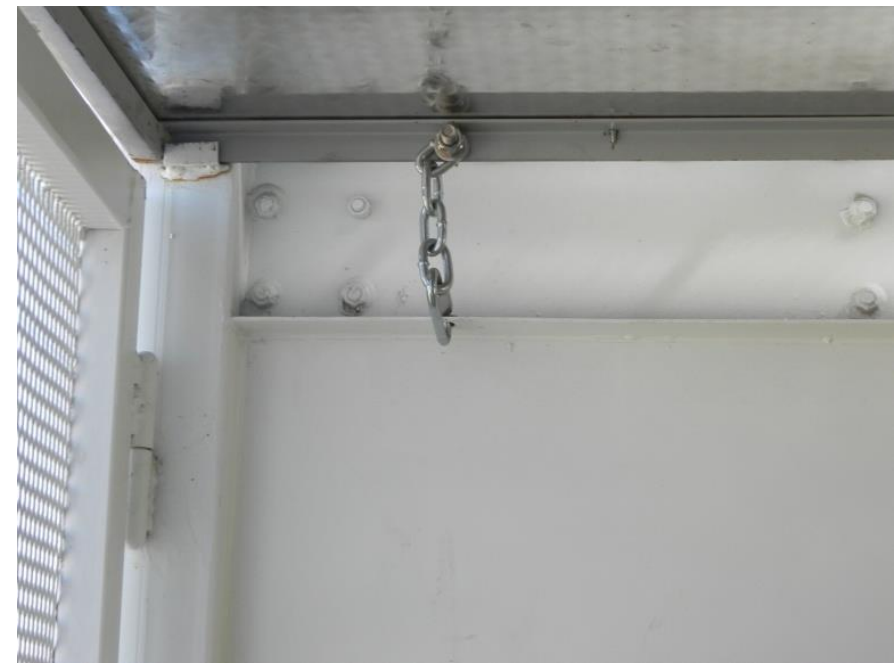

Figure 109. D Ring and chain securing the rear deck roof to the side of the container.

6. Unlock padlocks securing the J-hook on outside face of each door (Figure 110). 


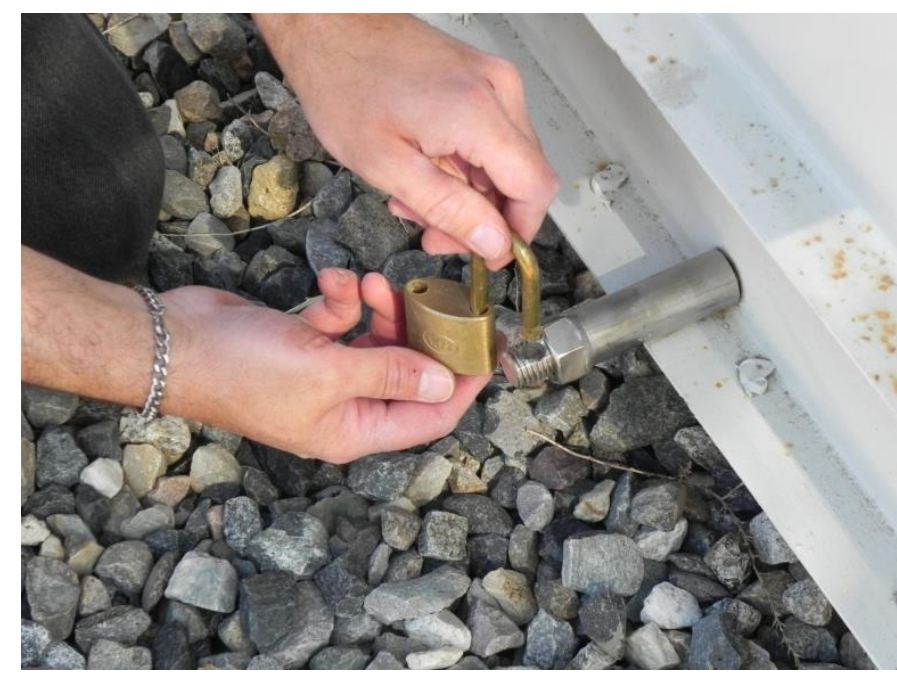

Figure 110. Unlocking padlock securing the J-hook and outside door in the open position.

7. Remove the J-hooks from the holes in container door and the oval holes in rear deck floor (Figure 111).

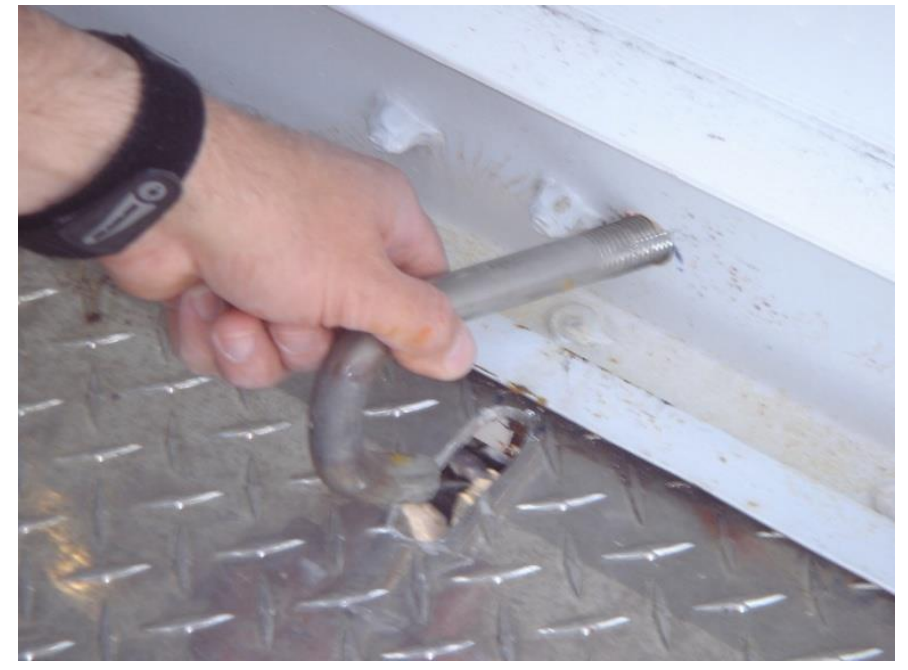

Figure 111. Unhooking the $\mathrm{J}$ hook from the rear deck floor and door.

8. Put the rear deck J-hooks in the cabinet, Drawer 4.

9. Unlatch left screen door spring-loaded latch by pulling spring and open the screen door.

The following steps (through Step 23) will be performed by two people.

10. One person supports the floor, the second person releases the left and right floor locking pin from the corresponding hole on the container doors (Figure 112). 


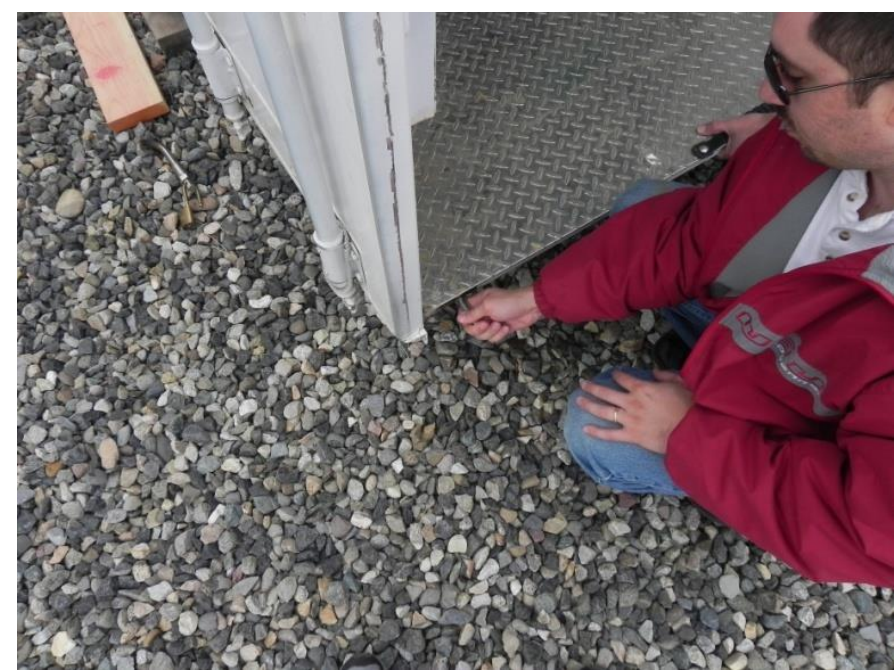

Figure 112. One person releases the floor-locking pin (while the second person supports the floor).

11. Stage the ladder at the center of the floor. Ensure that the ladder is standing securely on the ground.

12. Using the ladder, the taller of the two people raises the roof a few inches to disengage the left and right roof/door latch at the top of the doors (Figure 113).

13. When the door is disengaged, the second person should open the left container door wide open.

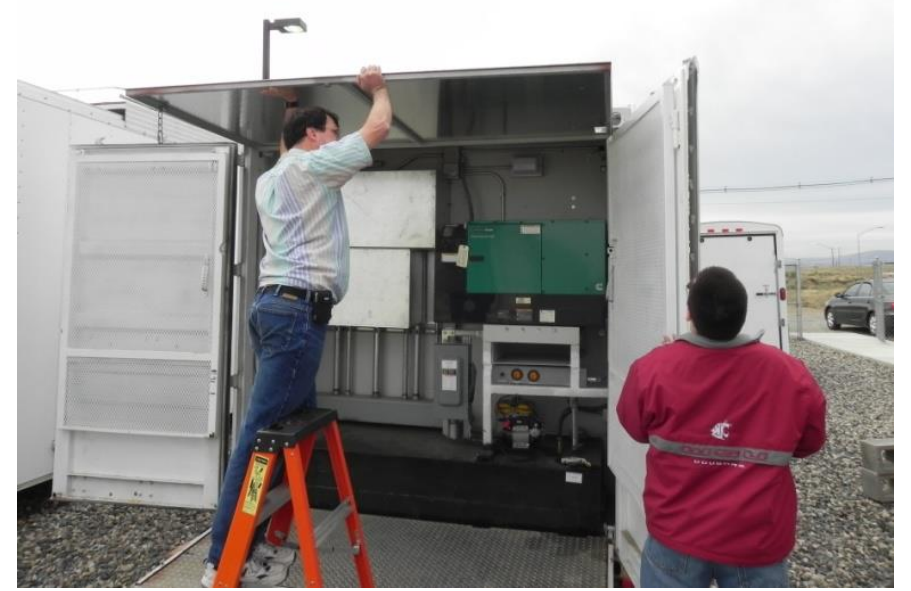

Figure 113. Raise the roof to disengage the roof-door latches.

14. Lower the roof to its vertical position (Figure 114). 


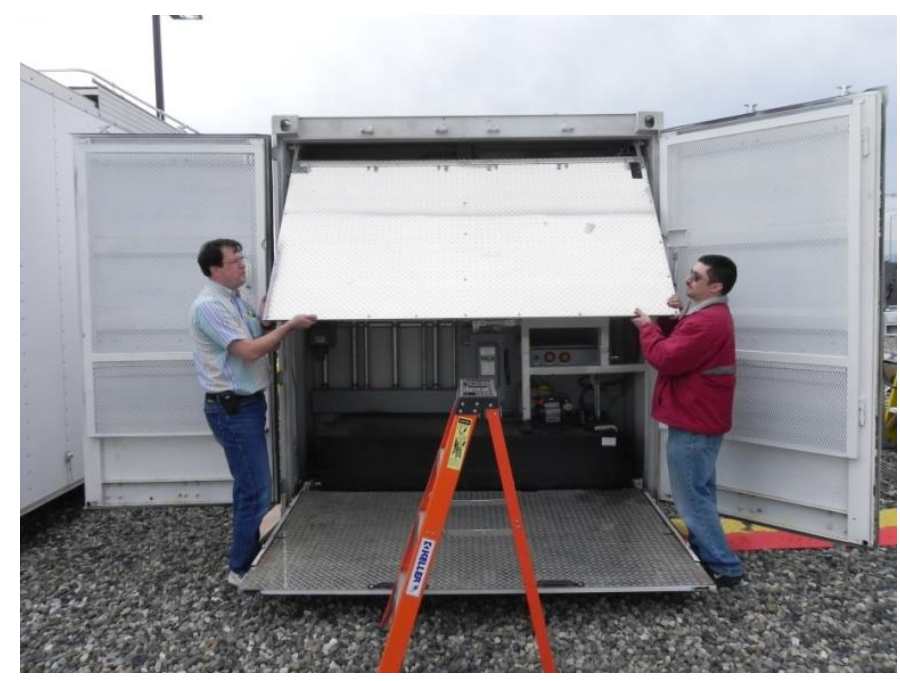

Figure 114. Lower the roof.

15. Remove the power cord. Return the power cord to the Jacks/Leveling Fixtures/AC Cord shipping box (Figure 115).

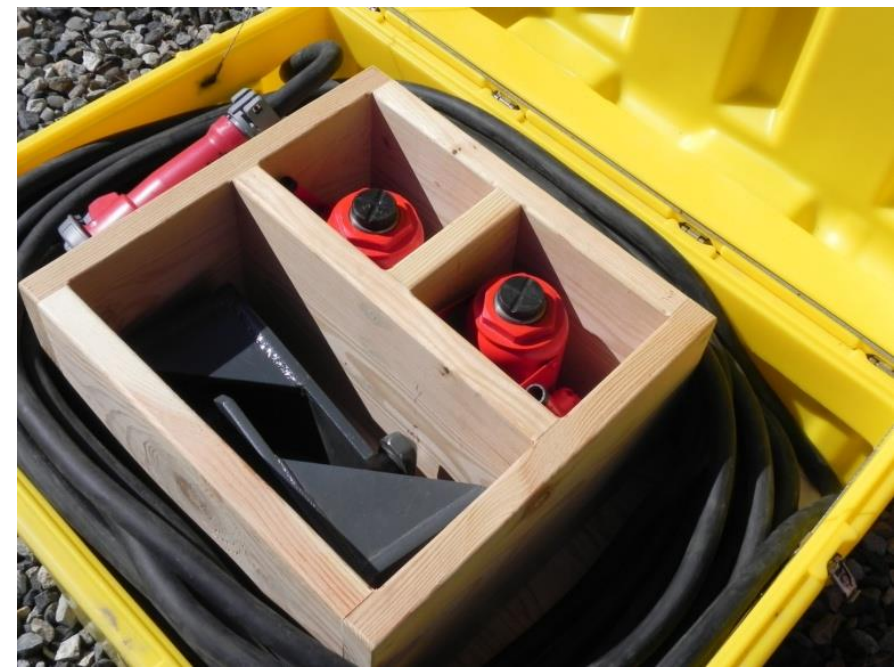

Figure 115. Stow the electrical power cord in the shipping box, along with jacks and leveling fixtures.

16. Coil the green grounding cable and store it next to the fuel tank. Make sure that the cable is stored in such a manner as to not be pinched when raising the floor or closing the container doors (Figure 116). 


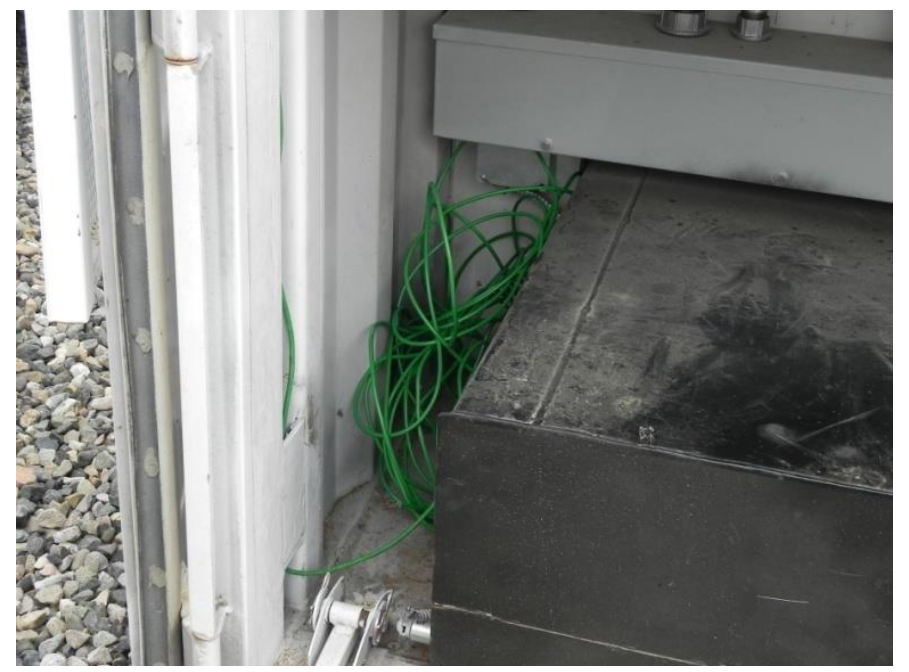

Figure 116. Coil the green grounding cable next to the fuel tank.

17. Loosen the four T-bolts located on the right and left sides of the floor frame (Figure 117), and slide the floor out fully (approximately10.5 in.[26.6 cm]) (Figure 118).

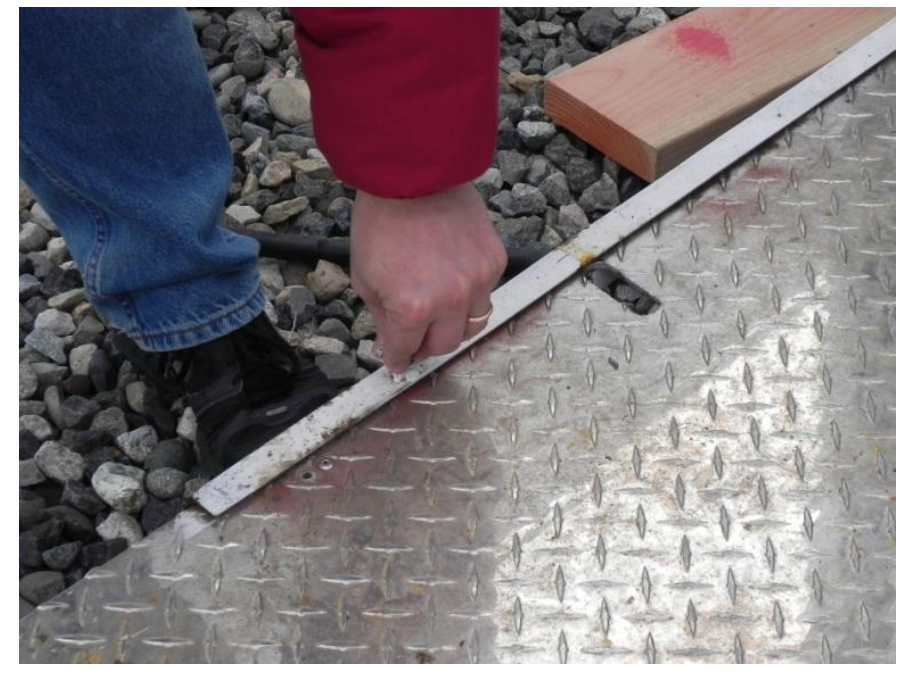

Figure 117. Loosen the T-bolts on the floor frame. 


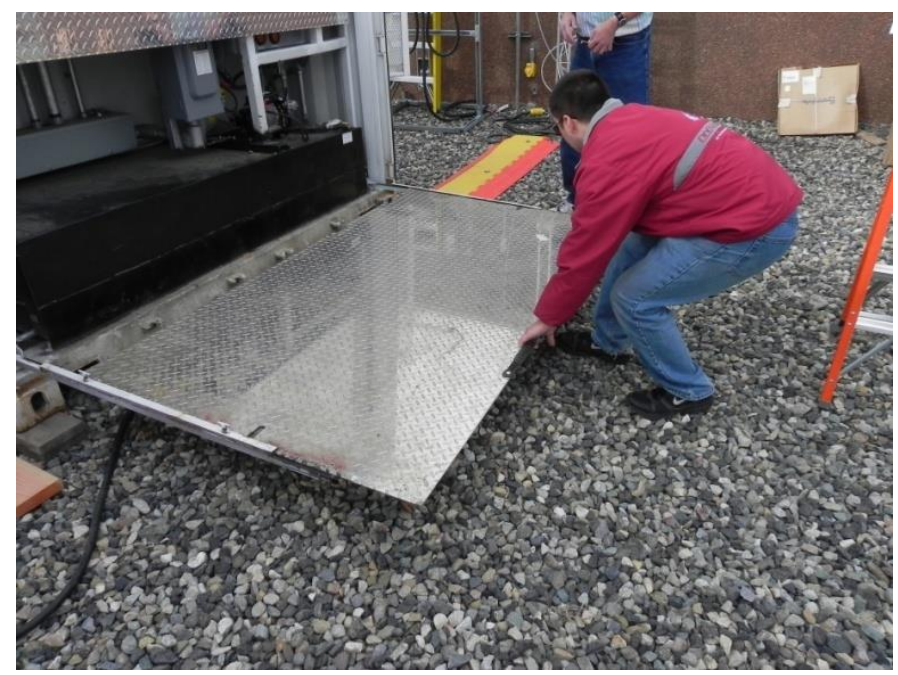

Figure 118. Slide out the rear deck floor.

18. Tighten the four T-bolts. Make sure that $\mathrm{T}$ bolt heads are not sticking out to the left or right.

19. Raise the floor to the vertical position (Figure 119).

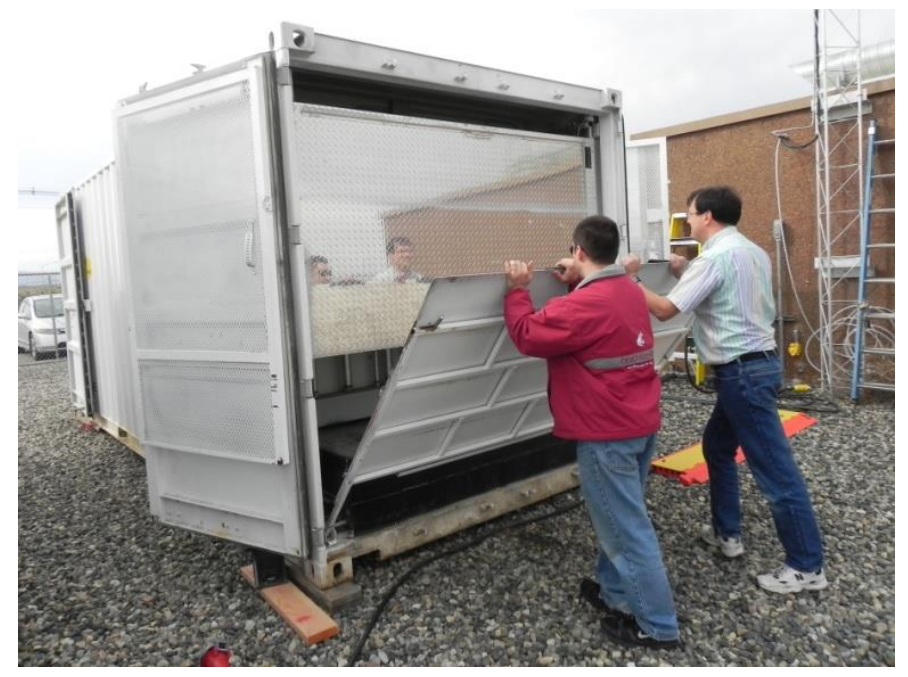

Figure 119. Raise the floor to the vertical position.

20. Engage the latch on the right side to secure the floor to the receptacle located on the container's right inner wall (Figure 120). 


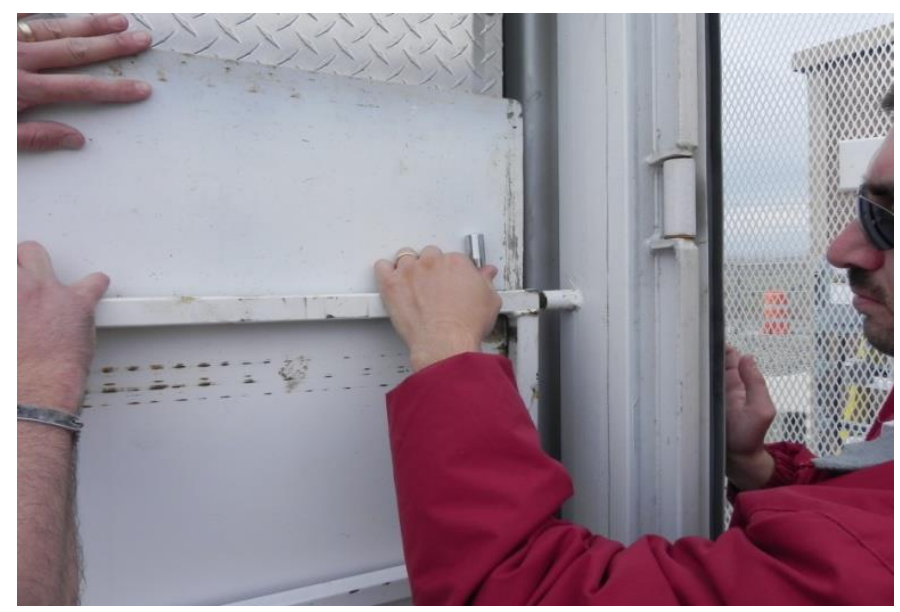

Figure 120. Engage the latch to secure the floor in the shipping position.

21. Close screen doors to a position flush against the inside of the container doors.

22. Close and latch the container doors.

23. Retrieve two shipping container locks from the bottom drawer of the tool cabinet. Secure each rear container door with exterior shipping container locks (Figure 121).

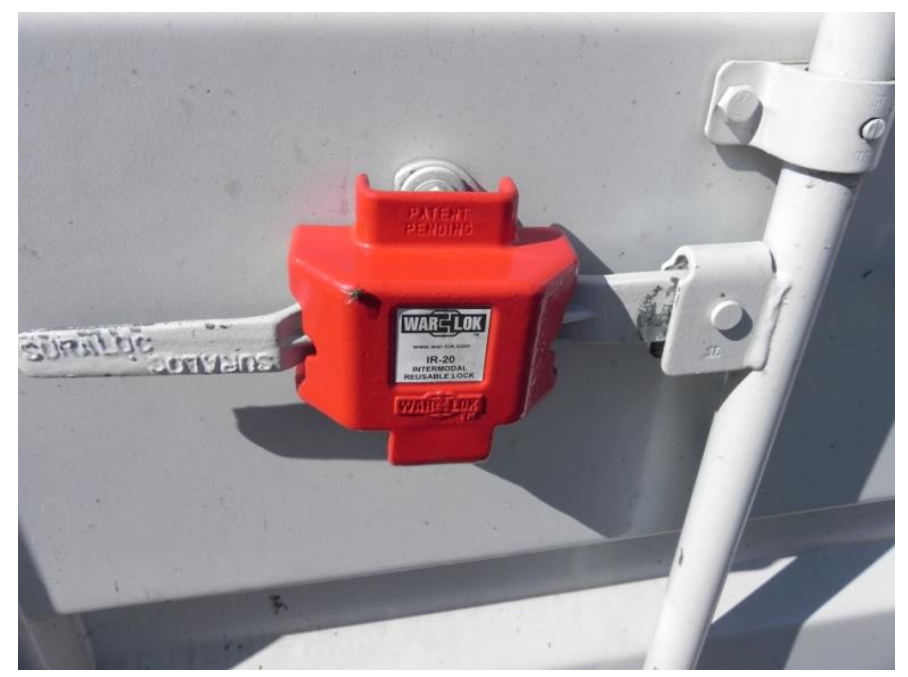

Figure 121. A lock is in place on one of the exterior shipping container doors.

END OF PROCEDURE V.J 


\section{K. Procedure for Removing the Dunnage from Under the Container}

1. Retreave the hydraulic jacks and leveling fixtures from the shipping box.

2. On the corners where dunnage was inserted to level the TXL, insert leveling fixture into the oval hole of the corner block. The lifting fixture may be inserted into either the end or side lifting hole of the corner block (Figure 122).

3. Rotate leveling fixture 90 degrees and place hydraulic jack under fixture on a piece of dunnage.

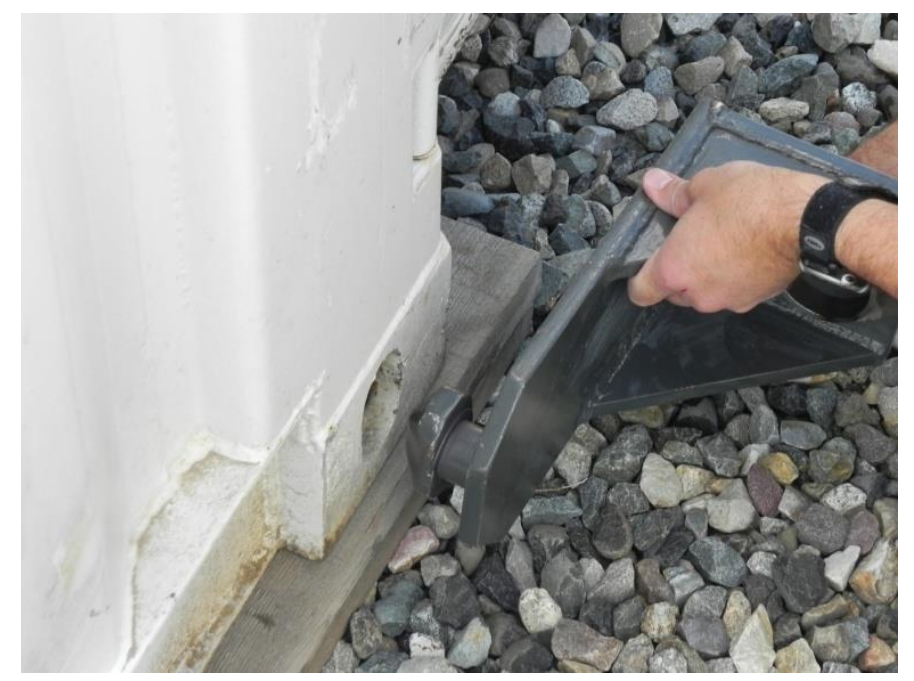

Figure 122. Insert the leveling fixtures into oval hole on the corner block.

4. Place at least one 18 -in. $(45.7-\mathrm{cm})$ piece of dunage on the ground where the jack will be positioned during the lifting process. While lifting up the leveling fixture, place the jack under the leveling fixuture. Align the jack such that the jack's central axis is verticle and directly under the lifting fixture's safety antislip ring (Figure 123). 


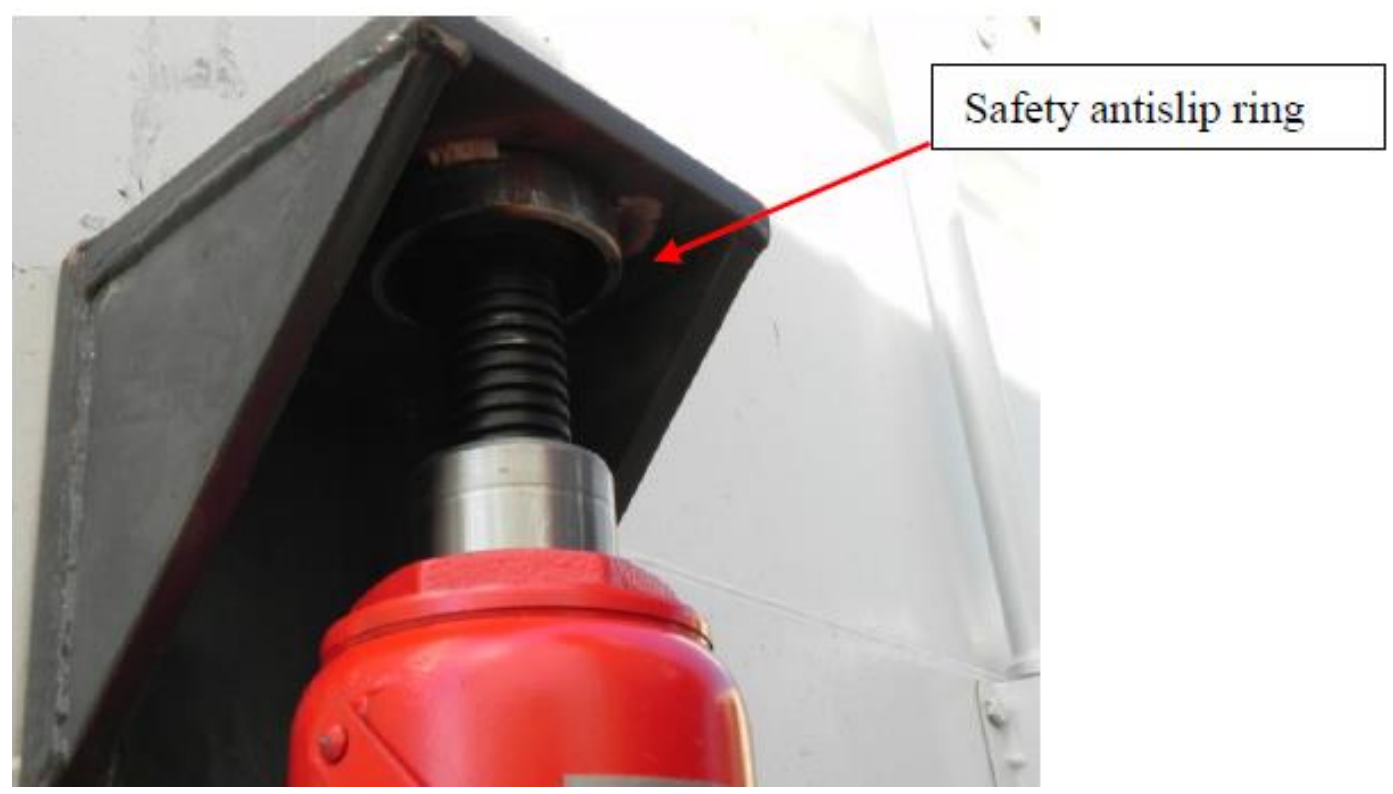

Figure 123. The hydraulic jack engages the leveling fixture inside the safety ring.

5. Adjust the height of the piston ram to engage the elevated lifting fixture. The height of the piston ram is adjusted by turning the head of the piston ram counterclockwise to unthread from the bore of the jack. The top of the piston ram should be within 1 in. $(2.5 \mathrm{~cm})$ of mating with the leveling fixture. The piston ram will unthread, and allow you more height for the bottle jack to engage or nearly engage the fixture. If additional dunnage is required to raise the jack body, place it underneath the jack to accomplish this, use no more than 4 in. $(10 \mathrm{~cm})$ of dunnage. Be sure that the jack's central axis is vertical and not on an angle as this can cause a dangerous situation.

6. Make sure that the hydraulic jack engages the leveling fixture inside the safety (antislip) ring (Figure 123).

7. Locate the valve at the bottom of the bottle jack. It is a small, flattened screw-top device that holds the pressure of the hydraulic piston when locked, and then releases the hydraulic pressure when opened. Using the tip of the bottle jack handle as a key for the valve, turn it clockwise until it is tight. The bottle jack is now in the locked position, and will allow the piston ram to raise.

8. Place the handle or handle assembly (sometimes there is a two-piece handle for leverage) into the pump shaft (Figure 124).

9. Raise the container using the hydraulic jack enough to remove the dunnage. Pump the handle up and then down. Each time the pump shaft moves in the down position, the hydraulic piston of the bottle jack raises. Make sure that the jack's cylinder in placed securely within the leveling fixture inside the safety (antislip) fixture. 


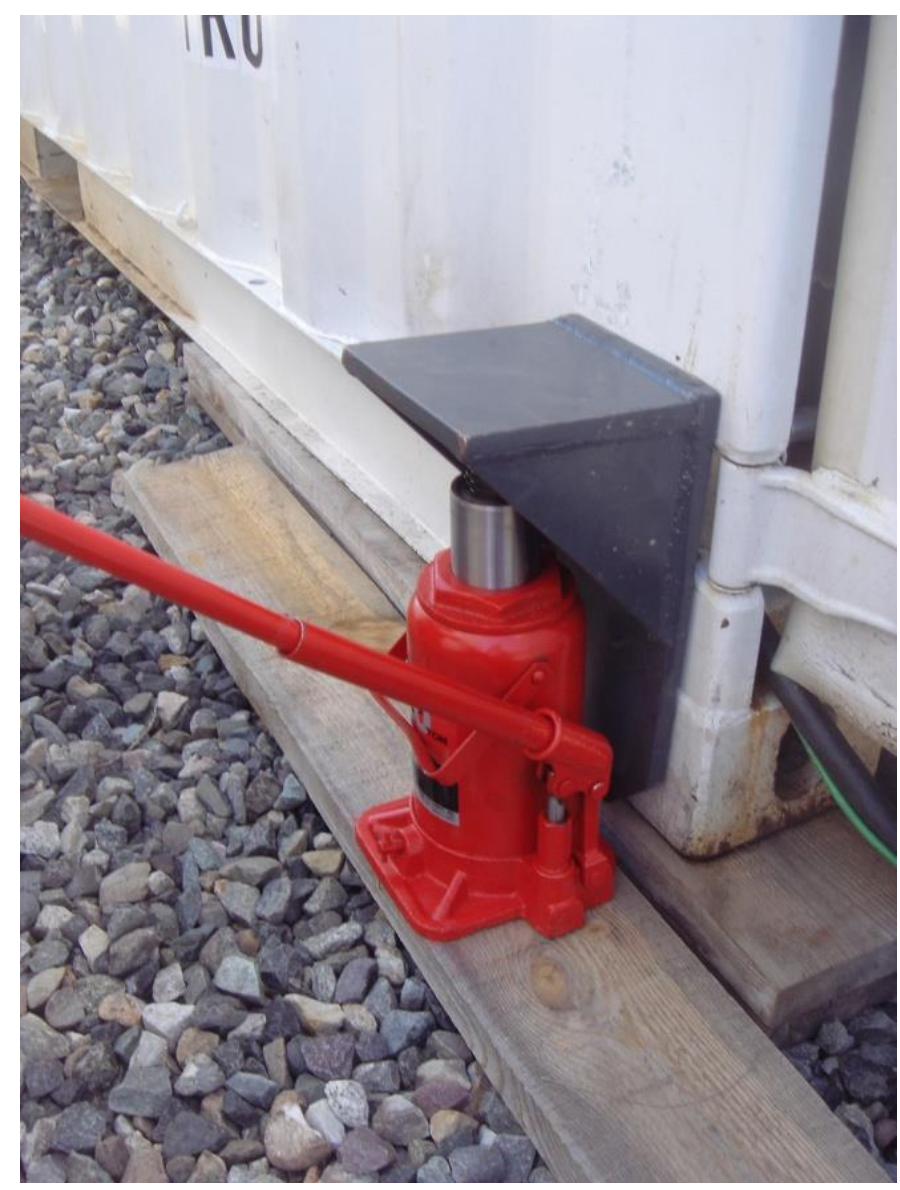

Figure 124. Pump the jack handle to raise the corner of TXL enough to remove dunnage.

10. If dunnage is placed at a second corner of the container, use a second jack and leveling fixture, to raise the container enough to remove dunage.

11. Carefully remove dunnage.

12. Remove the handle from the pump shaft, and place the tip back onto the valve when ready to lower the bottle jack. Turn the valve counterclockwise as slowly as possible to lower the container. Opening the valve quickly will result in dropping the piston rapidly, and can damage the TXL, or cause bodily injury.

13. Remove bottle jack(s) and leveling fixture(s). If piston ram head was raised by rotating it counter clockwise, return the piston ram head to its lowest position by turning it clockwise.

14. Store jacks and fixtures in the shipping box labeled Jacks/Leveling Fixtures/AC Cord.

15. Stage the dunnage outside the front door of the TXL. The dunnage will be placed in the shipping box labeled Dunnage/SAUNA Frame Shipping Brackets.

\section{END OF PROCEDURE V.K}





\section{Procedure for Closing the TXL, Securing Doors, and Checking the Oxygen Monitor}

1. Locate the remaining two shipping container locks for securing the outside container door and stage them outside the TXL.

2. Unlock the padlock securing the J-hook (Figure 125).

3. Remove nut.

4. Remove the J-hook from the hole on side of container (see photo) and from the hole (lower middle portion of door) in the container door (Figure 126).

5. Resecure the doors in the open position by placing the rope loop, located on the container door latch bar, over the hook welded to the container's exterior wall (Figure 127).

6. Replace the J-hooks, nuts, and locks in Drawer 4 of the tool cabinet.

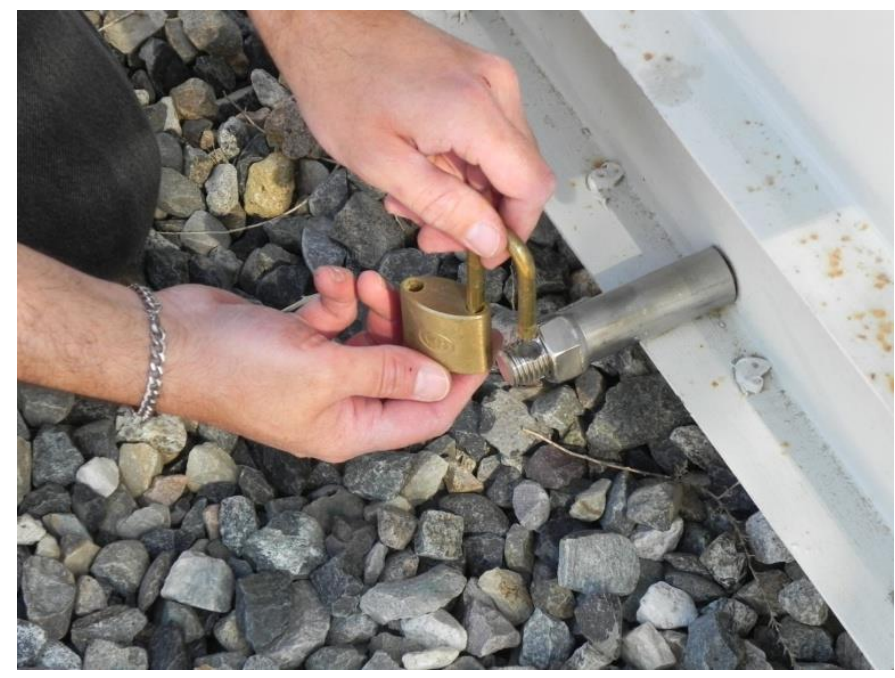

Figure 125. Unlocking the padlock securing the door.

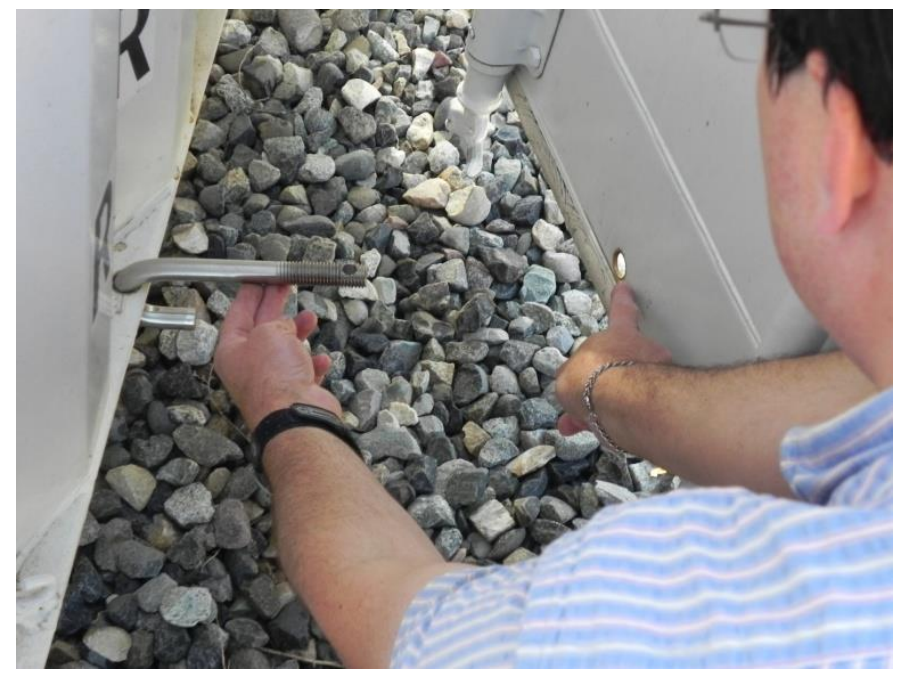

Figure 126. Removing the J-hook from the door. 


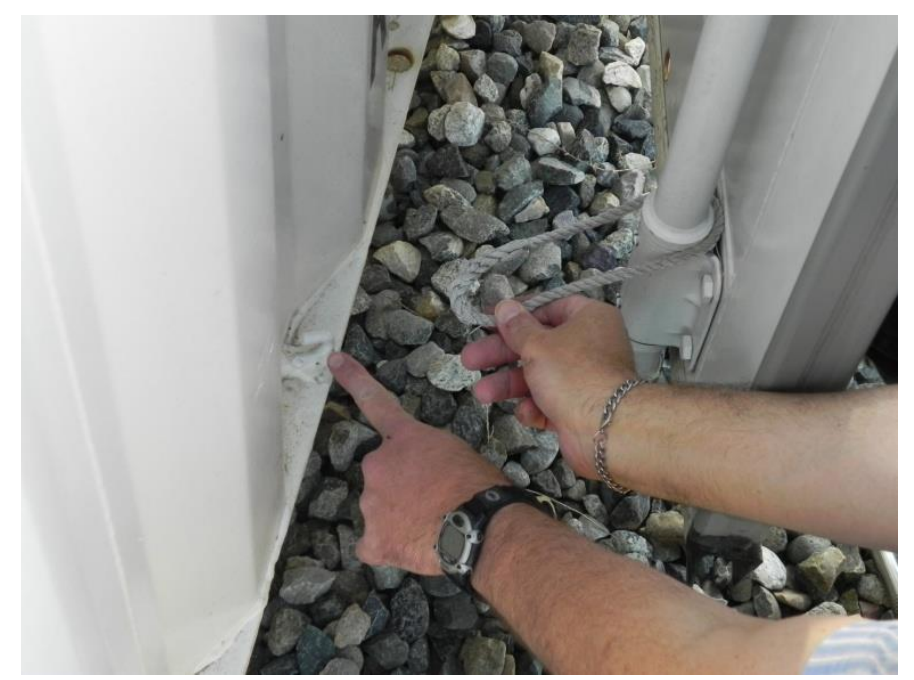

Figure 127. Securing the door in the open position with the rope loop.

7. Insert pink shipping eye bolts (Figure 35) in locations shown in Figure 128. If setscrews are inserted into threaded holes, remove them and store the set screws in a zippered bag within the red parts box marked Shipping eye bolts.

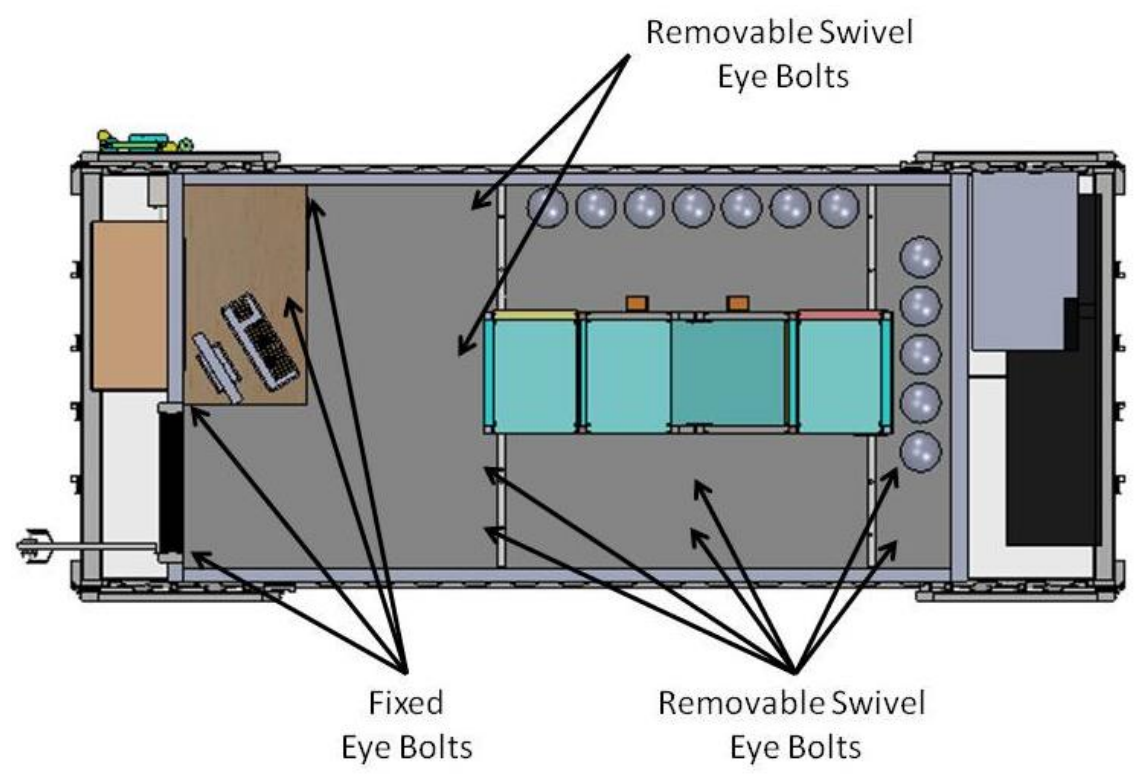

Figure 128. Insert the removable pink tie down eye bolts in the locations noted.

8. Position and secure spare parts shipping box in front of SAUNA with shipping straps from the Dunnage/SAUNA Shipping Brackets shipping box (Figure 129). 


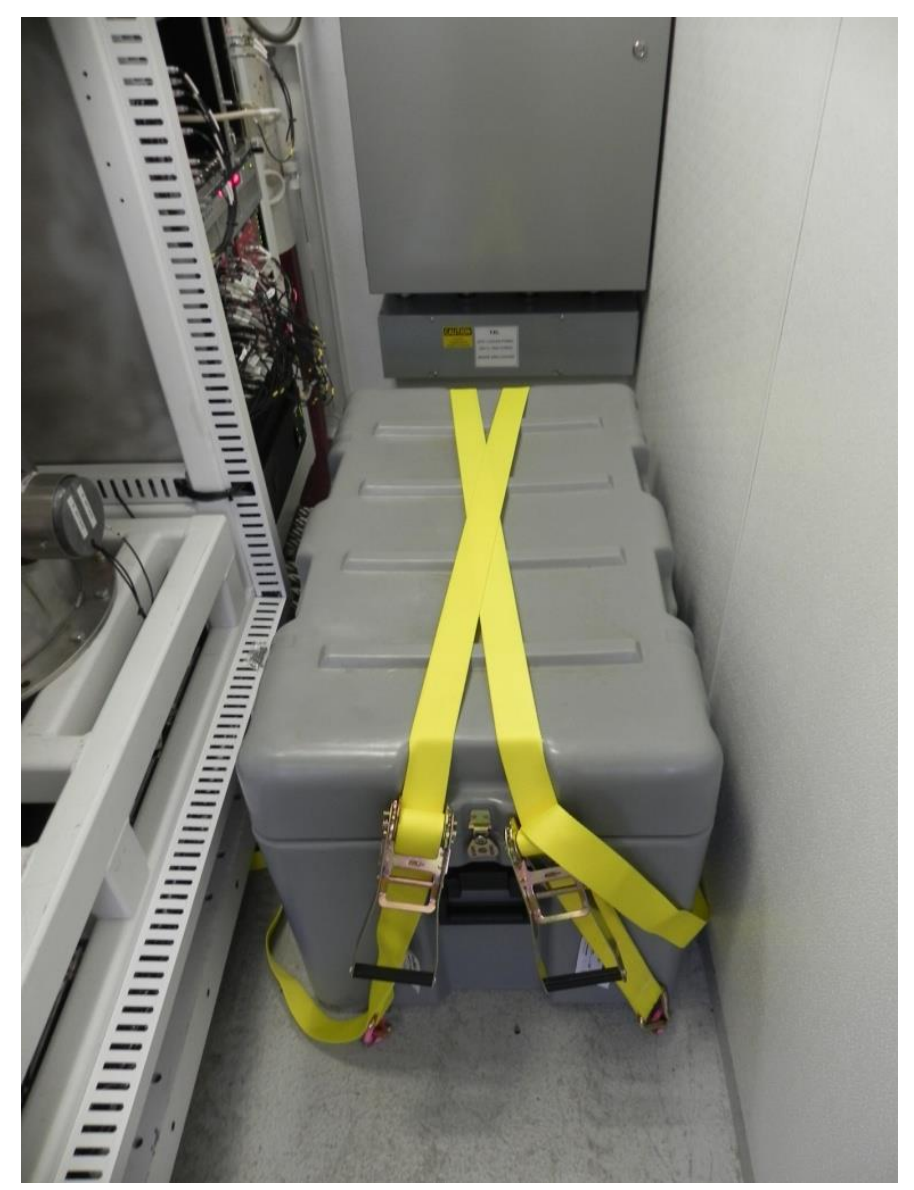

Figure 129. The spare parts shipping box is secured in front of the SAUNA system.

9. Retrieve two shipping container locks from the bottom drawer of the tool cabinet. Place locks under the HVAC unit on the front deck.

10. Close all tool cabinet drawers. Lock tool cabinet with key. Verify that all drawers cannot be opened.

11. Ensure that the Jacks/Leveling Fixture/AC Cord shipping box locks are secured. Place the shipping box on the floor between the tool cabinet and the SAUNA frame (Figure 130).

12. Place two orange 1-in. $(2.5 \mathrm{~cm})$ nylon shipping straps between the leveling jack shipping box and the dunnage box. These straps will be used to secure the ladder (Figure 131).

13. Place the empty Dunnage/SAUNA Shipping Bracket shipping box on top of the Jacks/Leveling Fixture/AC Cord shipping box. Verify that the shipping boxes align such that the raised interlocking portions of one box engage the receiving portions of the second box. Load the staged dunnage into the shipping box. Secure lid with integrated locks. 


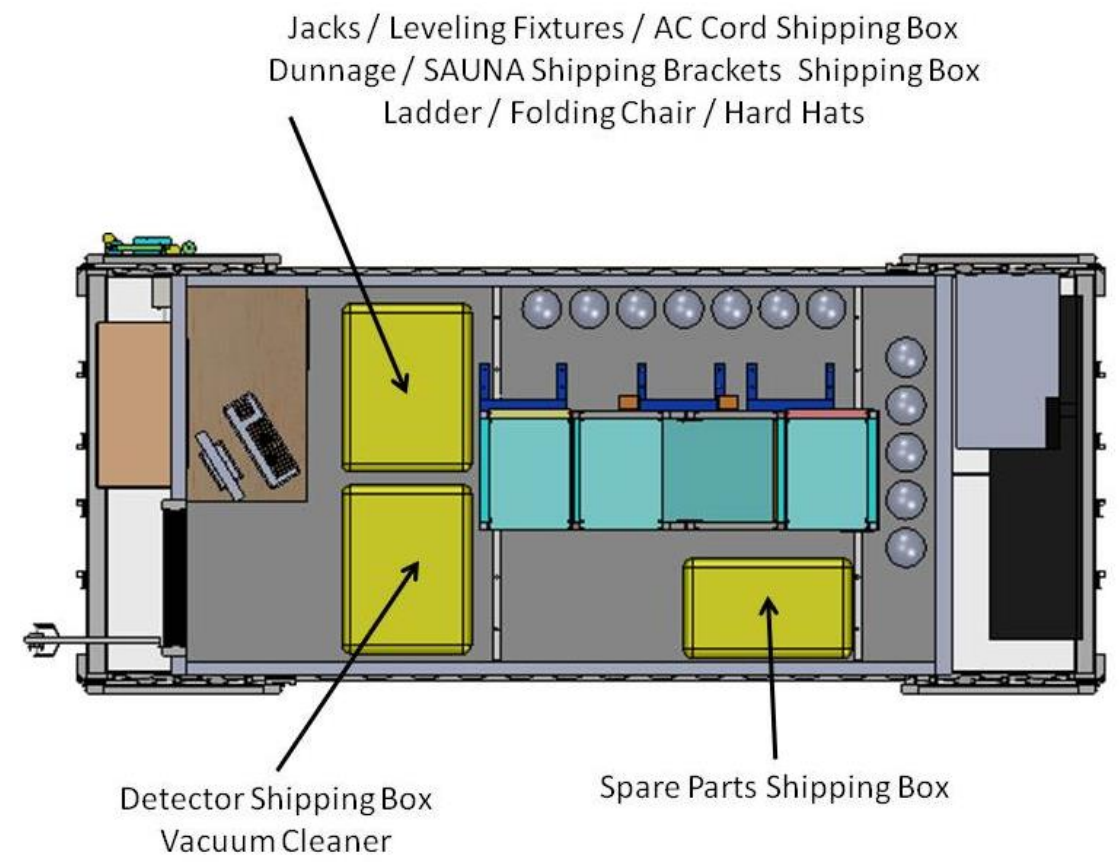

Figure 130. Place the shipping boxes and equipment in the locations noted.

14. Secure shipping boxes with nylon ratcheting straps using eye bolts in floor.

15. Place ladder and folding chair on top of large shipping boxes and secure with the prepositioned orange straps. Run orange straps through hard hats to secure them in place for transit.

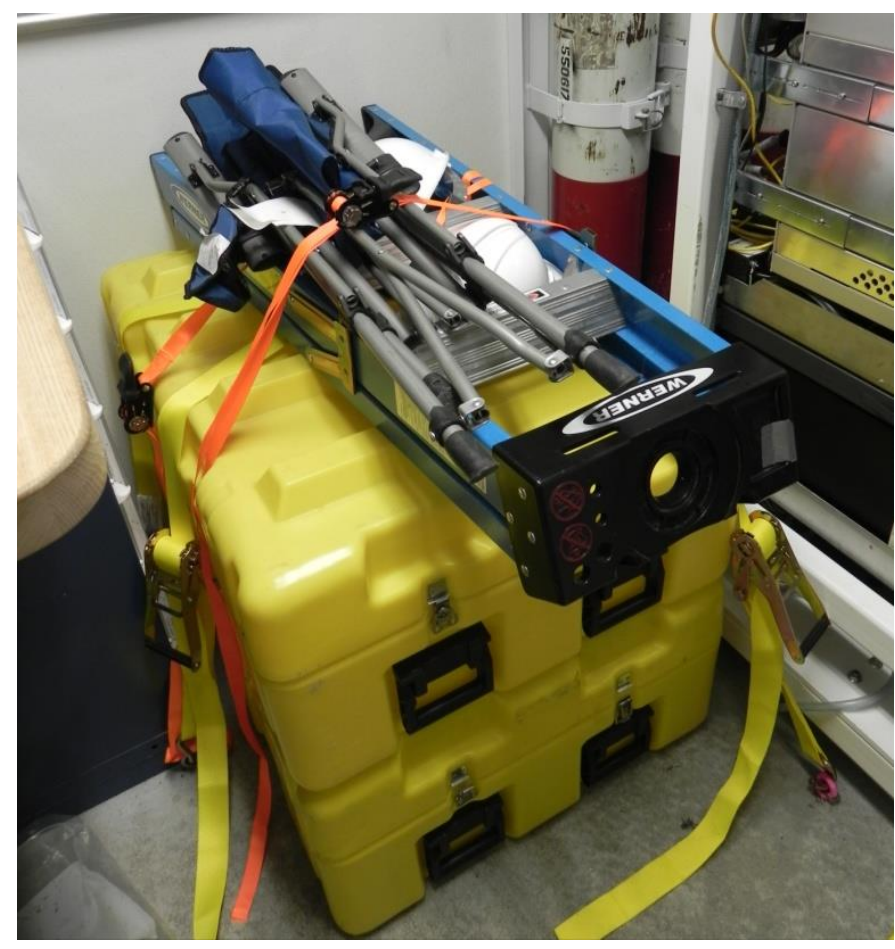

Figure 131. Use the orange straps to secure the ladder, folding chair, and hard hats to the shipping boxes. 
16. Place the Detector shipping box between the Dunnage/Leveling Jack shipping boxes and the right wall.

17. Secure the Detector shipping box in place with shipping straps and eye bolts.

18. Place vacuum cleaner on top of the Detector shipping box and secure with the orange straps (Figure 132).

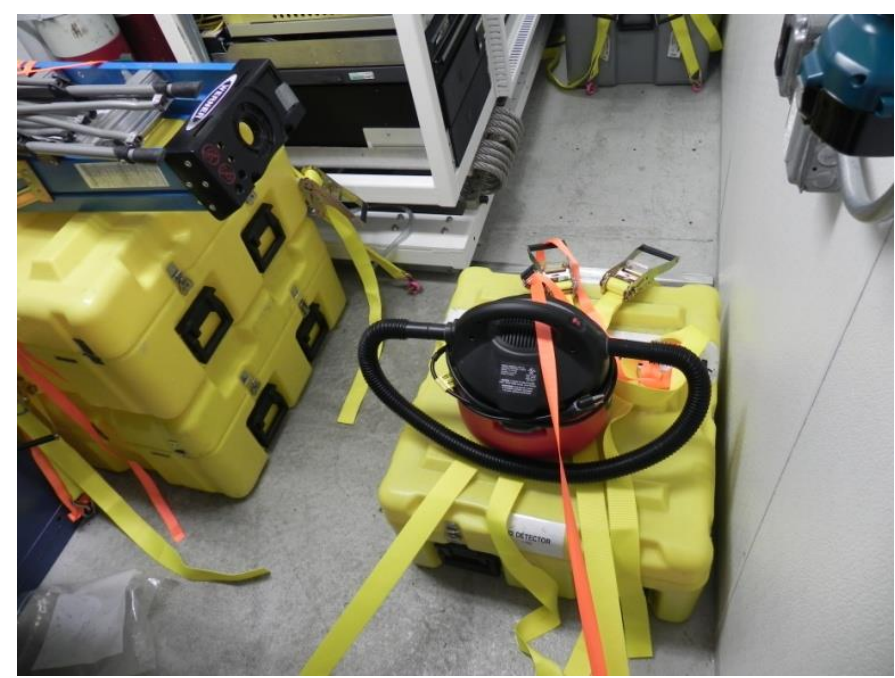

Figure 132. Secure the vacuum cleaner atop the Detector shipping box.

19. Verify that ALL shipping boxes are secure with nylon shipping straps.

20. Unlatch the pedestrian access door and close.

21. The master electrical activation key will be in the oxygen monitor's key switch located on the front porch, upper right corner (Figure 133).

22. Turn the switch to the OFF position.

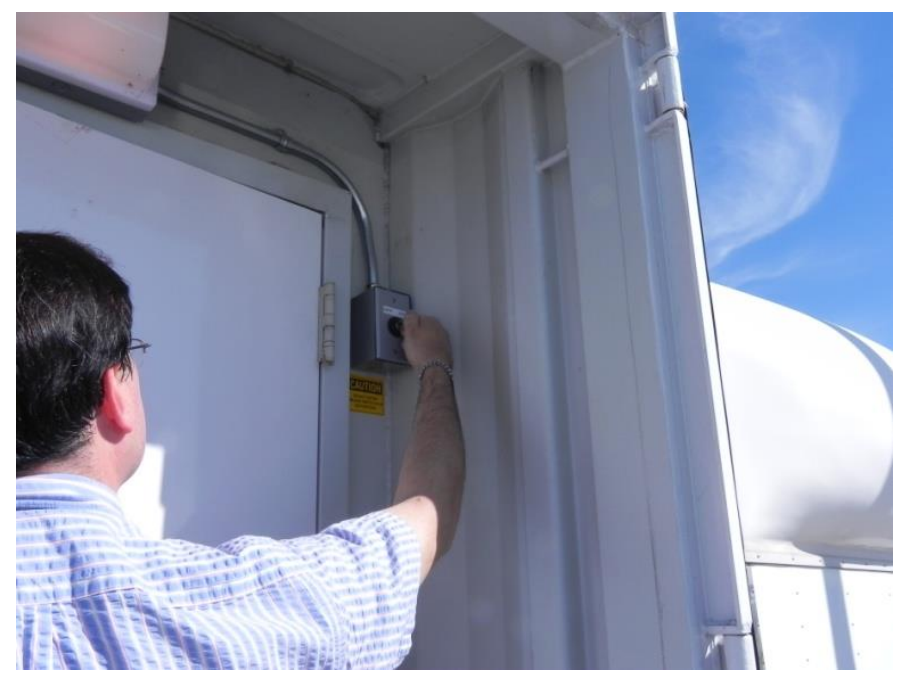

Figure 133. Turn off the power for the oxygen monitor. 
23. Place master electrical activation key and TXL personnel door key into black "hide a key" pouch and fasten it to the Velcro pad located near the oxygen monitor's key switch.

24. Retrieve the two remaining shipping container locks from under the HVAC unit on the front deck.

25. Close and latch the container doors (Figure 134).

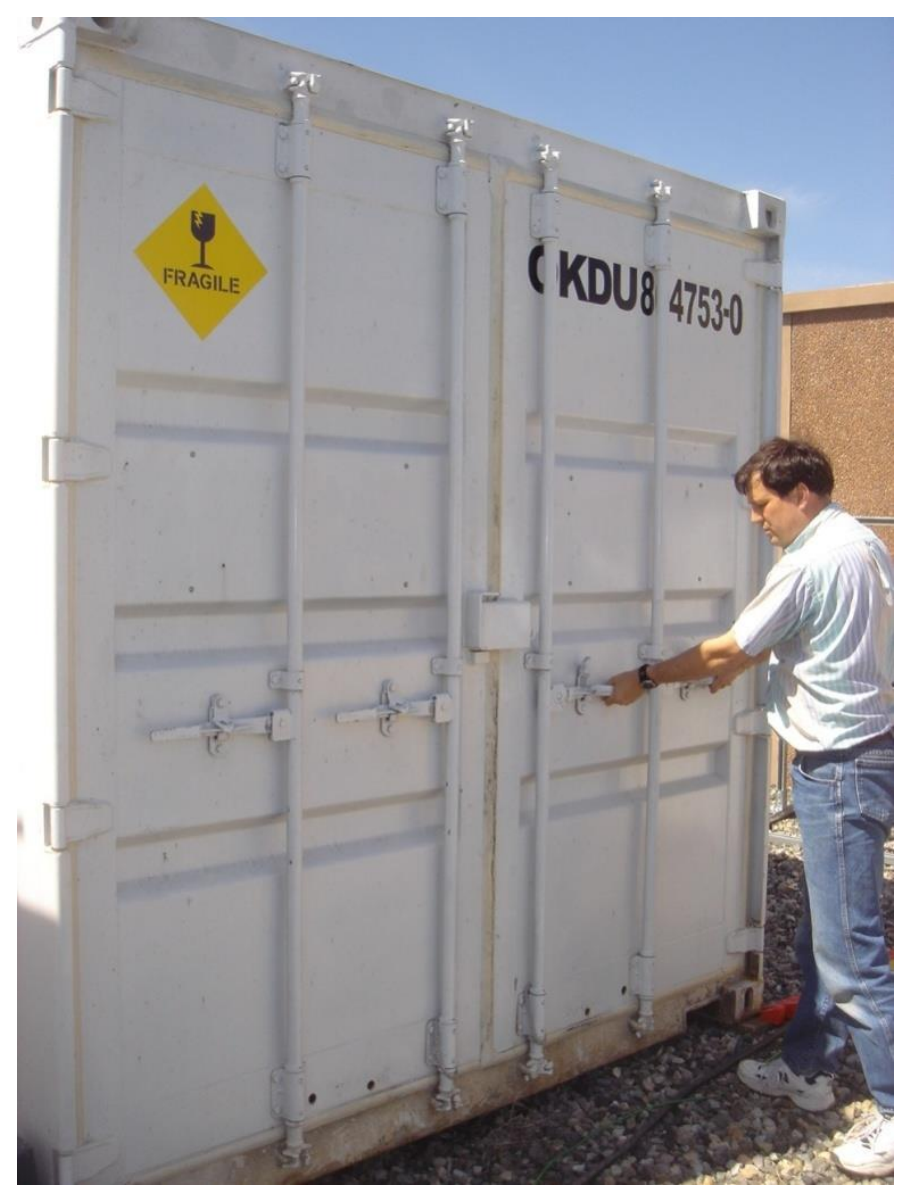

Figure 134. Latch the container doors.

26. Secure each front container door with exterior shipping container locks. Install locks on the inner-most handles (Figure 135), according to instructions (Figure 136). 


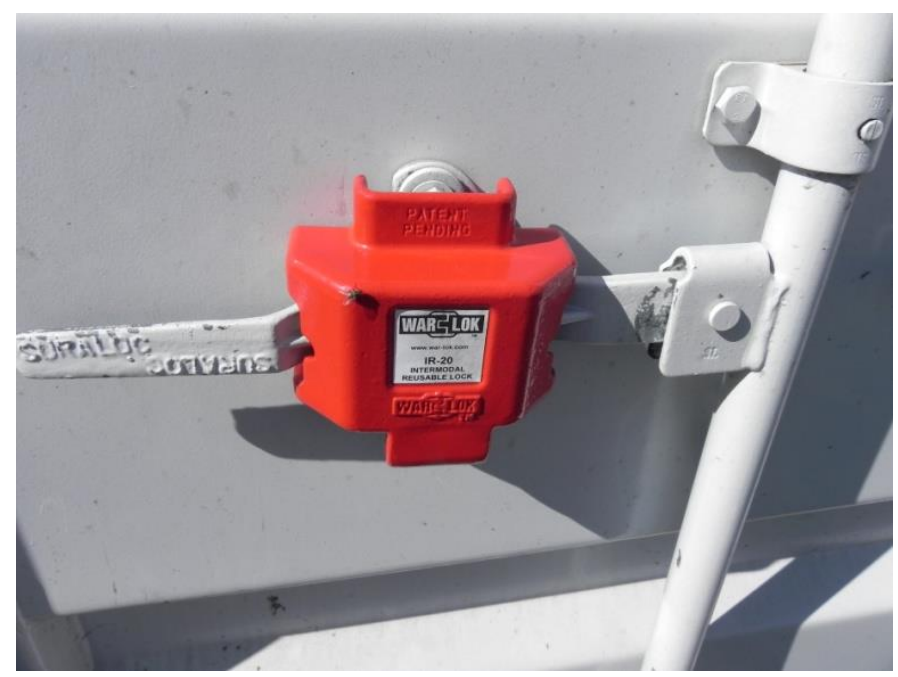

Figure 135. The lock is in place on one of exterior shipping container doors.

\section{WAR-LOK IR-20 INTERMODAL CONTAIMER LOGK INSTALLATION AND USE INSTRUCTIONS}

The WAR-LOK Intermodal Container Lock is designed to fit most standard container door latches. The lock hasp must be in good operating condition and not be excessively bent or deformed.

The WAR-LOK Intermodal Container Lock is intended to be used in conjunction with a metal or plastic indicative seal.

The Container Lock should be installed on the right door on the inside latch (if applicable).

To install the lock:

1. Insert and fasten an indicative seal through the latch hasp.

2. Hold the seal by the connector and gently pull to the side.

3. Place the WAR-LOK Container Lock over the hasp latch assembly and push the lock pin upward until it clicks into place.

To remove the lock:

1. Insert the key into the lock cylinder and turn clockwise approximately $3 / 4$ turn. The lock pin will spring extend to release the lock. Pull the pin fully down to remove the lock.

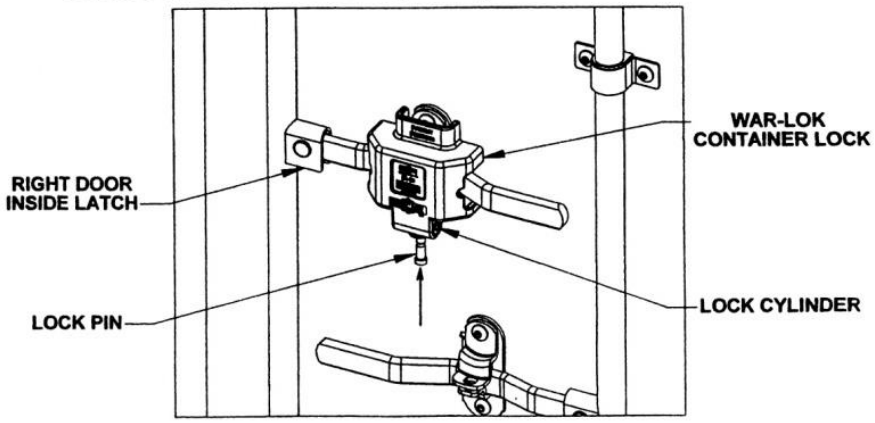

Figure 136. Instructions for installation of the lock on the exterior shipping container doors.

\section{END OF PROCEDURE V.L}

